\title{
ADAPTABILIDADE E ESTABILIDADE DE LINHAGENS EXPERIMENTAIS DE SOJA SELECIONADAS PARA CARACTERES AGRONÔMICOS E TOLERÂNCIA A INSETOS, ATRAVÉS DE MÉTODO UNI - MULTIVARIADO COM REAMOSTRAGEM
}

\author{
MARIA CLIDEANA CABRAL MAIA \\ Engenheiro Agrônomo
}

Orientador: Prof. Dr. NATAL ANTONIO VELLO

Tese apresentada à Escola Superior de Agricultura "Luiz de Queiroz", Universidade de São Paulo, para obtenção do título de Doutor em Agronomia, Área de Concentração: Genética e Melhoramento de Plantas.

P I R A C I C A B A

Estado de São Paulo - Brasil

Fevereiro - 2004 
Dados Internacionais de Catalogação na Publicação (CIP) DIVISĀO DE BIBLIOTECA E DOCUMENTAÇĀO - ESALQ/USP

\begin{abstract}
Maia, Maria Clideana Cabral
Adaptabilidade e estabilidade de linhagens experimentais de soja selecionadas para caracteres agronômicos e tolerância a insetos, através de método UNI multivariado com reamostragem / Maria Clideana Cabral Maia. - - Piracicaba, 2004.

$124 \mathrm{p}$.
\end{abstract}

Tese (doutorado) - Escola Superior de Agricultura Luiz de Queiroz, 2004. Bibliografia.

1. Biometria 2. Bootstrap Jacknife re-amostragem 3. Estabilidade fenotipica 4. Interação genótipo - Ambiente 5. Linhagens vegetais 6 . Resistência ao inseto 7. Soja I. Título

CDD 633.34 


\section{ERRATA}

MAIA, M.C.C. Adaptabilidade e estabilidade de linhagens experimentais de soja selecionadas para caracteres agronômicos e tolerância a insetos, através de método uni-multivariado com reamostragem

\begin{tabular}{|c|c|c|c|c|}
\hline Pág. & item & linha & onde se lê & leia-se \\
\hline 20 & 2.6 & terceira & simultaneamente & Respectivamente \\
\hline 21 & 2.6 & segunda & $\mathrm{N}$ espaços dimencionais & um espaço $\mathrm{N}$-dimensional \\
\hline 24 & 2.6 & vigésima & ordem $\mathrm{r}$ & posto $r$ \\
\hline 29 & 2.7 & primeira & $X_{2 i}$ & $X_{2}$ \\
\hline 32 & 2.7 & sétima & Teorema Central do Limite & Teorema do Limite Central \\
\hline 41 & 2.7 & primeira & ranqueamento & Ordenamento \\
\hline 41 & 2.7 & décima sétima & G & $\hat{G}$ \\
\hline 48 & 3.4 .1 .2 & vigésima sexta & $C_{k}(r)_{j}$ & $C_{k}(j)$ \\
\hline 49 & 3.4.1.2 & $\begin{array}{l}\text { vigésima } \\
\text { quinta }\end{array}$ & $Y_{i k j m l n}$ & $Y_{\text {pikjmln }}$ \\
\hline 49 & 3.4 .1 .2 & $\begin{array}{l}\text { vigésima } \\
\text { oitava }\end{array}$ & $\varepsilon_{\text {ipljm } l n}$ & $\bar{\varepsilon}_{\text {pikjmln }}$ \\
\hline 53 & 3.4 .3 .1 & décima & $g+e+1-(2 \times 1)$ & $g+e-1-(2 \times 1)$ \\
\hline 53 & 3.4.3.1 & $\begin{array}{l}\text { décima } \\
\text { primeira }\end{array}$ & $g+e+1-(2 \times 2)$ & $g+e-1-(2 \times 2)$ \\
\hline 53 & 3.4 .3 .1 & $\begin{array}{l}\text { décima } \\
\text { segunda }\end{array}$ & $g+e+1-(2 \times 3)$ & $g+e-1-(2 \times 3)$ \\
\hline 53 & 3.4.3.1 & décima quarta & $g+e+1-(2 x n)$ & $g+e-1-(2 x n)$ \\
\hline 54 & 3.4.3.1 & décima sexta & n-ésimo & k-ésimo \\
\hline 54 & 3.4 .3 .1 & décima oitava & vetor singular & elemento singular \\
\hline 56 & 3.4 .3 .1 & décima sexta & $\hat{Y}_{i j}=\bar{Y}_{i .}+\bar{Y}_{. j}-\bar{Y}_{. .}+\sum_{k-1}^{p} \lambda_{k} \gamma_{i k} \alpha_{j k}+\rho_{i j}$ & $\hat{Y}_{i j}=\bar{Y}_{i .}+\bar{Y}_{. j}-\bar{Y}_{. .}+\sum_{k=1}^{n} \lambda_{k} \gamma_{i k} \alpha_{j k}$ \\
\hline 57 & 3.4 .3 .1 & décima sexta & $\gamma_{i k}$ & $\gamma_{k}$ \\
\hline 57 & $3.4 .3 .1^{\circ}$ & décima oitava & $\alpha_{j k}^{\prime}$ & $\alpha_{k}^{\prime}$ \\
\hline 57 & 3.4.3.1 & $\begin{array}{l}\text { Vigésima } \\
\text { terceira }\end{array}$ & $\mathrm{GE}$ & $(g e)_{i j}$ \\
\hline 60 & 3.4.3.2 & $\begin{array}{l}\text { Vigésima } \\
\text { segunda }\end{array}$ & $\begin{array}{l}\text { fazendo a soma de } \\
\text { quadrados até } p\end{array}$ & $\begin{array}{l}\text { tomando-se os termos já } \\
\text { calculados da DVS da matriz GE }\end{array}$ \\
\hline 61 & 3.4 .3 .2 & décima sexta & corrigidos & Centrados \\
\hline 65 & 3.4 .3 .2 & décima sexta & $\mathrm{H}^{\mathrm{R}} \mathrm{H}$ & $\mathrm{H}^{* \prime}$ \\
\hline
\end{tabular}




\section{DEDICATÓRIA}

Ao Professor Roland Vencovsky pai da Genética Biométrica no país, pela transferência do conhecimento, pela expressiva contribuição científica, pela firmeza de propósito e pelo exemplo dado.

A minha mãe: Alba Cabral; Aos meus queridos irmãos e sobrinha:

Antônio Clidenor Cabral Maia (in

memoriam), Maria Fernanda Cabral

Façanha (in memoriam) e

João Fernando Cabral Façanha e

Pricilla Nobre Cabral Maia. 


\section{AGRADECIMENTOS}

A DEUS, pelo retorno justo e irreparável as nossas ações;

Ao Departamento de Genética desta Escola pela oportunidade da excelente formação acadêmica;

Ao Professor Natal pelo seu espírito humano, pelo zelo à pesquisa, ética, e respeito ao profissional, pela orientação segura e paciente, pela compreensão dispensada e, sobretudo pelos ensinamentos;

Aos Melhoristas, Estatísticos e Biometristas: Dr. Nelson da Silva Fonseca Júnior, Prof. Osmir José Lavoranti, Prof. Carlos Tadeu dos Santos Dias e Prof. Roland Vencovsky e Prof. José Baldin Pinheiro, pela colaboração imprescindível nas análises estatísticas deste trabalho e pelo encorajamento diante das dificuldades;

Aos amigos: Aldete Ferreira, pela ajuda na digitação e sugestões valiosas, Francisco Farias, Juliana Dantas, Maurisrael Rocha, Oriel Ramos, Raimundo Nonato, Salete Gaziola e Vanderlei dos Santos, pelo apoio e companheirismo;

Aos Professores: Giancarlo Conde Xavier de Oliveira, Natal Antonio Vello, Antônio Augusto Domingos Coelho e Carlos Alberto Labate que supervisionaram minha participação nas monitorias no Programa de Aperfeiçoamento de Ensino - PAE, pelos ensinamentos e confiança; 
A todos os Professores e Funcionários do Departamento de Genética, em especial: Amaral, Berdan, Carlos Veríssimo, Fernando Berlamino, Glória Eloy, José Monteiro, Léia, Maídia, Neusa, Sarah e Valdir Próspero;

Aos Servidores Não-Docentes: A. R. Congo, C. A. Didoné e M. C. Nekatschalow, do Setor de Genética Aplicada às Espécies Autógamas do Departamento de Genética da ESALQ/USP, pelos auxílios fornecidos no preparo e condução dos experimentos;

A todos os colegas do Programa LGN, especialmente: Ana Lúcia, Andréia Raposo, Dyeme Bento, Fábia Botelho, Fábio Pandini (in memoriam), Fernando Miranda, Frederico Pina, Maria Rita de Cássia, Maxwell Tassiano, Paulo Araújo, Rodrigo Luis, Rudimar Conte, Vanoli Fronza e Ubirajara Moreira pela demonstração de carinho e pelo convívio;

A minha família pelo repasse de experiência, do apoio irrestrito, pelo convívio prazeroso, pelo amor e

Ao CNPq instituição financiadora dos meus estudos em Genética e Melhoramento de Plantas. 


\section{SUMÁRIO}

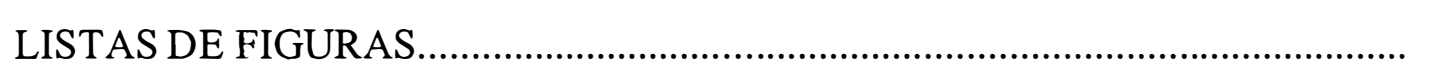

LISTAS DE TABELAS ..............................................................................

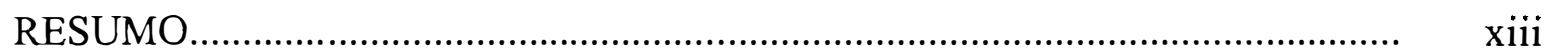

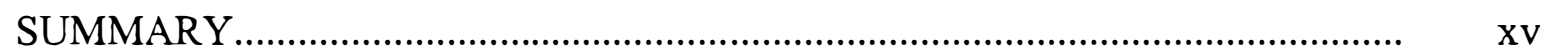

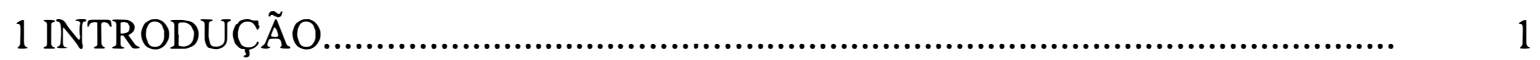

2 REVISÃO DE LITERATURA................................................................. 5

2.1 Pragas alvo da soja...................................................................................

2.2 Base genética da resistência.................................................................................

2.3 Interação entre genótipos e ambientes (GxE) .................................................... 10

2.4 Conceitos de adaptabilidade e estabilidade fenotípica............................................ 13

2.5 Métodos de avaliação da estabilidade fenotípica................................................... 16

2.6 Método AMMI........................................................................................... 18

2.7 Sobre métodos de reamostragem dos dados.................................................... 25

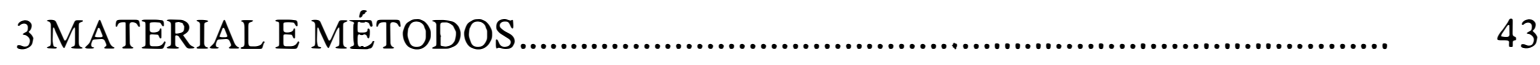

3.1 Material experimental.......................................................................... 43

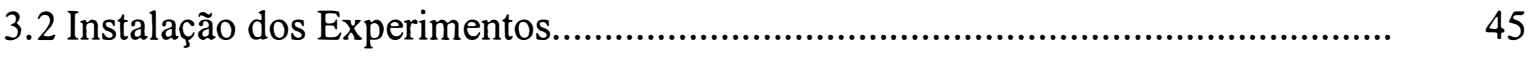

3.3 Caractere Avaliado.................................................................................. 45

3.4 Análises Estatísticas.................................................................................

3.4.1 Análises de variância...............................................................................

3.4.1.1 Análise de variância para as testemunhas.................................................... 47

3.4.1.2 Análise de variância para as linhagens............................................................... 48

3.4.3 Análise de adaptabilidade e de estabilidade fenotípica....................................... 51 
3.4.3.1 Via método AMMI................................................................................ 51

3.4.3.1 Via método "bootstrap" AMMI................................................................... 59

4 RESULTADOS E DISCUSSÃO.................................................................. 66

4. 1 Análises Individuais e Conjuntas................................................................... 67

4.2 Análise AMMI....................................................................................... 77

4.3 Análise "bootstrap" AMMI.............................................................................. 94

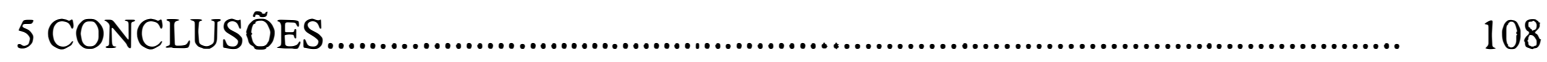

REFERÊNCIAS BIBLIOGRÁFICAS............................................................ 110 


\section{LISTA DE FIGURAS}

1Diagrama da distribuição "bootstrap" da estatística $T_{n}(x, F)$ (Lavoranti, 2003).

Página 37

2 Escores (ICPA 1 e 2) de componentes principais do modelo AMMI, para produtividade de grãos $(\mathrm{kg} / \mathrm{ha})$, de 20 linhagens (P1 a P20) da população PCI (População com Controle Total de Insetos), três testemunhas (T1 a T3) de soja e oito ambientes (E1 a E8).

3 Escores (IPCA 1 e 2) de componentes principais do modelo AMMI, para 20 linhagens (P1 a P20) população PRIS, três testemunhas (T1 a T3) de soja e oito ambientes (E1 a E8), para produtividade de grãos (kg/ha)

4 Escores (IPCA 1 e 2) de componentes principais do modelo AMMI, para 20 linhagens (P1 a P20) da população PRIM, três testemunhas (T1 a T3) de soja e oito ambientes (E1 a E8), para produtividade de grãos ( $\mathrm{kg} / \mathrm{ha})$.

5 Biplot AMMI1 segundo os escores de componente principal- IPCA1 x médias de produtividade de grãos $(\mathrm{kg} / \mathrm{ha})$, para 20 linhagens (P1 a P20) da PCI (População com Controle Total de Insetos em $\mathrm{F}_{2}$ ), três testemunhas ( $\mathrm{T} 1$ a T3) de soja e oito ambientes (E1 a E8)

6 Biplot AMMI1 segundo os escores de componente principal - IPCA1 x médias de produtividade de grãos $(\mathrm{kg} / \mathrm{ha}$ ), para 20 linhagens (P1 a P20) da PRIS (População com seleção para Resistência a Insetos Sugadores em $F_{2}$ ), três testemunhas (T1 a T3) de soja e oito ambientes (E1 a E8).

7 Biplot AMMI1 segundo os escores de componente principal - IPCA1 x média de produtividade de grãos ( $\mathrm{kg} / \mathrm{ha}$ ), para 20 linhagens (P1 a P20) da PRIM (População com seleção para a Resistência a Insetos Mastigadores em $\mathrm{F}_{2}$ ), três testemunhas (T1 a T3) de soja e oito ambientes (E1 a E8)

8 Gráficos de dispersão e regiões de confiança de $99 \%$ para os escores "bootstrap" de 20 linhagens (P1 a P20) da PCI (população com Controle Total de Insetos em $\mathrm{F}_{2}$ ) e três testemunhas ( $\mathrm{T} 1$ a $\mathrm{T} 3$ ) de soja, para produtividade de grãos $(\mathrm{kg} / \mathrm{ha})$ em oito ambientes. 
9 Gráficos de dispersão e regiões de confiança de $99 \%$ para os escores "bootstrap" de 20 linhagens (Pl a P20) da PRIS (População com seleção para Resistência a Insetos Sugadores em $F_{2}$ ) e três testemunhas (T1 a T3) de soja, para produtividade de grãos, $(\mathrm{kg} / \mathrm{ha})$ em oito ambientes..

10 Gráficos de dispersão e regiões de confiança de $99 \%$ para os escores "bootstrap" de 20 linhagens (P1 a P20) da PRIM (População com seleção para Resistência a Insetos Mastigadores em $F_{2}$ ) e três testemunhas (T1 a T3) de soja para produtividade de grãos $(\mathrm{kg} / \mathrm{ha})$ em oito ambientes.......................

11 Gráficos de dispersão e regiões de confiança de $99 \%$ para os escores "bootstrap" de ambientes (E1 a E8), para produtividade de grãos (kg/ha), de três populações (PCI, PRIS e PRIM) de soja. 


\section{LISTA DE TABELAS}

1 Resumo do avanço de endogamia com seleção dos três tipos de populações sintetizadas, com a geração, número de progênies, local e época de semeadura. Soja

Página

2 Análise conjunta de variância, a partir de médias, usando os procedimentos de Gollob (1968), Cornelius et al. (1992) e Piepho (1995), incluindo o

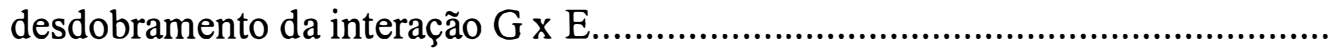

3 Quadrados médios para o caráter produtividade de grãos ( $\mathrm{kg} / \mathrm{ha}$ ) obtidos na análise individual em blocos ao acaso com repetições subdivididas em conjuntos experimentais com testemunhas comuns, em oito ambientes (E1 a E8, combinando os anos 1999/00 e 2000/01, os locais Anhembi e Areão, os manejos controle de intensivo de insetos ou CII e controle ecológico de insetos ou CEI), para a PCI (População formada a partir de plantas $F_{2}$ obtidas com Controle Total de Insetos).

4 Quadrados médios para o caráter produtividade de grãos $(\mathrm{kg} / \mathrm{ha})$ obtidos na análise individual em blocos ao acaso com repetições subdivididas em conjuntos experimentais com testemunhas comuns, em oito ambientes (E1 a E8 combinando os anos 1999/00 e 2000/01, os locais Anhembi e Areão, os manejos controle de intensivo de insetos ou CII e controle ecológico de insetos ou CEI), para a PRIS (População formada a partir de plantas $F_{2}$ selecionadas para Resistência a insetos Sugadores).

5 Quadrados médios para o caráter produtividade de grãos $(\mathrm{kg} / \mathrm{ha})$ obtidos na análise individual em blocos ao acaso com repetições subdivididas em conjuntos experimentais com testemunhas comuns, em oito ambientes (E1 a E8 combinando os anos 1999/00 e 2000/01, os locais Anhembi e Areão, os manejos controle de intensivo de insetos ou CII e controle ecológico de insetos ou CEI), para a PRIM (População formada a partir de plantas $F_{2}$ selecionadas para Resistência a insetos Mastigadores).

6 Quadrados médios para o caráter produtividade de grãos $(\mathrm{kg} / \mathrm{ha})$ obtidos na análise conjunta de três populações de soja (PCI, PRIS e PRIM) sem 
desdobramento (genótipos incluem linhagens e testemunhas comuns) em blocos ao acaso com repetições subdivididas em conjuntos experimentais com testemunhas comuns.

7 Quadro simplificado de quadrados médios para o caráter produtividade de grãos $(\mathrm{kg} / \mathrm{ha})$, obtidos na análise conjunta de três populações de soja (PCI, PRIS e PRIM) com desdobramento considerando apenas as linhagens (P), em blocos ao acaso com repetições subdivididas em conjuntos experimentais com testemunhas comuns.

8 Autovalor $\left(\lambda_{\mathrm{k}}{ }^{2}\right)$ e porcentagem da soma de quadrados acumulada (PA) por eixo singular. Análise conjunta de variância, incluindo o desdobramento da interação G x E para dados de produtividade de grãos (kg/ha).

9 Médias e escores (IPCA 1 e 2) de componentes principais do modelo AMMI para 20 linhagens (P1 a P20) da população com controle total de insetos (PCI), três testemunhas (T1 a T3) e oito ambientes (E1 a E8), para produtividade de grãos $(\mathrm{kg} / \mathrm{ha})$

10 Médias e escores (IPCA 1 e 2) de componentes principais do modelo AMMI para 20 linhagens (P1 a P20) população PRIS, três testemunhas (T1 a T3) de soja e oito ambientes (E1 a E8), para produtividade de grãos $(\mathrm{kg} / \mathrm{ha})$

11 Médias e escores (IPCA1 e 2) de componentes principais do modelo AMMI para 20 linhagens (P1 a P20) da PRIM (População com seleção para Resistência a Insetos Mastigadores em $\mathrm{F}_{2}$ ), três testemunhas (T1 a T3) de soja e oito ambientes (E1 a E8), para produtividade de grãos (kg/ha).

12 Classificação através de coeficiente "bootstrap" de estabilidade (CBE), de 20 linhagens (P1 a P20) da PCI (População com Controle Total de Insetos em $\mathrm{F}_{2}$ ) e três testemunhas comuns (T1 a T3), para produtividade de grãos (kg/ha), em oito ambientes.

13 Classificação através de coeficiente "bootstrap" de estabilidade (CBE), de 20 linhagens (P1 a P20) da PRIS (População com seleção para Resistência a Insetos Sugadores em $\mathrm{F}_{2}$ ) e três testemunhas comuns (T1 a T3) de soja, para produtividade de grãos $(\mathrm{kg} / \mathrm{ha})$ em oito ambientes.

14 Classificação através de coeficiente "bootstrap" de estabilidade (CBE), de 20 linhagens (P1 a P20) da PRIM (População com seleção para Resistência a Insetos Mastigadores em $\mathrm{F}_{2}$ ) e três testemunhas (T1 a T3) de soja para produtividade de grãos $(\mathrm{kg} / \mathrm{ha})$ em oito ambientes.

15 Classificação através de coeficiente "bootstrap" de estabilidade (CBE), de ambientes (E1 a E8), para produtividade de grãos $(\mathrm{kg} / \mathrm{ha})$ de populações 
(PCI, PRIS e PRIM) de soja................................................................ 102

16 Identificação das linhagens e cruzamentos de maior destaque em cada população.

17 Identificação das linhagens (P1 a P20) das populações PCI (formada a partir de plantas $\mathrm{F}_{2}$ obtidas com controle total de insetos), PRIS (formada a partir de plantas $F_{2}$ selecionadas para tolerância a insetos sugadores) e PRIM (formada a partir de plantas $F_{2}$ selecionadas para tolerância a insetos mastigadores) e testemunhas. 


\title{
ADAPTABILIDADE E ESTABILIDADE DE LINHAGENS EXPERIMENTAIS DE SOJA SELECIONADAS PARA CARACTERES AGRONÔMICOS E TOLERÂNCIA A INSETOS, ATRAVÉS DE MÉTODO UNI - MULTIVARIADO COM REAMOSTRAGEM
}

\author{
Autora: Maria Clideana Cabral Maia \\ Orientador: Prof. Dr. Natal Antonio Vello
}

\section{RESUMO}

Esta pesquisa visou estudar a interação entre genótipos e ambientes ( $G \times E)$, a adaptabilidade e estabilidade fenotípica, com o auxílio da reamostragem "bootstrap" no modelo biométrico AMMI para avaliação da produtividade de grãos de linhagens experimentais $\left(F_{10}\right.$ e $\left.F_{11}\right)$ de soja. $O$ material envolveu três populações obtidas de um dialelo parcial $4 \times 4$ quatro genitores tolerantes a insetos (IAC-100, Crokett, Lamar e D72-9601-1), e quatro cultivares adaptadas (BR-6, IAS-5, Davis, Ocepar-4). Em $F_{2}$, foram empregados três procedimentos distintos de seleção de plantas individuais: PCI, população formada a partir de plantas $\mathrm{F}_{2}$ obtidas com controle total de insetos; PRIM e PRIS formadas a partir de plantas $F_{2}$ selecionadas para tolerância a insetos mastigadores e sugadores, respectivamente. De $F_{3}$ a $F_{11}$ foi praticada seleção entre progênies para produtividade de grãos e tolerância ao fotoperíodo. Foram conduzidos 24 experimentos delineados em blocos ao acaso com duas repetições subdivididas em conjuntos experimentais com testemunhas comuns, combinando as três populações e oito ambientes. Os ambientes (El a E8) combinaram dois locais (Anhembi, Areão), dois anos agrícolas (1999/00, 2000/01) e dois sistemas de manejo (controle intensivo de insetos ou CII e controle ecológico de insetos ou CEI). Os experimentos de 1999/00 e 2000/01 incluíram respectivamente 40 e 20 linhagens de uma população. Com base 
produtividade de grãos, concluiu-se: nas três populações, existe variabilidade genética remanescente entre as linhagens; o manejo diferenciado (CII vs. CEI) mostrou ser um representante eficiente de ambientes diversos; a variação fenotípica foi explicada em ordem decrescente de magnitude pelos efeitos de: ambientes, interação $\mathrm{G} \times \mathrm{E}$ e genótipos; o método AMMI evidenciou como linhagens $F_{11}$ estáveis e produtivas $70 \%$ da PCI, $65 \%$ da PRIS e 55\% da PRIM; o local Anhembi destacou-se como de alta produtividade em todas as situações (três populações, dois anos e dois manejos; para as três populações, dentre os ambientes mais produtivos, o método AMMI destacou E1 (Anhembi, 1999/00, CII) como de máxima estabilidade e E6 (Anhembi, 2000/01, CEI) como de máxima instabilidade; f) o método AMMI com reamostragem (bootstrap) mostrou resultados diferentes daqueles observados com AMMI; todos os genótipos foram classificados como estáveis; para as três populações, foram formados quatro grupos de genótipos com diferentes níveis de estabilidade, tendo a soma dos dois grupos de estabilidade mais elevada incluido pelo menos $50 \%$ das linhagens e duas das três testemunhas; os dois métodos diferiram principalmente na classificação da estabilidade dos ambientes; o método AMMI com reamostragem destacou o ambiente E8 (Areão, 2000/01, CEI) como de estabilidade máxima e os ambientes E1 (Anhembi, 1999/00, CII) e E3 (Areão, 1999/00, CII) como instáveis; para a capacidade de gerar linhagens superiores em adaptabilidade e estabilidade, sobressaíram-se os genitores IAC-100, D72-9601-1, BR-6, Davis e IAC-5; destaques especiais envolveram os cruzamentos do genitor IAC-100 com IAC-5, Davis, OCEPAR-4 e BR-6. 


\title{
ADAPTABILITY AND STABILITY OF SOYBEAN EXPERIMENTAL LINES SELECTED FOR AGRONOMIC TRAITS AND INSECT TOLERANCE, BY UNI - MULTIVARIATE METHOD WITH BOOTSTRAP
}

\author{
Author: Maria Clideana Cabral Maia \\ Adviser: Prof. Dr. Natal Antoni Vello
}

\section{SUMMARY}

This research aimed to study the genotype $\mathrm{x}$ environment $(\mathrm{G} x \mathrm{E})$ interaction, the adaptability and phenotypic stability, by applying AMMI (ㅁdditive Main Effects and Multiplicative Interaction Analysis) and bootstrap methods for evaluating seed yield of soybean lines in $\mathrm{F}_{10}$ and $\mathrm{F}_{11}$ generations. The material included three populations derived from a $4 \times 4$ partial diallel having four insect resistant parents (IAC-100, Crockett, Lamar, D72-9601-1) and other four parents (BR-6, IAS-5, Davis, Ocepar-4) with high seed yield and earliness. In the $\mathrm{F}_{2}$ generation was used three procedures of plant selection: PCI, population derived from $\mathrm{F}_{2}$ plants under total control of insects; PRIM and PRIS, populations obtained from $\mathrm{F}_{2}$ plants after the selection for resistance to leaf-feeder (defoliating) and pod-feeder (stink bug complex) insects, respectively. From $F_{3}$ to $F_{11}$, it was practised among progeny selection, for seed yield and photoperiod tolerance. The 24 experiments were carried out in randomized complete block design with two replications subdivided in sets with common checks, by testing the three populations in eight environments (E1 to E8): two locations (Anhembi, Areão), two agriculture years (1999/00, 2000/01), and two management systems (CII: intensive control of insects; CEI: ecological control of insects). Each experiment included 40 and 20 lines from a population in 1999/00 and 2000/01, respectively. Based on the seed yield, were taken the following conclusions: it remains genetic variability among lines in the three populations; the management systems were efficients as representative of the environmental diversity; the phenotipic variation was explained by environmental effect, $\mathrm{G} \times \mathrm{E}$ interaction, and genotypic effect, in a decreasing order of magnitude; the AMMI 
method evidenced large percentage of high yielded and stable lines in all three populations: $70 \%$ in PCI, $65 \%$ in PRIS, and 55\% in PRIM; the Anhembi location exceeded with high seed yield in all situations; for the three populations, among the environments with high seed yield, the AMMI method classified E1 (Anhembi, 1999/00, CII) and E6 (Anhembi, 2000/01, CEI) as the most stable and unstable environment, respectively; AMMI and (AMMI bootstrap) methods showed different results. The (AMMI bootstrap) method classified as stable all the those were jointed in four groups with different stability levels; the sum of two groups with higher stabilities included at least $50 \%$ of the lines and two from three checks; the two methods differed mainly in classifying the environments; the (AMMI + bootstrap) method exceeded E8 (Areão, 2000/01, CEI) as the most stable environment; in the opposite way, El (Anhembi, 1999/00, CII) and E3 (Areão, 1999/00, CII) were classified as unstable environments; for the ability in originating lines with superior adaptability and stability, the followig parents exceeded: IAC-100, D72-9601-1, BR-6, Davis, and IAS-5; the best outstanding biparental crosses occurred when the IAC-100 parent was crossed with IAC-5, Davis, OCEPAR-4, and BR-6. 


\section{INTRODUÇÃO}

A soja [Glycine $\max$ (L.) Merrill] é uma das espécies de maior importância econômica no contexto mundial, com uma safra de cerca de 196 milhões de toneladas de grãos em 2002/03. Atualmente, o Brasil é o segundo maior produtor de grãos dessa leguminosa (antecedido apenas pelos Estados Unidos) com uma produção de cerca de 52 milhões de toneladas em 2003 (IBGE, 2003). Do ano de 2002 para 2003, o Brasil teve um aumento de $39,56 \%$ na exportação de soja, ocupando o segundo lugar como exportador (Agrianual, 2004), com previsão para ser o maior exportador mundial de soja de 2003 para 2004.

A soja é a espécie em que se conseguiu aproximar mais da maximização da produtividade, através da associação do uso racional e eficiente do ambiente com o melhoramento genético. O ponto relevante do melhoramento é o fato do uso de novas cultivares não representarem custos adicionais aos agricultores (Vello, 1992).

Nos programas de melhoramento maior ênfase tem sido dada aos caracteres relacionados à produtividade de grãos e ao fotoperíodo. Contudo, a ocorrência de pragas e doenças tem se tornado fator limitante da produção. Com isto existe uma nova tendência de se dar maior atenção à incorporação destas características de resistência, no sentido de torná-las também fatores estabilizadores da produtividade.

No Brasil, a perda de produção por causa do ataque de insetos é de $7,1 \%$, em média, variando de 2 a $30 \%$. Estes dados representam algo em torno de US\$ 2,2 bilhões de dólares ao ano (Bento, 1999). Segundo a FAO (2000), chegam a $14 \%$ da produção agrícola mundial.

A inclusão do melhoramento para resistência a insetos-pragas em programas de melhoramento é uma tendência nova, sendo que tal abordagem deve-se ao 
comprometimento da produção com a ocorrência de insetos que atacam a soja e que até então tinham como principal método de controle o uso de produtos químicos.

Dada a importância e magnitude de perdas quantitativas e qualitativas que os ataques de insetos provocam na cultura de soja, Pinheiro (1998) destacou que a utilização da resistência genética a insetos em cultivares de soja constitui-se numa estratégia no mínimo complementar ao uso de inseticidas, por apresentar vantagens adicionais, como: maior equilíbrio ecológico, ausência de gastos adicionais para os agricultores e desenvolvimento de tecnologia nacional.

Apesar da importância dos inseticidas no controle de pragas como os percevejos sugadores (Piezodorus guildinii, Nezara viridula e Euschistus heros) e insetos mastigadores de folhas como as lagartas (Anticarsia gemmatalis) e besourinhos (Colaspis sp., Cerotoma arcuata, Diabrotica speciosa e Diphaulaca viridipennis), o uso intensivo dos mesmos tem sido ecologicamente nocivo, causando o surgimento de resistência nos insetos aos produtos empregados, além de permanecer resíduos indesejáveis no ambiente. Uma estratégia adicional é representada pela resistência genética das plantas de soja aos insetos-pragas. As primeiras evidências experimentais indicam que a herança da tolerância da soja ao complexo de percevejos é de natureza poligênica e aditiva (Souza \& Toledo, 1995). No Brasil, existem apenas duas cultivares tolerantes a insetos (sugadores e mastigadores), IAC-100 (Rossetto et al., 1995) e IAC17 (Lourenção et al., 1999). Apesar de IAC-100 possuir a característica altamente vantajosa de tolerância aos insetos, apresenta limitações em outros caracteres agronômicos, principalmente, estabilidade e a própria magnitude da produtividade de grãos. Outros genótipos com tolerância a insetos são genótipos com adaptação restrita às condições ambientais norte-americanas: Crokett, Lamar e D 72-9601-1.

O cultivo extensivo da soja, contemplando ambientes diversificados, provoca uma resposta diferencial dos genótipos. Neste sentido, a interação entre genótipos e ambientes (GxE) representa aspecto relevante no contexto do melhoramento. Assim sendo, Duarte \& Vencovsky (1999) afirmam que o entendimento deste fenômeno tornase imprescindível aos programas de melhoramento que procuram minimizar a inconsistência das características relacionadas à produtividade frente à variação 
ambiental, para recomendações mais acertadas. Para Nunes (2000), além desse inconveniente, a interação reduz a correlação entre os valores genotípicos e fenotípicos, diminuindo os ganhos genéticos com a seleção e complicando o trabalho dos melhoristas.

Paradoxalmente, se não houvesse interação $(\mathrm{GxE})$, uma cultivar adaptar-se-ia à maioria dos ambientes de cultivo (locais, anos e estações), de forma que um único experimento, conduzido num só local (ainda com repetições), seria suficiente para fornecer resultados universais. Contudo, na realidade, cultivares de ampla adaptação normalmente apresentam produtividades subótimas, o que desperta para a possibilidade de explorar vantajosamente os efeitos dessa interação. Assim, embora os melhoristas tendam a desenvolver uma atitude negativa contra a interação $\mathrm{GxE}$ (barreira às elevadas herdabilidades e ganhos com a seleção), deve ser lembrado que interações positivas, associadas com características previsíveis do ambiente, oferecem a oportunidade das produtividades mais elevadas. Logo, interação não é apenas um problema, mas também uma oportunidade a ser aproveitada (Duarte \& Vencovsky, 1999).

Adaptações específicas de genótipos a ambientes podem fazer a diferença entre uma boa e uma excelente cultivar (Gauch \& Zobel, 1996). Pela mesma razão, sob o ponto de vista de recursos genéticos, a exploração dessa interação feita através do zoneamento ecológico é interessante para manter a variabilidade genética da espécie, principalmente, porque a soja cultivada possui base genética estreita. Contudo, para que seja possível tirar proveito desses efeitos positivos, de acordo com Brasil (1990) e Duarte \& Zimmermann (1995), é preciso dispor de metodologias estatísticas adequadas para se estimar e explorar a interação, permitindo assim recomendações regionalizadas. Uma discriminação da interação pode ser feita através da estimação da adaptabilidade e da estabilidade fenotípica quando se avalia respectivamente, o nível de resposta ao estímulo ambiental e a previsibilidade, isto é, a manutenção da produtividade frente a ambientes diversos. Para tanto, o procedimento AMMI (Additive Main Effects and Multiplicative Interaction Analysis) tem mostrado maior robustez no tratamento da interação GxE do que os métodos usuais existentes. Adicionalmente, Lavoranti (2003) apresenta desenvolvimento de técnica via reamostragem "bootstrap", no modelo AMMI 
em conjunto com representações gráficas de regiões de confiança para a estabilidade e gráficos de dispersões dos escores "bootstrap" em biplot como um recurso estatístico que melhora a qualidade para predições das estabilidades fenotípicas, quando comparado ao método tradicional AMMI, com representação gráfica em diagrama de dispersão multivariado (biplot).

Os seguintes fatos podem ser considerados como justificativas para pesquisas envolvendo o desenvolvimento e estudo de novos genótipos de soja com tolerância a insetos: a) número restrito (dois) de cultivares de soja tolerantes a insetos, insuficiente para atender a uma área cultivada que se estende de $33^{\circ}$ Sul a $4^{\circ}$ Norte de Latitude; b) evidências de um controle genético da tolerância a insetos; c) importância da interação genótipos $\mathrm{x}$ ambientes sobre a produtividade de grãos e outros caracteres em soja.

Esta pesquisa visa estudar a interação entre genótipos e ambientes e a estabilidade fenotípica, com o auxílio da reamostragem "bootstrap" no modelo biométrico AMMI para avaliação de linhagens experimentais de soja, com a finalidade de identificar genótipos que reúnam características de alta produtividade e tolerância a insetos mastigadores e sugadores. 


\section{REVISÃO DE LITERATURA}

\subsection{Pragas alvo da soja}

Pragas alvo são aquelas que, por seu potencial de danos, abundância, freqüência e abrangência geográfica necessitam maior atenção por parte do agricultor. Nesta categoria estão incluídas a lagarta da soja e três espécies de percevejos (Costa, 1977).

De acordo com Campo et al. (1996), na soja, o complexo de percevejos, formado pelas espécies Nezara viridula (L.), Piezodorus guildinii (West) e Euschistus heros (Fabr.), pode representar uma séria ameaça à produção e qualidade do grão, dependendo da densidade populacional e da época de ataque à cultura. Para Lourenção et al. (1999), além dos percevejos fitófagos da família Pentatomidae, as lagartas desfolhadoras (principalmente Anticarsia gemmatalis Hüb) constituem as principais pragas da soja para muitas regiões brasileiras.

O dano causado pela lagarta da soja é constituído pela redução de área foliar, na forma de pequenos buracos nas folhas. À medida que aumenta o desfolhamento, os buracos unem-se e, nos casos mais severos, há perda total da folha, inclusive das nervuras e do pecíolo. Em função da época de ataque e das condições ambientais, a redução da área foliar pode redundar em perdas de produção variáveis (Gazzoni \& Yorinori, 1995).

Diversos danos de diferentes ordens são observados na planta de soja atacada por percevejos, pois, ao se alimentarem, os insetos podem provocar: puncturas, manchas, deformações; reduções do tamanho das sementes, do teor de óleo, do poder germinativo e da produtividade; aumento do teor de proteína; atraso na maturação foliar, causando a retenção foliar; vectação de patógenos de sementes, em especial fungos (Daugherty et al. 
1964; Miner 1966; Jensen \& Newsom 1972; Todd et al. 1973; Yeargan 1977; Panizzi \& Slansky Jr. 1985 e Gazzoni \& Yorinori, 1995).

Informações a respeito dos mecanismos genéticos da resistência são de grande interesse em várias etapas dos programas de melhoramento e podem auxiliar na identificação de fontes de resistência; orientar cruzamentos e seleção de progênies; ampliar a base genética com inclusão de acessos resistentes, assim como, desenvolver linhagens isogênicas que podem ser usadas no estudo de mecanismos de resistência.

A resistência de plantas é regra na natureza e os mecanismos que conferem essa proteção sobrepõem sistematicamente os mecanismos ou "armas" de ataque das pragas, de maneira que uma cultivar possui diversos meios para resistir ao ataque de uma praga. Painter (1951) propôs a categorização dos mecanismos de resistência em três tipos: a não-preferência (antixenose), em que uma planta é não preferida para alimentação, oviposição ou abrigo porque tem resistência baseada na sua habilidade de diminuir a probabilidade de reconhecimento e utilização pelo inseto. Este tipo de resistência pode ser conferida por aleloquímicos ou por fatores estruturais. No entanto, é importante distinguir entre dois tipos de não-preferência, isto é, não-preferência expressa apenas na ausência de outro hospedeiro, e não-preferência manifestada apenas na presença de outro hospedeiro mais atraente ao inseto (Overman \& MacCarter, 1972). Este segundo tipo tem se tornado muito limitado devido ao sistema de agricultura prevalecente (monocultura, uniformidade genética, ausência de ervas daninhas). Assim, nãopreferência tem tido uma importância secundária em programas de melhoramento. $\mathrm{O}$ tipo antibiose, no qual na planta consumida pelo inseto ocorre um efeito adverso sobre o inseto, alterando seu comportamento e sua biologia. O crescimento e desenvolvimento dos insetos são fortemente influenciados pela qualidade e abundância de planta hospedeira. Sintomas típicos de resistência por antibiose incluem morte do inseto nos estágios (instars) iniciais; redução na razão de crescimento e fecundidade; mal formação morfológica; menor longevidade do período reprodutivo; aumento da mortalidade durante o estágio pupal e comportamento atípico (Tingey, 1981). Antibiose é a modalidade de resistência mais freqüentemente explorada nos programas de melhoramento genético. $O$ terceiro tipo foi denominado tolerância, que permite 
regeneração ou capacidade da planta em suportar o ataque do inseto. Kogan (1975), propôs ainda um tipo de resistência através de barreiras estruturais, neste caso, fatores morfológicos que limitam a ovoposição, alimentação e mobilidade foram conjuntamente apontados como fatores de resistência genética; dentre estes se incluem pubescência, dureza, aparência e exudado gomoso.

Para Tingey (1981), a resistência é herdável e controlada por um ou mais genes; é relativa, podendo ser medida apenas por comparação com outros genótipos; seu mecanismo e magnitude podem ser qualitativamente e quantitativamente determinada pela análise da resposta metabólica do hospedeiro e pela avaliação do crescimento e desenvolvimento em resposta à alimentação ou ovoposição do inseto. A resistência é variável e pode ser modificada pelo ambiente.

Para Van Der Plank (1968), a resistência genética pode ser ainda do tipo horizontal, quando uma cultivar infestada por uma série de biótipos diferentes na mesma espécie de inseto, não apresenta interações diferenciais. O nível de resistência que os indivíduos oferecem é igual contra todos os biótipos do inseto ou vice-versa. Também se aplicam os termos resistência não específica para o biótipo ou resistência geral. Este tipo de herança é poligênica e também é considerada estável e permanente. Na resistência vertical, o genótipo infestado por outra série de biótipos diferentes do mesmo inseto, apresenta interações diferenciais. Neste caso, algumas cultivares classificam-se como resistentes e sofrem pouco ou nenhum dano, enquanto que outras são suscetíveis ao mesmo biótipo do inseto. A resistência vertical depende de genes principais ou oligogenes e é considerada menos estável que a resistência horizontal.

Verifica-se uma hierarquia com diferentes graus de complexidade na estrutura das populações de plantas e insetos, bem como nos processos evolucionários que nelas atuam, como por exemplo: combinação de fluxo e extinção gênica, deriva genética, migração, várias formas de seleção natural, fatores ecológicos como sobrevivência dos insetos, mudança na abundância do hospedeiro, variáveis estas que ocorrem geralmente ao acaso e funcionam como pressão em determinar a dinâmica genética e os resultados dessas competições de armas evolucionárias. 
Dada a importância da identificação dos mecanismos de resistência a insetos em linhagens e ou cultivares para programas de melhoramento genético que buscam desenvolver cultivares de soja resistentes e/ou tolerantes, estudos desses eventos têm sido comuns, sendo que a antixenose (ou não-preferência) foi verificada para as pragas Anticarsia gemmatalis (Ariel, 1990) e para Diphaulalaca viridipennis (Pooprom Pan et al. 1992); já a resistência do tipo antibiose foi identificada para Heliothis virescens (Beland \& Hatchett, 1976), Heliothis armigera (Pooprom Pan et al. 1992) e para Epilachna varivestis (Burden \& Norris, 1994).

\subsection{Base genética da resistência}

O conhecimento do modo de ação gênica e tipo de herança envolvidos no controle da resistência constitui uma ferramenta valiosa em várias etapas dos programas de melhoramento, uma vez que ajuda na escolha do melhor método a ser usado e pode colaborar para a obtenção de ganhos com seleção mais elevados.

Para determinar o controle genético e a herança da resistência, usualmente são feitos cruzamentos entre plantas contrastantes para resistência/tolerância e são estudadas as segregações em populações $F_{2}, F_{3}$ e retrocruzamentos; às vezes, é necessária a presença de um nível relativamente alto de infestação nesse tipo de experimento utilizando-se então, infestações artificiais. Esses estudos indicam o modo de ação gênica (aditiva, recessiva, dominante ou epistática) e o tipo de herança monogênica (gene principal) ou poligênica (genes menores cada um de pequeno efeito e pode estar associada com muitas características quantitativas como vigor e produtividade da planta). A natureza complexa da resistência poligênica fornece considerável tamponamento contra biótipos específicos.

Para Tingey (1981), o conhecimento da natureza genética da resistência pode ser de grande valor em programas de melhoramento por fornecer uma base quantitativa para recombinação e seleção, e por identificar aqueles produtos gênicos (fatores condicionadores de resistência) mais estáveis contra a plasticidade genética da praga. 
Segundo Van Duyn et al. (1971) e Clark et al. (1972), a resistência da soja a insetos é conhecida há pelo menos 30 anos; a partir daí, vários programas de melhoramento passaram a ter esse componente como critério para seleção além dos demais. Entretanto, Lin et al. (1990) logo mostraram que essa resistência possui herança poligênica. Kenty et al. (1996) e Kilen \& Lambert (1998) encontraram herança do tipo poligênico com ação gênica aditiva em soja para reação à praga Pseudoplusia includens. Posteriormente, demonstrou-se que os agentes inibidores tinham ação de antibiose e/ou de antixenose em insetos (Lambert \& Kilen, 1984). Adicionalmente, inferiu-se que os fatores de resistência em soja variavam durante o desenvolvimento e Rowan et al. (1993) observaram diminuição da resistência com a senescência da planta; segundo Lambert \& Heatherly (1995), a resistência é reduzida se a planta sofre estresse hídrico.

Considera-se que a resistência em soja é controlada geneticamente por um ou mais fatores químicos presentes na planta (All et al. 1999a). Johnston et al. (1993) referiram-se aos inibidores de tripsina como componentes de soja responsáveis pelo efeito antibiótico em insetos suscetíveis. Outras substâncias químicas sugeridas por Lin et al. (1990), como os isoflavonóides e vários componentes fenólicos, estão envolvidas na resistência da soja a insetos. Contudo, não houve muitas pesquisas que confirmassem a eficiência destes fatores químicos na resistência de soja a insetos; conseqüentemente, ainda não foi realizada seleção de linhagens com altos níveis de inibidores de protease e isoflavonóides/fenóis em programas de melhoramento de soja.

O desenvolvimento de cultivares de soja com resistência/tolerância, que apresentem altos rendimentos e outras características de qualidade desejáveis têm sido um desafio para melhoristas e entomologistas (All et al. 1999b). Um dos problemas associados ao desenvolvimento de cultivares resistentes a insetos é a dificuldade na obtenção de fenótipo estável e o fato da seleção em gerações sucessivas estar sujeita a segregações.

Geralmente, na cultura da soja, os programas de seleção para resistência a insetos ganharam grande impulso a partir da identificação das características de resistência a percevejos e/ou a desfolhadores nas introduções de plantas (PIs); estes materiais revelaram características de resistência a mastigadores ou sugadores, o que favoreceu o 
surgimento de programas de incorporação dessas características em cultivares comerciais de soja.

\subsection{Interação entre genótipos e ambientes (GxE)}

A manifestação fenotípica dos caracteres métricos resulta do efeito conjunto do genótipo, do ambiente específico e da interação destes fatores. Obviamente, se a amostra do material genético pesquisado fosse representativo da população original e sua avaliação fosse feita em um grande número de ambientes contrastantes, a média dos caracteres em estudo não representaria teoricamente, um desvio fenotípico significativo; neste caso, era de se esperar aleatoriedade dos efeitos e a média dos caracteres considerados se ajustaria à da população, admitindo-se não ter havido seleção, migração ou mutação. Na prática, contudo, tal procedimento toma-se inexeqüível, sendo que, basicamente, todos os programas de melhoramento genético envolvem pelo menos três etapas: escolha dos parentais que darão origem à população-base, seleção das progênies superiores dessa população e sua avaliação em um grande número de ambientes. Quando se avalia materiais geneticamente distintos em uma série de ambientes, comumente, o componente interação entre genótipos e ambientes $(\mathrm{GxE})$ aparece afetando o ganho com a seleção.

A interação $(\mathrm{GxE})$ é definida como o comportamento diferencial dos genótipos em função da diversidade ambiental. Neste sentido, na presença da interação, os resultados das avaliações podem mudar de um ambiente para outro, ocasionando mudanças na posição relativa dos genótipos ou mesmo na magnitude das suas diferenças (Falconer \& Mackay, 1996). Para Chaves (2001), a interação (GxE) deve ser encarada como um fenômeno biológico em suas implicações no melhoramento de plantas e não como um simples efeito estatístico, cumprindo buscar a explicação evolutiva do evento se se quiser tirar proveito de seus efeitos benéficos, bem como para contornar seus efeitos indesejáveis sobre a avaliação de genótipos e recomendação de cultivares. Diferenças em adaptação de genótipos em populações resultam, evidentemente, de diferenças de 
constituição gênica para os caracteres importantes nesta adaptação. A reação diferencial às mudanças ambientais pode-se dar desde os mecanismos de regulação gênica até caracteres morfológicos finais.

Cockerham (1963) atribuiu o aparecimento de interações (GxE) como sendo devido a respostas diferenciais do mesmo conjunto gênico em ambientes distintos ou pela expressão de diferentes conjuntos gênicos em diferentes ambientes. Quando um mesmo conjunto de genes se expressa em diferentes ambientes, as diferenças nas respostas podem ser explicadas pela heterogeneidade das variâncias genéticas e experimentais ou por ambas, e, quando diferentes conjuntos de genes se expressam em ambientes distintos, as diferenças nas respostas explicam-se pela inconsistência das correlações genéticas entre os valores de um mesmo caráter em dois ambientes (Falconer, 1989). Segundo Cruz \& Regazzi (1994), a interação (GxE) também pode surgir em função de fatores fisiológicos e bioquímicos próprios de cada genótipo cultivado. Chaves (1989) relata ainda que a falta de ajuste do modelo estatístico adotado ao conjunto de dados pode ser uma das causas da interação (GxE) significativa.

No que concerne à contribuição dos diferentes ambientes para a interação, sua variância é atribuída a uma porção previsível (fixa) que faz parte da variação e que pode ser medida em magnitude e em direção, seu caráter sistemático facilita razoável controle; já a sua porção imprevisível (aleatória), faz parte da variação experimental não controlada, por ter natureza indeterminada, isto é, de sentido e direção incertos. Cruz (2001) ressalta que o ambiente atua isoladamente ou em interação com os genótipos, de tal forma que, quando se considera uma série de ambientes, sua magnitude pode ser estimada e seus efeitos devem ser avaliados. Estudos sobre a interação genótipos $\mathrm{x}$ ambientes devem pormenorizar o comportamento tanto dos genótipos disponíveis, em estudos de adaptabilidade e estabilidade, quanto dos ambientes estudados. Para Fehr (1987), as variáveis imprevisíveis são as que mais contribuem para as interações genótipos x anos. Portanto, Chaves (2001) entende ser o efeito do ambiente, em realidade, um confundimento de efeitos fixos e aleatórios. Então, quão mais previsível for o ambiente da lavoura, maior será a possibilidade de aproveitamento dos efeitos da interação, sendo ideal que os efeitos de ambientes pudessem ser tomados como fixos ou, 
pelo menos, que a porção fixa da interação pudesse ser medida e os resultados utilizados na recomendação de cultivares.

Segundo Vencovsky \& Barriga (1992), o fato de a interação (GxE) mostrar-se significativa não diz muito, havendo a necessidade de subdividi-la para saber o que ela contém. Quando um grupo de genótipos é avaliado no mínimo em dois ambientes é possível decompor o componente interação em duas partes (Vencovsky, 1987). A interação (GxE) neste caso, contém uma parte que é função da diferença entre a variância genética do caráter nos dois ambientes e outra parte que decorre da falta de correlação genética entre os tratamentos genéticos, de um ambiente para outro. A primeira parcela é denominada interação simples e não acarreta maiores problemas para a seleção; a segunda parcela é denominada complexa, e pela falta de correlação, representa dificuldade na seleção de genótipos de adaptação mais ampla.

Entre as aspirações dos melhoristas está a busca de materiais genéticos que, ao serem avaliados nos vários ambientes, não mostrem interações significativas com eles, conferindo, assim, uma maior segurança na recomendação de cultivares. No entanto, somente uma pequena porção da interação pode ser atribuída a determinantes ambientais conhecidos, sendo que a maior parte é inexplicável na análise estatística (Rosse, 1999). Existem na literatura várias alternativas para se atenuar o efeito significativo da interação (GxE).

Uma opção seria a identificação de cultivares específicos para cada ambiente; porém, seu alto custo de execução a inviabiliza (Ramalho et al. 1993; Ribeiro, 1999).

A segunda maneira é realizar zoneamento ecológico de uma área extensa, ou seja, promover estratificação de uma área heterogênea em sub-regiões mais uniformes, de forma que, dentro das regiões os genótipos não interajam significativamente com os ambientes (Rosse, 1999). A principal crítica feita a essa técnica está no fato de o agrupamento ser feito com base nas diferenças macroambientais, fato que o torna vulnerável às oscilações imprevisíveis que possam ocorrer no ambiente. Além disso, o zoneamento ecológico permite a redução do número de locais para avaliação de cultivares, pois identifica aqueles com características mais semelhantes. Como agravante, Rosse (1999) acrescenta que essa técnica não permite o controle da interação 
entre genótipos e anos. $\mathrm{O}$ agrupamento de ambientes pode ser feito por meio de características edafo-climáticas ou do comportamento dos genótipos (Millgan, 1994). No entanto, a maioria dos métodos tem utilizado as informações referentes à interação GxE (May \& Kozub, 1995; Atlin et al. 2000).

A última alternativa, que é a que tem sido mais empregada, consiste em identificar genótipos com maior estabilidade fenotípica (Vencovsky \& Barriga, 1992; Ramalho et al. 1993). Um grande número de métodos estatístico-genéticos foram propostos para mensurar a estabilidade, auxiliando sobremaneira a seleção e descarte de cultivares. As diferenças entre estes vários métodos dependem dos conceitos de estabilidade adotados pelos pesquisadores e dos próprios procedimentos estatísticos empregados na sua estimação (Rosse, 1999).

\subsection{Conceitos de adaptabilidade e estabilidade fenotípica}

Adaptabilidade e estabilidade, embora sejam fenômenos relacionados, não devem ser considerados iguais (Vencovsky \& Barriga, 1992).

Lin et al. (1986) classificaram o conceito de estabilidade em três tipos. No tipo 1, o genótipo é considerado estável se sua variância entre os ambientes for pequena. Este conceito acomoda de certa forma a definição de estabilidade feita por Lewis (1954) e previsibilidade de comportamento de Mariotti et al. (1976); é chamado de "estabilidade no sentido biológico" (Becker, 1981), que caracteriza um genótipo com comportamento constante com a variação do ambiente e está em concordância com o termo homeostase proposto por Lerner (1954) ou "canalização" de C. H. Waddington em 1953 (citado por Mettler \& Gregg, 1973); está no mesmo sentido de estabilidade de produção designado por Heinrich et al. (1983) e na consistência no ranqueamento denotado por Yue et al. (1997); correspondente a genótipo "bem tamponado" ou "bem ajustado" de Allard \& Brasdshaw (1964), sendo também equivalente às definições de estabilidade absoluta propostas por Finlay \& Wilkinson (1963) e coincidente à denominação de estabilidade de Eberhart \& Russel (1966); análogo ainda ao termo estático de J. Léon de 1985 (citado por Becker \& Léon, 1988). Vencovsky \& Torres (1988) e Fox et al. (1997) usaram 
estabilidade temporal fazendo referência à variação não significativa do genótipo frente às flutuações climáticas ao longo de anos agrícolas, dentro de uma localidade. Assim sendo, esse comportamento pode não ser desejado, pois o genótipo não responde à melhoria do ambiente com o aumento da produção, além de estar comumente relacionado a uma menor produtividade (Becker \& Léon 1988 e Ramalho et al. 1993). A estabilidade do tipo 1 pode ser medida pela variância de cada genótipo nos diferentes ambientes e é útil para características que devem ser mantidas, tal como resistência a patógenos e pragas (Nunes, 2000).

$\mathrm{Na}$ estabilidade do tipo 2, o genótipo é considerado estável se sua resposta ao ambiente for paralela à resposta média de todos os materiais avaliados no experimento, 0 que ocorre quando o genótipo possui interações mínimas com o ambiente. É denominada por Becker (1981) como "estabilidade no sentido agronômico"; contempla o conceito de estabilidade dinâmica de J. Léon de 1985 (citado por Becker \& Leon, 1988); sendo chamada pelo termo adaptabilidade (Mariotti et al. 1976), representando um nível paralelo de resposta do genótipo de forma a aproveitar vantajosamente os estímulos ambientais; ajustando-se à denominação de adaptabilidade de Eberhart \& Russel (1966). Ratificada posteriormente por (Cruz \& Regazzi 1994); nesta mesma linha, Vencovsky \& Torres (1988) apresentaram adaptabilidade como sinônimo de estabilidade espacial ou geográfica. Nestes termos, é esperado que não haja interações significativas entre o desempenho produtivo e as oscilações climáticas entre anos. Fox et al. (1997) adotaram este mesmo conceito ao se referir à adaptabilidade como reflexo às dimensões espaciais. Ela também tem sido preferida por identificar genótipos com o potencial de se manterem estáveis entre os melhores em todos os ambientes. Entretanto, alguns autores comentam que as inferências neste tipo de estabilidade são exclusivas ao grupo de genótipos avaliados. Dessa forma, um material estável em determinado grupo de cultivares não o será necessariamente em um segundo grupo avaliado (Lin et al. 1986). Por conseguinte, se o interesse do melhorista é obter cultivares com adaptação específica ou ampla a uma gama de ambientes, é preciso que o faça testando a adaptabilidade dos materiais (Duarte, 1988). 
A estabilidade do tipo 3 é aquela na qual o genótipo seria considerado estável se o quadrado médio dos desvios de regressão for pequeno, classificando-o como de alta confiabilidade de resposta. Segundo Lin et al. (1986), todos esses conceitos apresentam restrição, em especial, aquele baseado nos desvios de regressão. Posteriormente, Lin \& Binns (1988) propuseram um novo tipo de estabilidade, a qual denominaram de tipo 4. Para identificação da estabilidade tipo 4, é preciso que as cultivares sejam avaliadas em um determinado número de anos e alguns locais. A análise de variância é realizada estimando o quadrado médio do efeito de anos dentro de locais para cada cultivar; aquela que apresentar o menor quadrado médio será a mais estável às variações imprevisíveis dos anos.

Alliprandini (1992) definiu estabilidade com relação à estatística do coeficiente de determinação $\left(R^{2}\right)$ e dos desvios de regressão $\left(s^{2} d_{i}\right)$, e adaptabilidade com base no desempenho do genótipo em relação à média dos genótipos avaliados e da responsividade medida pelo coeficiente de regressão $\left(b_{i}\right)$. Chaves (2001) menciona que valores elevados de $\mathrm{R}^{2}$ estão, geralmente, associados a genótipos responsivos. Duarte \& Zimmerman (1995) demonstraram que existe uma correlação intrínseca entre a medida do $\left(R^{2}\right)$ com os valores de $\left(b_{i}\right)$, inferindo que a utilização do $R^{2}$ como parâmetro de estabilidade deve ser evitada.

Além de existir conceitos diversificados para adaptabilidade e estabilidade, acrescente-se, de acordo com Vencovsky \& Torres (1986), um problema concernente à falta ou insignificância da correlação entre a estabilidade temporal (anos) e a estabilidade geográfica (locais). Esses autores encontraram em milho, correlação não significativa, indicando que ambas apresentam controle genético independente. Vencovsky (1987) comenta que a estabilidade apresenta uma herdabilidade menor do que a obtida para produtividade de grãos. Assim sendo, mesmo a herdabilidade da produtividade sendo baixa, a seleção para esse caráter é mais efetiva do que para os parâmetros de estabilidade, pois a repetibilidade da produtividade tem se mostrado superior, tanto àquela do coeficiente de regressão, quanto da variância dos desvios de regressão. Verma et al. (1978) consideraram que um genótipo ideal seria aquele com alta resposta à melhoria das condições ambientais e, ao mesmo tempo, tolerante às condições 
de ambientes desfavoráveis. Vencovsky \& Torres (1988) enfatizaram que, para o produtor rural, é mais importante que uma cultivar seja estável ao longo dos anos.

\subsection{Métodos de avaliação da estabilidade fenotípica}

Segundo Duarte \& Vencovsky (1999), dentre os métodos que procuram identificar os genótipos que menos contribuem para a interação (genótipos estáveis) e que poderiam ser recomendados para toda população de ambientes, desde que mostrem também uma performance média desejável, incluem-se aqueles baseados na regressão linear simples (Yates \& Cochran, 1938; Finlay \& Wilkinson, 1963; Eberhart \& Russel, 1966) ou múltipla (Verma et al. 1978; Silva \& Barreto, 1985; Cruz et al. 1989; Storck, 1989; Brasil, 1990; entre outros).

Os primeiros relatos da exploração da técnica de regressão linear para estudo da resposta de cultivares à variação dos ambientes reporta ao trabalho de Yates \& Cochran (1938).

O uso de técnicas que empregam métodos de regressão tem como objetivo traçar curvas para representar o comportamento de cada genótipo nos diferentes ambientes, adotando como variável independente um índice ambiental formado pelo contraste entre a média de cada ambiente e a média geral de todos eles e, como variável dependente, a produtividade média do genótipo em cada ambiente (Rosse, 1999). A simplicidade do uso juntamente com a facilidade na interpretação biológica dos resultados tem estimulado e generalizado seu emprego. Por estas mesmas razões, sua eficiência em fornecer informações seguras são questionáveis; inicialmente, por não obedecer à independência entre o índice ambiental e o conjunto de dados analisados, tornando o coeficiente de regressão um estimador inconsistente no que tange à teoria estatística. Uma restrição ao seu emprego pressupõe linearidade das variáveis; é fato, porém, que entidades biológicas são bastante complexas, sendo um erro primário admitir ajustamento a um modelo que considera componentes aditivos também para o efeito da interação. Segundo Vencovsky \& Barriga (1992), este relacionamento pode mostrar-se até curvilíneo. 
Para Duarte \& Vencovsky (1999), a violação da pressuposição de independência da variável explanatória (o índice ambiental é obtido a partir dos próprios dados), não parece relevante quando o número de genótipos é elevado. Ressaltam o fato de que, para se ajustar regressões individuais dos genótipos às variações ambientais, o desdobramento tradicionalmente feito não toma apenas a variação devida à interação GxE, mas aquela decorrente das fontes de variação: Ambientes + Interação GxE (efeitos ambientais dentro de genótipos). Esse procedimento usual, sem dúvida, auxilia no processo de recomendação de cultivares, pois fornece uma descrição do padrão médio de resposta de cada genótipo frente à melhoria da qualidade ambiental. No entanto, obscurece a identificação de relações importantes no discernimento das verdadeiras causas da interação GxE em si.

Crossa (1990) argumenta que a análise de regressão linear não é informativa se a linearidade falhar, sendo fortemente dependente do grupo de genótipos e ambientes incluídos e tende a simplificar modelos de resposta por explicar a variação devida à interação em uma única dimensão, quando na realidade ela pode ser bastante complexa, alertando para o risco em sacrificar informações relevantes para facilitar interpretações estatísticas e biológicas.

A essa crítica, Duarte \& Vencovsky (1999) acrescentam ainda o fato de esses procedimentos, em geral, não informarem sobre interações específicas de genótipos com ambientes (se positivas ou negativas) dificultando explorar vantajosamente os efeitos da interação.

Neste sentido, pode-se esperar, inicialmente, que o ajustamento de dois ou mais segmentos de reta poderia explicar melhor a resposta daqueles genótipos cujos desvios de regressão linear simples se mostrassem elevados (Rosse, 1999). Fundamentando-se nesta nova tendência foram desenvolvidos métodos segmentados (Verma et al., 1978; Silva \& Barreto, 1985; Cruz et al., 1989; Storck, 1989; Brasil, 1990). Algumas implicações de ordem estatística e biológica levantadas relativas a esses procedimentos são, respectivamente: ineficiência se o número de ambientes é reduzido e dependência entre as linhas de regressão; inconsistência dos testes de hipótese para os parâmetros; tendenciosidade nas conclusões pelo inconveniente relacionado ao emprego do 
coeficiente de determinação $\left(\mathrm{R}^{2}\right)$; comprometimento das interpretações biológicas quando os dados são representados graficamente, além de admitirem um ponto de fixação arbitrário para o índice de ambientes, o que faz com que as recomendações extraídas deles sejam vistas com alguma ressalva, prejudicando conseqüentemente sua aplicabilidade.

Duarte \& Vencovsky (1999) informam que a implicação estatística básica para uma interação de fatores significativa está diretamente relacionada à impossibilidade de uma interpretação apenas aditiva dos efeitos principais (Mandel, 1971; Kang \& Magari, 1996). Isso pode resultar simplesmente da desigualdade das variâncias nas respostas genotípicas de um ambiente para outro, sem modificação no posicionamento relativo dos genótipos (interação simples), até a completa falta de correlação nos comportamentos genotípicos entre os ambientes (interação complexa ou cruzada). Nesse último caso, a presença da interação determina uma inconsistência na ordenação (ranking) dos genótipos de um ambiente para outro. Diante desse quadro, vários métodos estatísticos têm sido empregados buscando um melhor entendimento dos efeitos da interação GxE.

\subsection{Método AMMI}

Vários pesquisadores estão empregando técnicas multivariadas (ACP - análise de componentes principais, análise de agrupamento e AMMI (Additive Main Effects and Multiplicative Interaction analysis) para abordar tal assunto. Essas técnicas são mais complexas, além de necessitarem, comumente, de programas computacionais específicos para o seu desenvolvimento. Por outro lado, os resultados gerados permitem que as interpretações sejam mais coerentes com a realidade dos sistemas vegetais (Rosse, 1999). Pode-se notar, nos últimos anos, de acordo com Duarte \& Vencovsky (1999), uma mudança importante na escolha dos modelos de análise que substituem o enfoque tradicional univariado, no estudo e aproveitamento do fenômeno da interação de genótipos com ambientes, como é o caso da análise AMMI.

Visando minimizar possíveis erros de estimação e garantir uma maior acurácia e eficiência à análise da interação GxE, Zobel et al. (1988), Crossa (1990), Gauch \& Zobel 
(1996) e De Cauwr \& Ortiz (1998) sugeriram a introdução de procedimentos multivariados.

Rosse (1999) cita que alguns desses métodos, como a ACP e a análise de agrupamentos, não apresentam as limitações decorrentes da análise de regressão linear, porém, mostram-se de difícil interpretação em relação à interação GxE. Outras técnicas (ou uma combinação delas) mostram-se de mais fácil interpretação biológica, como o é, o enfoque dado pelo procedimento additive main effects and multiplicative interaction analysis (modelo AMMI) (Kang \& Gauch Jr., 1996).

Zobel et al. (1988) chamam atenção ao fato de que a análise de variância usual é fraca em detectar interação de fatores, mesmo nas situações de elevada magnitude em termos de soma de quadrados (SQ). Exemplificam o caso em que $20 \%$ a $50 \%$ da variação verificada na $S Q_{\text {TOTAL }}$ foi devida a $\mathrm{SQ}_{\mathrm{GxE}}$; ainda assim, o quadrado médio dessa interação GxE não atingiu significância estatística. Discutem que a regressão linear, geralmente, também pouco explica a porção da $S_{\mathrm{GxE}}$. Verificaram que cerca de $8 \%$ dessa $\mathrm{SQ}_{\mathrm{GxE}}$ foi captada na análise de regressão linear usando o modelo de Finlay \& Wilkinson (1963), enquanto o fez para $71 \%$ com uso do procedimento AMMI. Por conseguinte, inferiram que o AMMI representa uma análise poderosa em captar padrões agronômicos e estatísticos importantes presentes na interação GxE; neste sentido, o AMMI mostrou-se bastante arrojado.

Segundo Gauch \& Zobel (1996), esta análise pode auxiliar tanto na identificação de genótipos de alta produtividade e de adaptação ampla, quanto na realização do zoneamento agronômico, objetivando recomendações regionalizadas e, também, ajuda na seleção de locais de testes. R. W. Zobel e colaboradores em 1988 (citados por Duarte \& Vencovsky, 1999), sustentam que o método AMMI permite uma análise mais detalhada da interação GxE, garante a seleção de genótipos mais produtivos (capazes de capitalizar interações positivas com ambientes), propicia estimativas mais precisas das respostas genotípicas e possibilita uma fácil interpretação gráfica dos resultados da análise estatística.

Duarte \& Vencovsky (1999) preconizam o modelo AMMI como uma alternativa para a interpretação e melhor compreensão do fenômeno da interação de fatores, com 
ênfase na interação GxE. Para tanto, o procedimento modela efeitos principais e interação, seqüencialmente, combinando análise de variância (técnica univariada) e análise de componentes principais ACP (técnica multivariada), simultaneamente. Nesse tipo de aplicação, seguindo a abordagem aqui adotada, a ACP pode ser tratada diretamente através da técnica matemática denominada decomposição por valores singulares (DVS) (Eckart \& Young, 1936; Mandel, 1971), aplicada à matriz de interações. Dessa forma, como salientam Zobel et al. (1988), o modelo incorpora componentes aditivos e multiplicativos em uma análise de quadrados mínimos integrada e poderosa.

Para Duarte \& Vencovsky (1999), embora existam outros enfoques no estudo de interação GxE, como por exemplo os propostos por G. Wricke em 1965 (citado por Wricke \& Weber, 1986), Shukla (1972) e Magari \& Kang (1997), que procuram avaliar a contribuição de cada genótipo para a interação propriamente dita, esse tipo de procedimento, em geral, é preterido em relação aos métodos de regressão. Assim, a crítica feita anteriormente recai especialmente sobre esses últimos, que têm tido aplicação muito maior. Por outro lado, a pressuposição de que toda a $S_{\mathrm{GxE}}$ é importante para descrever o padrão de resposta diferencial dos genótipos aos ambientes, admitida no método de G. Wricke em 1965 (citado por Wricke \& Weber, 1986), e no método de Shukla (1972), torna-os também sujeitos a questionamentos. A abordagem estatística sobre a qual se assenta a análise AMMI, por exemplo, procura destacar um resíduo adicional presente na $\mathrm{SQ}_{\mathrm{GxE}}$, comumente denominado de ruído.

Os procedimentos multivariados assim como aqueles que modelam efeitos principais e interação de uma forma seqüencial como o caso da metodologia AMMI, foram propostos com o objetivo de eliminar os ruídos presentes nos dados, além de, sumarizar e revelar a estrutura dos dados. Para Crossa (1990), os dados gerados em experimentos conduzidos em muitos ambientes possuem estrutura bastante complexa, apresentando pelo menos três aspectos intrínsecos: padrão estrutural; ruídos nãoestruturais e relações entre genótipos, ambientes e interação $\mathrm{GxE}$, sendo que a função da análise multivariada é elucidar a estrutura interna dos dados a partir de hipóteses que podem ser geradas e depois testadas por métodos estatísticos, considera ainda que a 
resposta de um dado genótipo $\mathrm{G}$ em $\mathrm{E}$ ambientes pode ser conceituada como um padrão em $\mathrm{N}$ espaços dimensionais; por esse conceito, o padrão significa que um número de genótipos responde a determinados ambientes de forma sistemática, significante e explicável, enquanto que o ruído implica que elas são imprevisíveis e não interpretáveis, fazendo parte integrante da variabilidade estranha contida nos dados. Assim sendo, conforme Duarte (2001), nesse tipo de abordagem não se parte da premissa de que os desvios de aditividade decorrentes do ajuste dos efeitos principais sejam inteiramente resultantes da interação GxE. Com efeito, tais desvios podem conter ruídos (variação não controlada). O descarte destes ruídos permitirá caracterizar melhor os fatores genéticos e ambientais realmente envolvidos na interação (GxE), e melhor estimar as respostas dos genótipos aos ambientes. De acordo com Crossa (1990), a principal finalidade do AMMI é selecionar modelos que expliquem o padrão relacionado à interação ( $\mathrm{SQ}_{\mathrm{GxE}}$ Padrão), desprezando os ruídos presentes nos dados e sem interesse para a seleção dos materiais genéticos.

O procedimento AMMI é também, uma ferramenta apropriada para diagnósticos em situações em que a interação significativa é acompanhada por não significância dos efeitos aditivos principais de genótipos e ambientes, ou, quando a estrutura da interação é influenciada por valores anômalos (outliers) (Shafii \& Price, 1998).

O tratamento da interação via AMMI, como já mencionado, é feito através da ACP. Shafii \& Price (1998) afirmam que, geralmente, o número de eixos ou componentes principais retidos é o menor possível (dois ou três no máximo), com o(s) qual (is) se pretende reduzir a dimensão do sistema e fornecer uma descrição mais parcimoniosa à estrutura da interação. Para Crossa (1990), o objetivo principal dessa técnica consiste em transformar os dados a partir de um grupo de eixos de coordenadas, em outro grupo, que preserve no máximo a configuração original do grupo de pontos e concentre a maior parte da estrutura dos dados no(s) primeiro(s) eixos da ACP. Para tanto, a ACP admite que as variáveis originais definem um espaço euclidiano no qual a similaridade entre itens é medida como distância euclidiana.

O método AMMI engloba uma família de modelos que podem ser denotados por: AMMI0 (não inclui nenhum termo da interação); AMMIl, AMMI2,..,AMMIn (inclui, 
respectivamente, somente o primeiro eixo da interação, o segundo eixo da interação, e n eixos da interação). Idealmente, segundo Chaves (2001), quando o modelo AMMI1 ou AMMI2 é suficiente para captar um padrão de variação dos dados, a técnica se torna muito útil por permitir a interpretação da interação em uma ou duas dimensões, livre de ruídos que afetem a compreensão do fenômeno. Neste caso, Gauch \& Zobel (1996) inferiram que a média de um genótipo em um dado ambiente, estimada pelo modelo AMMI, pode ser mais precisa que a média observada, por levar em conta toda a matriz de dados na estimativa, ao invés das poucas repetições de um experimento. $\mathrm{O}$ uso dos testes estatísticos tem sido o critério mais adotado para a definição do número de eixos da análise de componentes principais da interação (ACPI) a serem retidos, ou seja, do modelo mais preditivo e parcimonioso sobre a estrutura da interação (Cornelius et al., 1996).

Duarte \& Vencovsky (1999) mencionam que um dos procedimentos usuais adotados para definição do número de eixos a serem retidos, de maneira a explicar o padrão relacionado à interação, consiste em determinar o número de graus de liberdade associados à parcela da $\mathrm{SQ}_{\mathrm{GxE}}$ relacionada a cada membro da família AMMI. Obtém-se, então, o quadrado médio (QM) correspondente a cada parcela (ou modelo). Em seguida, é obtido um teste $\mathrm{F}$ avaliando-se a significância de cada componente em relação a $\mathrm{SQ}_{\text {етто }}$ médio. Desta forma, o ponto de parada que determina a seleção do modelo (AMMI0, AMMI1,..., ou AMMIn) baseia-se na significância do teste F para os sucessivos eixos da interação. O resíduo AMMI, reunindo os eixos descartados da interação, também pode ser testado de maneira a assegurar o seu caráter desprezível. Gauch \& Zobel (1996) citam os sistemas de Gollob (1968) e Mandel (1971) como sendo os sistemas mais amplamente adotados para atribuir graus de liberdade ao modelo AMMI. Para Gauch (1992), a proposta de Gollob (1968) é fundamentada na definição clássica de graus de liberdade. Pelo teste F de Gollob (1968), o ponto de parada para seleção do modelo é a significância do n-ésimo componente principal da interação (CPI).

Como salienta Chaves (2001), a determinação exata do número de graus de liberdade para cada parcela da interação, ou cada eixo da análise de componentes principais $\left(\mathrm{IPCA}_{\mathrm{k}}\right)$, não é simples. Considerado um ponto de entrave do método, e que 
ainda suscita pesquisa. Neste contexto, testes alternativos têm sido propostos, como por exemplo, a razão de sinal para o ruído sugerido por (Gauch, 1992), os testes $\mathrm{F}_{\mathrm{GH} 1}$ e $\mathrm{F}_{\mathrm{GH}}$ (Cornelius, 1993) e $\mathrm{F}_{\mathrm{R}}$ (Cornelius et al. 1992 e Piepho, 1995); neste, o ponto de parada é o n-ésimo CPI no qual o seu resíduo seja não significativo. A escolha do teste depende do número de genótipos, locais e anos de teste (Annicchiarico, 1997).

De acordo com Dias \& Krzanowski (2003), métodos paramétricos baseados no teste F são "pos-dictivos" e dependem pesadamente das suposições distribucionais (normalidade dos dados e validade das distribuições $\mathrm{F}$ para os quadrados médios), além de selecionar muitos componentes da interação, o que pode não ser apropriado em muitos casos, podendo apresentar recomendações conflitantes para um conjunto particular de dados; estes autores preconizam o uso de métodos que são essencialmente "data-based" e livres de distribuições teóricas; tais métodos envolvem reamostragem de um determinado conjunto de dados, usando técnicas tais como "jacknife", "bootstrap" e validação cruzada por aleatorização (avaliação preditiva, o teste é feito aprioristicamente com os dados originais), como métodos que fazem o mais eficiente uso dos dados e resulta em modelos mais parcimoniosos, com o objetivo de adequadamente, selecionar o número de componentes multiplicativos a serem retidos no modelo AMMI para explicar o padrão na interação.

Estudos comparativos dos testes para seleção de famílias do modelo AMMI, indicam, no geral, que o teste F de Gollob (1968) tende a ser mais liberal que os testes $\mathrm{F}_{\mathrm{GH} 1}$ e $\mathrm{F}_{\mathrm{GH} 2}$, e estes, mais que o teste $\mathrm{F}_{\mathrm{R}}$, tendendo a selecionar mais eixos do que o verdadeiro modelo contempla. $\mathrm{O}$ teste $\mathrm{F}_{\mathrm{R}}$ apresentou resultados semelhantes ao teste da razão de sinal para o ruído e foi o que mais se aproximou dos resultados verificados pela validação cruzada.

A representação gráfica dos dados em diagrama de dispersão multivariado (biplot) tem a importante propriedade de sumarizar os dados, permitindo uma melhor visualização da tendência da distribuição de dados e de pontos discrepantes, facilitando, conseqüentemente, sua interpretação. Considere de acordo com Duarte \& Vencovsky (1999), outra vantagem apresentada pelo modelo AMMI, relacionada à representação gráfica, na qual são plotados os escores dos efeitos da interação, para cada genótipo e 
para cada ambiente, simultaneamente. A interpretação é feita observando a magnitude e o sinal dos escores de genótipos e ambientes para o eixo de componentes principais. Escores baixos indicam genótipos e/ou ambientes que contribuem pouco ou quase nada para a interação $\mathrm{GxE}$, sendo, portanto, estáveis. Tais genótipos podem ser recomendados amplamente desde que tenham médias elevadas. Em ambientes estáveis, o ordenamento dos genótipos deve ser mais consistente. Esse tipo de informação permite aos melhoristas selecionar também locais de testes, conforme seus interesses. Portanto, esse gráfico fornece informações sobre a estabilidade de genótipos e também de ambientes, além de permitir a realização de zoneamentos ecológicos, com a seleção de locais chaves.

Segundo Lavoranti (2003), a representação dos dados em biplot, é uma técnica bastante útil na análise de componentes principais pois, o gráfico usado para apresentar simultaneamente as linhas e colunas, referentes a uma matriz de dados, pode indicar a existência de agrupamentos entre as observações, assim como, mostrar as variâncias e correlações entre as variáveis. Essa técnica foi introduzida por Gabriel (1971) e é baseada no fato de que, uma matriz de ordem maior do que dois pode ser aproximada por uma matriz de ordem dois, sendo que cada elemento da matriz é representado pelo produto interno dos vetores correspondentes à sua linha e coluna. Dessa forma, qualquer matriz de $\mathrm{n}$ observações e $\mathrm{p}$ variáveis pode ser representada por um biplot. Ou seja, toda matriz $Y(n x p)$ de ordem $r$ pode ser fatorada como $Y=G H^{\prime}$, em que $G$ é uma matriz (nxr) e H uma matriz (pxr), ambas necessariamente de posto $r$ (Rao, 1965). Assim, a fatoração pode ser escrita como $Y_{i j}=$ gih $_{j}$ para cada i, j, em que i $=1,2, \ldots, g$ (g: número de genótipos); $\mathrm{j}=1,2, \ldots, \mathrm{e}$ (e: número de ambientes); $\mathrm{y}_{\mathrm{ij}}$ é o elemento na i-ésima coluna de $\mathrm{Y}, \mathrm{g}_{\mathrm{i}}$ é a i-ésima linha de $\mathrm{G}$ e $\mathrm{h}_{\mathrm{j}}$ é a j-ésima coluna de $\mathrm{H}$. Ou seja, a fatoração associa cada um dos vetores $g_{1}, g_{2}, \ldots, g_{g}$, a cada uma das $n$ linhas de $Y$, e os vetores $h_{1}, h_{2}, \ldots, h_{e}$ a cada uma das $\mathrm{p}$ colunas de $\mathrm{Y}$. Cada um dos vetores tem ordem $\mathrm{r}$ e fornece a representação de $Y$ através de $(g+e)$ vetores no espaço $r$-dimensional. Os vetores $g_{1}$, $\mathrm{g}_{2}, \ldots, \mathrm{g}_{\mathrm{g}}$ podem ser considerados como efeito de linhas e os vetores $\mathrm{h}_{1}, \mathrm{~h}_{2}, \ldots, \mathrm{h}_{\mathrm{e}}$ como efeito de colunas. 
Yan et al. (2001) apresentaram uma técnica para estudar a adaptabilidade e estabilidade fenotípica apoiada na análise gráfica denominada de biplot GGE (efeitos de genótipos e da interação $\mathrm{GxE}$ ). O gráfico é constituído plotando-se os dois primeiros componentes principais de uma ACP, fazendo uso de modelos de regressões de locais (SREG), com a finalidade de selecionar genótipos superiores para recomendações aos agricultores e identificar locais que melhor representem ambientes específicos ou megaambientes, com representação gráfica em diagrama de dispersão multivariado (biplot).

Entretanto, os principais pontos negativos dessa metodologia estão relacionados à dificuldade na interpretação da interação, quando há baixa explicação do primeiro componente principal; a dificuldade para quantificar os escores como baixos, considerando estável os genótipos e/ou ambientes, além de não apresentar o padrão de resposta do genótipo, o que caracteriza os padrões de adaptabilidade dos grupos formados através de parâmetros significativos. Nesse contexto, essa metodologia apresenta alguns inconvenientes de ordem estatística. A atribuição dos graus de liberdade, associados à parcela da $\mathrm{SQ}_{\mathrm{GxE}}$, relacionada a cada membro da família $\mathrm{AMMI}$, também é vista com ressalva e merece um estudo mais detalhado (Lavoranti, 2003).

$\mathrm{Na}$ literatura, são poucos os relatos sobre a aplicação do procedimento AMMI nos programas de melhoramento, especialmente, da cultura da soja, porém, é patente a valorização crescente que a ele se tem dado, com notável tendência para seu emprego por parte dos melhoristas, biometristas e estatísticos, visto que o mesmo apresenta vantagens significativas quando comparado aos métodos clássicos (Gauch, 1988, 1990 e 1992; Gauch \& Zobel, 1996; Zobel et al., 1988; Crossa, 1990; Crossa et al., 1991; Piepho, 1995; De Cauwr \& Ortiz, 1998; Duarte \& Vencovsky, 1999; Thallainathan \& Fernandez, 2001; Yan et al., 2001; Vargas et al., 2001; Lavoranti et al., 2001a e 2001b; Rocha, 2002; Lavoranti et al., 2002; Oliveira et al., 2003 e Lavoranti, 2003).

\subsection{Sobre métodos de reamostragem dos dados}

Técnicas de reamostragem, conhecidos como métodos estatísticos computacionalmente intensivos foram propostos a décadas, e se apresentam como 
alternativas interessantes para analisar dados de origem ecológica e evolutiva. Porém, sua difusão era limitada por exigirem grandes quantidades de cálculos. Devido a grande capacidade de processamento das máquinas e pelo desenvolvimento de programas de computadores, estes procedimentos vêm tendo aplicabilidade cada vez maior. Dentre estas metodologias, pode-se destacar o "jacknife" e o "bootstrap", apresentados por Efron (1979).

O “jacknife” foi introduzido em 1949 por M. H. Quenouille, para reduzir o viés de um estimador de correlação, com base na divisão da amostra original em duas semiamostras. Anos depois, este estudo foi completado com a generalização do método (Quenouille, 1956). Assim, a amostra original de tamanho $n$ passa a ser dividida em $g$ sub-amostras de tamanho $h$, de modo que se tem $n=g h$. O tamanho $h$ fixo em um, faz com que a amostra original passe a ser dividida em $n$ grupos com unidade observacional (Lavoranti, 2003). O termo "jacknife" foi criado por Tukey (1958), fazendo analogia aos canivetes de bolso com múltiplas funções, que embora versáteis, dificilmente realizam alguma das funções de modo ideal. Essa comparação refere-se à abordagem geral para testar hipóteses e construir intervalos de confiança quando outros métodos mais indicados não podem ser aplicados facilmente. Contudo, esse método produz melhores estimativas amostrais de alguns parâmetros de posição, como por exemplo, a média e a curtose, também fornecem freqüentemente variância e intervalos de confiança aproximados para estas estimativas.

É um processo de reamostragem, em que o parâmetro de interesse $\theta$, em uma amostra com $n$ observações é estimado apropriadamente como $\hat{\theta}$. Pseudovalores $\hat{\theta}_{\mathrm{j}}$, associados a cada observação j, são obtidos como $\hat{\theta}_{\mathrm{j}}=\hat{\theta}-(n-1)\left(\hat{\theta}_{-\mathrm{j}}-\hat{\theta}\right)$, em que $\hat{\theta}_{-\mathrm{j}}$ é o cálculo do parâmetro com a j-ésima observação excluída da amostra. O lado direito da expressão é a estimativa do parâmetro amostral menos um termo de tendenciosidade, refletindo o desvio da j-ésima estimativa $\hat{\theta}_{-\mathrm{j}}$ desconsiderada da estimativa $\hat{\theta}$ da amostra total. A média dos pseudovalores $\hat{\theta}_{(.)}$é a estimativa "jackknife" de $\hat{\theta}$. A diferença $\hat{\theta}_{-\mathrm{j}}$ $\hat{\theta}_{(.)}$, mede o viés amostral geral da estimativa original $\hat{\theta}$ (Crowley, 1992). 
Para um melhor entendimento da técnica, Lavoranti (2003) propõe a seguinte situação clássica de análise de dados: seja $\left[x_{1}, x_{2}, \cdots, x_{n}\right]$ uma amostra de variáveis aleatórias independentes e identicamente distribuídas (i.i.d.). Seja $p(X, \theta)$ a função de verossimilhança dessa amostra aleatória (a.a.), com dependência do parâmetro $\theta$. Supondo-se que o estimador de $\theta$ seja a estatística $\hat{\theta}=T_{n}(x)$ e que $\hat{\theta}_{i}=T_{n-1}(x)$, seja o estimador baseado na amostra de tamanho $n-1$ obtida retirando-se o i-ésimo ponto amostral. Com esses valores constrói-se os pseudovalores (Tukey, 1958):

$$
\widetilde{\theta}=n \hat{\theta}-(n-1) \hat{\theta}_{i} \quad i=1,2, \cdots, n .
$$

A média aritmética dos $n$ pseudovalores $\widetilde{\theta}_{i}$ dada por:

$$
\widetilde{\theta}=\frac{1}{n} \sum_{i=1}^{n} \widetilde{\theta}_{i}
$$

é chamada de estimador "jackknife" do parâmetro $\theta$.

De uma forma geral, o erro-padrão "jackknife" para a estatística $\hat{\theta}$ é dado por Tukey (1958):

$$
\hat{S} D=\left[\frac{1}{n(n-1)} \sum_{i=1}^{n}\left(\tilde{\theta}_{i}-\tilde{\theta}\right)^{2}\right]^{\frac{1}{2}} .
$$

É importante observar que dada a (a.a.) $\left[\left(x_{1}, y_{1}\right),\left(x_{2}, y_{2}\right), \cdots,\left(x_{n}, y_{n}\right)\right]$ da distribuição bivariada de probabilidade $\mathrm{F}$, é possivel calcular uma estimativa da esperança do vetor aleatório bivariado e, além disso, pode-se avaliar sua precisão. Para tanto, basta calcular a expressão do vetor média amostral $[\bar{x}, \bar{y}]$ e a matriz de covariância amostral:

$$
\left|\begin{array}{ll}
\hat{\sigma}_{x}^{2} & \hat{\sigma}_{x y}^{2} \\
\hat{\sigma}_{x y}^{2} & \hat{\sigma}_{y}^{2}
\end{array}\right|
$$


Contudo, quando se deseja avaliar a precisão de outros estimadores, como por exemplo a correlação amostral $\hat{\rho}_{X Y}=\frac{\hat{\sigma}_{x y}}{\hat{\sigma}_{x} \hat{\sigma}_{y}}$, não é possível fazê-lo sem o conhecimento de F. A solução, neste caso, seria usar resultados assintóticos.

No caso da variância do estimador de $E[X], \bar{X}$, não existe problema para a sua estimação. Conhecendo-se ou não a distribuição da variável aleatória (v.a.), tem-se acesso à precisão da estatística $\bar{X}$. Dada a (a.a.) $\left[x_{1}, x_{2}, \cdots, x_{n}\right]$, da (v.a.) $\mathrm{X}$, com distribuição desconhecida $\mathrm{F}$, o estimador do parâmetro $\mu=E[X]$ é dado por:

$$
\bar{X}=\frac{1}{n} \sum_{i=1}^{n} x_{i}
$$

Para o cálculo dos pseudovalores de $\tilde{\theta}_{i}$ precisa-se de $\hat{\theta}_{(i)}$ dados por:

$$
\hat{\theta}_{(i)}=\bar{X}_{(i)}=\frac{n \bar{X}-X_{i}}{n-1}(i=1,2, \cdots, n)
$$

e, assim, tem-se os pseudovalores:

$$
\widetilde{\theta}_{(i)}=n \bar{X}-(n-1) \bar{X}_{(i)} \quad(i=1,2, \cdots, n),
$$

que produzem o estimador "jackknife" de $E[X]$,

$$
\widetilde{\theta}=\frac{1}{n} \sum_{i=1}^{n} \hat{\theta}_{i}=n \bar{X}-(n-1) \frac{1}{n} \sum_{i=1}^{n} \bar{X}_{(i)}
$$

Pode-se mostrar através das equações (1) e (3) que, nesse caso, $\tilde{\theta}=\bar{X}$ : 


$$
\begin{aligned}
\tilde{\theta} & \left.=n X-(n-1) \frac{1\left[n \bar{X}-X_{1}\right.}{n}, \frac{\left.n \bar{X}-X_{2 i}, \ldots, n \bar{X}-X_{n}\right]}{n-1} n^{-1}\right] \\
& =n \bar{X}-(n-1) \frac{1}{n(n-1)}\left[n n \bar{X}-\sum_{i=1}^{n} X_{i}\right] \\
& =\frac{1}{n} \sum_{i=1}^{n} X_{i}=\bar{X}
\end{aligned}
$$

e, ainda, por (2) e (4) tem-se: $\widetilde{\theta}_{(i)}-\theta=X_{i}-\bar{X}$ pois,

$$
\begin{aligned}
& \tilde{\theta}_{(i)}-\theta=n \quad \bar{X}-(n-1) \bar{X}_{(i)}-\bar{X}=(n-1) \bar{X}-(n-1) \bar{X}_{(i)} \\
& =(n-1) \quad\left(\bar{X}-\bar{X}_{(i)}\right)=(n-1)\left[\bar{X}-\frac{n \bar{X}-X_{i}}{n-1}\right] \\
& =X_{i}-\bar{X}
\end{aligned}
$$

Logo, $V[\bar{X}]$ será dada por:

$$
V[\bar{X}]=\left[\frac{1}{n(n-1)} \sum_{i=1}^{n}\left(\widetilde{\theta}_{(i)}-\tilde{\theta}\right)^{2}\right]=\left[\frac{1}{n(n-1)} \sum_{i=1}^{n}\left(X_{i}-\bar{X}\right)^{2}\right]=\frac{s^{2}}{n} .
$$

Portanto, seja $\tilde{\theta}=\frac{1}{n} \sum_{i=1}^{n} \widetilde{\theta}_{i}$ o estimador “jackknife” correspondente a um estimador viciado do parâmetro $\theta, \hat{\theta}=T_{n}(x)$. Então $\widetilde{\theta}$ elimina o termo de ordem $\frac{1}{n}$ do vício de $\hat{\theta}$.

Segundo Tukey (1958), os $n$ pseudovalores poderiam ser tratados como v.a.'s aproximadamente i.i.d. e, dessa forma, poder-se-ia construir a quantidade pivotal: 


$$
\frac{\tilde{\theta}-\theta}{\left[\frac{1}{n(n-1)}\left[\frac{\sum_{i=1}^{n}\left(\tilde{\theta}_{i}-\tilde{\theta}\right)}{n-1}\right]\right]^{-\frac{1}{2}}},
$$

que tem aproximadamente distribuição $t_{n-1}$, e pode ser usada como pivô na estimação por intervalo do parâmetro $\theta$.

Bickel \& Freedman (1981) citam o vício como sendo um dos fatores importantes para a escolha de um estimador. Esse exprime a quantidade de erro sistemático que ocorre na estimação do parâmetro e, por isso, é preferível que tenha valor nulo e baixa variância. No entanto, isso nem sempre é possível, sendo assim, o conhecimento do vício é importante para avaliar a precisão das estimativas.

Dada (a.a.) $X=\left[x_{1}, x_{2}, \cdots, x_{n}\right]$ da distribuição de probabilidade desconhecida $\mathrm{F}$, é comum estimar-se o parâmetro de interesse $\theta$, usando-se um estimador natural $\hat{\theta}=T_{n}(x)$. Caso o estimador seja viciado, uma aplicação de destaque do "jackknife" é o estimador do vício, $b(\theta, \hat{\theta})$, de um estimador $\hat{\theta}$. Dessa forma, tem-se:

$$
\begin{aligned}
& E(\hat{\theta})=\theta+b(\theta, \hat{\theta}) \\
& =\theta+\frac{a_{1}(F)}{n}+\frac{a_{2}(F)}{n^{2}}+\frac{a_{3}(F)}{n^{3}}+\cdots,
\end{aligned}
$$

como, $\hat{\theta}_{.}=\frac{1}{n} \sum_{i=1}^{n} \hat{\theta}_{i}$ e $\hat{\theta}=\frac{1}{n} \sum_{i=1}^{n} X_{i}=\bar{X}$, pela equação (1), tem-se:

$$
\hat{\theta}=\frac{1}{n} \sum_{i=1}^{n} \hat{\theta}_{i}=\frac{1}{n} \sum_{i=1}^{n}\left[\frac{n \bar{X}-X_{i}}{n-1}\right]=\frac{1}{n}\left[\frac{n^{2} \bar{X}-n X}{n-1}\right]=\left[\frac{n(n-1) \bar{X}}{n(n-1)}\right]=\bar{X},
$$

portanto, $\hat{b}(\theta, \bar{X})=(n-1)(\bar{X}-\bar{X})=0$. 
Para a estimação "jackknife" do vício do estimador de máxima verossimilhança $T_{n}(x)=\hat{\theta}^{2}=\frac{1}{n} \sum_{i=1}^{n}\left(X_{i}-\bar{X}\right)^{2}$, da variância $\sigma^{2}$, da distribuição $\mathrm{F}$, conhecida ou não, temse:

$$
E\left(\hat{\theta}^{2}\right)=E\left[\frac{1}{n} \sum_{i=1}^{n}\left(X_{i}-\bar{X}\right)^{2}\right]=\frac{1}{n}(n-1) \sigma^{2}=\sigma^{2}-\frac{\sigma^{2}}{n} .
$$

Logo, $b\left(\theta^{2}, \hat{\theta}^{2}\right)=\frac{-\sigma^{2}}{n}$, e da equação (8) vê-se que a aproximação vai somente até o termo $\frac{1}{n}$, sendo os demais nulos. E, como o estimador "jacknife" elimina esse termo da aproximação de $E\left[\hat{\sigma}^{2}\right]$, conclui-se que $\tilde{\theta}$ é não-viciado para $\sigma^{2}$. A estimativa do vício é dada por:

$$
\begin{aligned}
& b\left(\theta^{2}, \hat{\theta}^{2}\right)=\hat{\sigma}-\tilde{\sigma}=\frac{1}{n} \sum_{i=1}^{n}\left(X_{i}-\bar{X}\right)^{2}-\frac{1}{n-1} \sum_{i=1}^{n}\left(X_{i}-\bar{X}\right)^{2} \\
& =\frac{1}{n-1} \sum_{i=1}^{n}\left(X_{i}-\bar{X}\right),{ }^{2}
\end{aligned}
$$

que, em alguns casos, são exatamente iguais aos da teoria clássica.

É importante destacar que, no caso da estimação do vício de $\sigma^{2}$, obtém-se uma estatística cuja esperança é $\frac{-\sigma^{2}}{n}$ :

$$
E\left[b\left(\theta^{2}, \hat{\theta}^{2}\right)\right]=\frac{-1}{n(n-1)} E\left[\sum_{i=1}^{n}\left(X_{i}-\bar{X}\right)^{2}\right]=\frac{-1}{n(n-1)} \sigma^{2}(n-1)=\frac{-\sigma^{2}}{n} .
$$

Portanto, o "jackknife” fornece um estimador não-viciado para o vício de $\hat{\sigma}^{2}$.

Para Efron \& Stein (1981), esse resultado ocorre sempre que a estatística for uma função quadrática. 
Crowley (1992) lembra que para o parâmetro de interesse $\theta$, é possível obter com "jackknife" a estimativa do parâmetro, de sua variância e seu intervalo de confiança. A variância "jackknife" é calculada considerando-se nulas as correlações entre pseudovalores, contudo, não se sabe sob que condições esse pressuposto é validado. O intervalo de confiança obtido é paramétrico, pois se parte do pressuposto de que as estimativas "jackknife" estão baseadas em erros com distribuição normal. Esta pressuposição é apoiada no Teorema Central do Limite se as amostras forem grandes, porém, nos casos de tamanho pequeno da amostra é difícil avaliar a validade desse pressuposto.

Manly (1997) considera uma das vantagens desse método como sendo a de transformar muitos problemas de estimação no simples problema de estimar a média. Basta que o estimador convencional seja função de $n$ valores amostrais. Menciona que correlações entre pseudovalores são indesejáveis, causando viés na estimativa da variância, podendo esta ser sub ou superestimada.

Uma vantagem adicional deste método é que ao substituir o estimador convencional pelo estimador "jackknife" há uma redução de ordem $1 / p$ no viés (Efron \& Tibshirani, 1993); um "jackknife" de $p$-ésima ordem pode ser usado para remover viés de ordem $1 / n^{p}$ (Manly, 1997).

Além disso, ao estimar o parâmetro de interesse sem uma observação de cada vez, o método "jackknife" permite identificar as observações mais divergentes na amostra, pois, é possível verificar quais observações promovem maiores alterações na estimativa quando são retiradas (Carlini-Garcia, 2001).

Para Efron \& Tibshirani (1993), uma deficiência do método "jackknife" refere-se a estatísticas dadas por funções não-diferenciáveis, ou seja, aquelas que são pouco influenciadas por pequenas alterações no conjunto de dados, como por exemplo, a mediana. Neste caso, o estimador "jackknife" do erro-padrão dessas estatísticas torna-se inconsistente. Propõe remover $d$ observações por reamostragem "jackknife" ao invés de apenas uma, tomando como aproximação $(\sqrt{n} \leq d \leq n)$, sendo $n$ o número de observações da amostra. Outra desvantagem importante consiste no fato de o método não fornecer a distribuição do parâmetro. 
Segundo Efron \& Tibshirani (1993), no caso do cálculo do viés, o "jackknife" é uma aproximação do "bootstrap", sendo que se pode generalizar esse comportamento apenas para estatísticas do tipo não-linear.

Outro método computacionalmente intensivo que vem sendo cada vez mais utilizado é o "bootstrap", este termo surgiu da frase "to pull oneself up one's bootstrap" retirado do texto: "The Barom had fallen to the of a deep lake. Just when it looked like all was lost, he thought to pick himself up by his own bootstrap" de "Adventures of Baron Munchausem" de R. E. Raspe, século XVII. No qual relata uma situação em que o Barão estava afundando em um lago e vendo que tudo estava perdido, pensa que conseguirá emergir puxando os cadarços dos próprios sapatos (Efron \& Tibshirani, 1993).

A metáfora "bootstrap" refere-se ao fato de os dados serem usados em sua própria análise estatística. Dessa forma, todo resultado "bootstrap" depende diretamente da amostra original observada, isto é, os resultados "bootstrap" são consistentes para a amostra original. Este método é baseado na reamostragem de dados reais com reposição, para revelar algum padrão-estrutural neles presentes. A noção básica é de que os dados em si, vistos como distribuição de freqüências, representam a melhor imagem disponível da distribuição de freqüências da qual eles são amostrados (Crowley, 1992).

$\mathrm{Na}$ estatística, as situações difíceis podem ser vistas como os problemas de soluções analíticas complexas, e, as mais variadas soluções possíveis devem ser tentadas; essas seriam a utilização de uma metodologia com grande quantidade de cálculos para analisar um pequeno conjunto de dados. A solução para esses casos, com o uso de métodos computacionalmente intensivos, é obtida substituindo-se o poder analítico das expressões teóricas pelo poder de processamento das máquinas. Operacionalmente, o procedimento "bootstrap" consiste na reamostragem de mesmo tamanho e com reposição dos dados da amostra original, e cálculo da estatística de interesse para cada reamostra "bootstrap" (pseudodados) (Lavoranti, 2003). Foi definido por Efron (1979) como técnica desenvolvida para fazer certos tipos de inferências estatísticas. 
O método "bootstrap" é baseado no princípio "plug-in", um método simples de estimar parâmetros a partir de amostras. Considerando o parâmetro $\theta$ e uma função $t$ de probabilidade de uma distribuição $F$ qualquer de uma variável aleatória, a estimativa "plug-in" do parâmetro $\theta=t(F)$ é dada por $\hat{\theta}=t(F)$. Assim, estima-se a função $\theta=t(F)$ da distribuição de probabilidades $F$ pela mesma função da distribuição empírica $F, \hat{\theta}=t(F)$. A vantagem deste método consiste em produzir tendências e erros-padrões de forma automática, não importando quão complicada $\theta=t(F)$ seja. Este princípio é conveniente se a informação disponível sobre $F$ é proveniente de uma amostra $x$. Nesta situação, $\hat{\theta}=t(F)$ não pode ser melhorada como um estimador de $\theta=t(F)$. Contudo é menos apropriado em situações onde há informações sobre $F$, além das fornecidas pela amostra $x$. Sendo assim, pode-se assumir que $F$ é um membro da família paramétrica (Efron \& Tibshirani, 1993).

O "bootstrap" pode ser implementado tanto na estatística não-paramétrica quanto na paramétrica, dependendo apenas do conhecimento do problema. No caso paramétrico, o método "bootstrap" reamostra os dados com reposição, de acordo com uma distribuição empírica estimada, tendo em vista que, em geral, não se conhece a distribuição subjacente aos dados. É dita paramétrica quando se tem informação suficiente sobre a forma da distribuição dos dados; a amostra "bootstrap" é formada realizando-se a amostragem diretamente nessa distribuição com os parâmetros desconhecidos substituídos por estimativas paramétricas. A distribuição da estatística de interesse aplicada aos valores da amostra "bootstrap", condicional aos dados observados, é definida como a distribuição "bootstrap" dessa estatística (Lavoranti, 2003).

Uma outra aplicação da metodologia "bootstrap" segundo Crowley (1992), é nos testes de hipóteses, por exemplo, com dados de cada nível de tratamento, amostrados separadamente, com reposição. Os testes podem ser formulados de acordo com a extensão de sobreposição entre intervalos de confiança ou por combinar amostras "bootstrap" para calcular um teste estatístico. 
Lavoranti (2003) apresenta um esquema para melhor compreensão do método "bootstrap", conforme é mostrado a seguir.

Sejam o parâmetro $\theta$ e seu estimador a estatística $T_{n}(X, F)$, em que $X=\left[x_{1}, x_{2}, \cdots, x_{n}\right]$ é a (a.a.) disponível da v.a. com função de distribuição desconhecida $F(X \sim$ i.i.d.F $), \mathrm{e}$

$$
\hat{F}_{(n)}(x)=\frac{\left[\sum_{i=1}^{n} I\left(X_{i} \leq x\right)\right]}{n},
$$

em que:

$\hat{F}_{(n)}(x)$ : estimador não-paramétrico de máxima verossimilhança de $F$; $I\left(X_{i} \leq x\right)$ : função indicadora.

Assim, essa distribuição empírica é construída colocando-se massa probabilística $\frac{1}{n}$ em cada ponto amostral.

De $\hat{F}_{(n)}(x)(9)$ toma-se $B$ amostras "bootstrap" de mesmo tamanho $n$,

$$
\begin{array}{cc}
X_{1}^{*}=\left[x_{11}^{*}, x_{12}^{*}, \cdots, x_{1 n}^{*}\right] & X_{1 i}^{*} \sim i . i . d . \hat{F}_{n} \\
X_{2}^{*}=\left[x_{21}^{*}, x_{22}^{*}, \cdots, x_{2 n}^{*}\right] & X_{2 i}^{*} \sim \text { i.i.d. } \hat{F}_{n} \\
\vdots & \vdots \\
X_{B}^{*}=\left[x_{B 1}^{*}, x_{B 2}^{*}, \cdots, x_{B n}^{*}\right] \quad X_{B i}^{*} \sim \text { i.i.d. } \hat{F}_{n}
\end{array}
$$

calculam-se as $B$ estatísticas "bootstrap" $T_{n}^{*}\left(x_{l}^{*}\right)(l=1,2, \cdots, B)$, correspondentes às $B$ amostras "bootstrap", e forma-se o conjunto:

$$
\left\{T_{n}\left(x_{i}^{*}\right), \quad l=1,2, \cdots, B\right\}
$$

que é uma simulação da verdadeira distribuição amostral da estatística $T_{n}(x, F)$. 
Com o conjunto (10) pode-se obter a medida da variabilidade $\operatorname{de} T_{n}(x, F)$, como erro-padrão "bootstrap" $\left(\hat{\theta}^{*}=s\left(x^{*}\right)\right)$. A estimativa do vício da estatística $T_{n}(x, F)$ que é dada por:

$$
b\left[\theta, T_{n}(x, F)\right]=T_{n}(x, F)-T_{n}^{*},
$$

em que,

$$
T_{n}^{*}=\frac{\sum_{l \neq}^{B} T\left(x_{l}^{*}\right)}{B},
$$

que corresponde à estimativa "bootstrap" do parâmetro de interesse. 
Na figura 1, está apresentado um diagrama esquemático ilustrando a construção da distribuição "bootstrap"

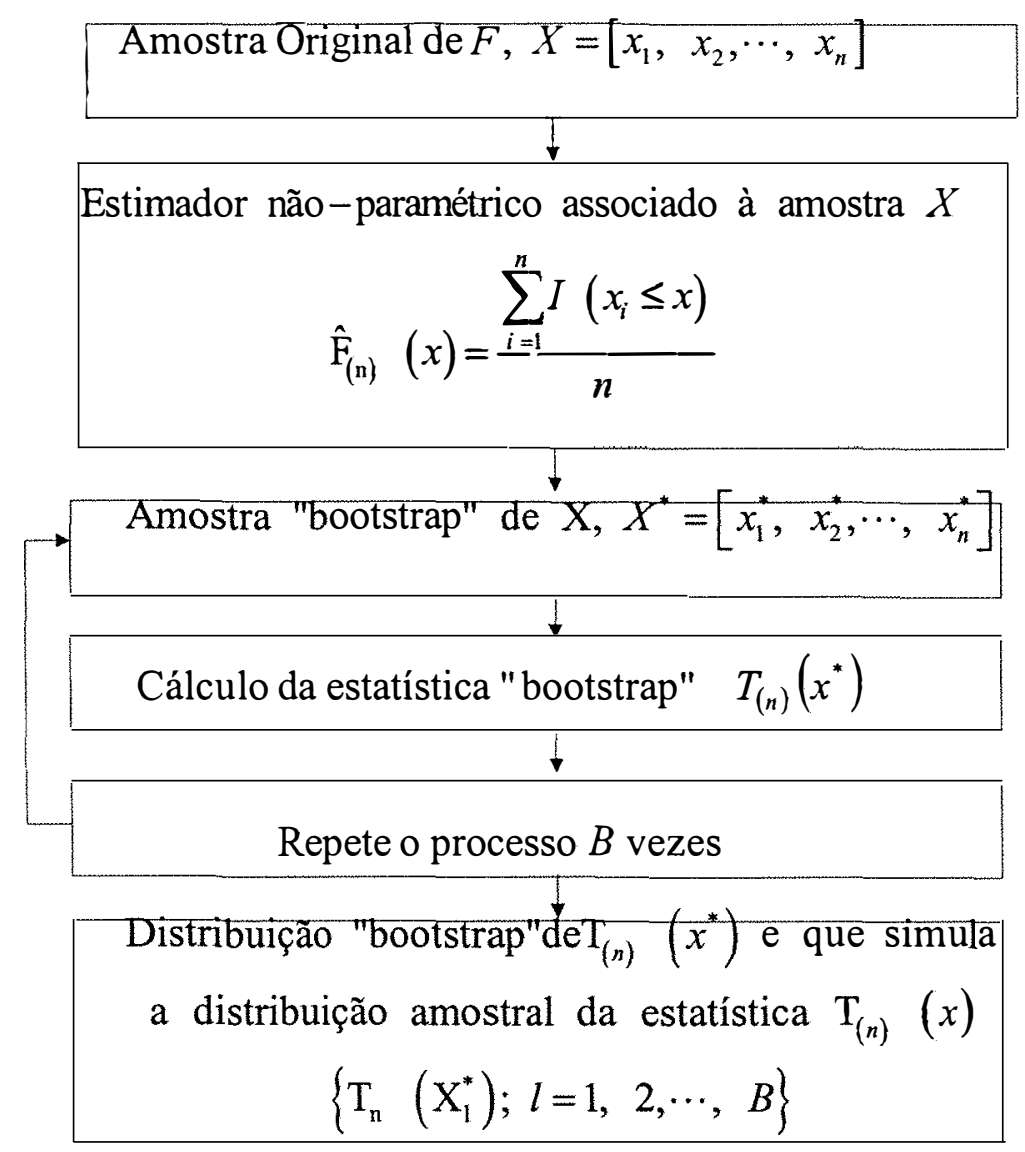

Figura 1. Diagrama da distribuição "bootstrap" da estatística $T_{n}(x, F)$ (Lavoranti, 2003)

Na prática, constrói-se a distribuição "bootstrap", (9), de $T_{n}(x, F)$ por simulação Monte-Carlo com um número de repetições, $B$, suficientemente grande. Um indicador do tamanho adequado de $B$, independentemente do custo computacional, é a qualidade da convergência da estimativa "bootstrap" do parâmetro para a estimativa natural do parâmetro $T_{n}^{*}(B \rightarrow \infty) \mapsto T \quad(x, F)$. A construção do algoritmo Monte-Carlo para obtenção da distribuição "bootstrap" das estatísticas usuais é em geral simples. Sua convergência está garantida pela lei dos Grandes Números, pois 
$T_{n}^{*}\left(X_{1}^{*}\right), T_{n}^{*}\left(X_{2}^{*}\right), \cdots, T_{n}^{*}\left(X_{B}^{*}\right)$ nada mais são do que uma amostra de v.a.'s i.i.d. com distribuição condicional de $T_{n}^{*}(X, \hat{F}) / X=x$.

Assim, quando $B$ tende a infinito, a média amostral $T_{n}^{*}$ (11) aproxima-se de $E\left[T_{n}(X, \hat{F}) / X=x\right]$. Efron (1979) sugeriu que a distribuição condicional "bootstrap" de $T_{n}(X, \hat{F}) / X=x$, pode ser usada como a distribuição de $T_{n}(X, F) / X=x$. Como se vê, no procedimento "bootstrap", os pontos da amostra original $\left[x_{1}, x_{2}, \cdots, x_{n}\right]$ são considerados como uma população com função de distribuição $\hat{F}$ e média $\bar{x}$. A estatística "bootstrap" $T_{n}^{*}=T_{n}^{*}(x, \hat{F})$ é considerada como um estimador de $T_{n}(x, F)$.

A distribuição de $T_{n}\left(x^{*}, \hat{F}\right)$ pode ser usada para aproximar a distribuição amostral desconhecida de $T_{n}(x, F)$, assim como, a distribuição de $\sqrt{n}\left(t_{n}^{*}-T_{n}\right)$ pode ser usada para aproximar a distribuição amostral de $\sqrt{n}\left(T_{n}-\theta\right)$ (Bickel \& Freedman, 1981 e Efron \& Tibshirani, 1993). A normalidade assintótica de $\sqrt{n}\left(T_{n}^{*}-T_{n}\right)$, e a convergência em probabilidade da variância "bootstrap" (12) foram apresentadas por Bickel \& Freedman, (1981).

$$
s^{* 2}=\frac{1}{B-1} \sum_{l=1}^{B}\left[T_{n}\left(x_{l}^{*}\right)-T_{n}^{*}\right]^{2}
$$

O número de vezes em que o ponto amostral $x_{i}$ é selecionado no procedimento "bootstrap" $\left(X^{*}=x^{*}\right)$ é representado por:

$$
N_{i}^{*}=\#\left\{X_{i}^{*}=x_{i}\right\},
$$


conseqüentemente, $\sum_{i}^{n} N_{i}^{*}=n$, e o vetor $N^{*}=\left[N_{1}^{*}, N_{2}^{*}, \cdots, N_{n}^{*}\right]$ tem distribuição multinominal. Vê-se que $N_{i}^{*} \sim b\left(n, \frac{1}{n}\right)$ e, em correspondência a esses números existe uma distribuição de freqüências relativas $f_{i}=\frac{N_{i}^{*}}{n}$, sendo que $f_{i}$ assume valores no conjunto $f\left\{0, \frac{1}{n}, \frac{2}{n}, \cdots, \frac{n}{n},\right\}$. A v.a. $f_{i}$ possui média e variância dadas por:

$$
N_{i}^{*} \sim b\left(n, \frac{1}{n}\right) \rightarrow\left\{\begin{array}{c}
E\left[f_{i}\right]=E\left[\frac{N_{i}^{*}}{n}\right]=\frac{1}{n} E\left[N_{i}^{*}\right]=\frac{1}{n} \\
V\left[f_{i}\right]=V\left[\frac{N_{i}^{*}}{n}\right]=\frac{1}{n^{2}} V\left[N_{i}^{*}\right]=\frac{n-1}{n^{3}}
\end{array}\right.
$$

Intervalos de confiança para parâmetros podem ser construídos com base em estatística "bootstrap" (Efron \& Tibshirani, 1986).

Conforme Efron \& Tibshirani (1993), a construção de intervalos de confiança baseados nas distribuições normal padronizada e $t$ podem ser obtidos desde que se obedeça às pressuposições usuais necessárias para tanto. Com os intervalos baseados nas distribuições normal e $t$, os pontos porcentuais são simétricos em relação a zero e, conseqüentemente, os intervalos de confiança resultantes são também simétricos em relação à estimativa pontual $\hat{\theta}$. Contudo, os percentis obtidos com esse tipo de intervalo podem apresentar assimetria em relação ao zero, fazendo com que os intervalos se desloquem à direita ou à esquerda. Esses autores lembram que este procedimento pode ser empregado para estimar intervalos de confiança de estatística de posição. Porém, não é recomendável quando aplicado em casos mais gerais como por exemplo, para construção de intervalos de confiança para coeficiente de correlação. Salientam que podem fornecer resultados errôneos e podem sofrer influência de valores anômalos.

Dentre os vários tipos de intervalos de confiança que podem ser construídos a partir da reamostragem "bootstrap", o mais simples dos intervalos "bootstrap" e que é 
também o mais difundido é o método percentil. Para Manly (1997), o uso desse tipo de intervalos baseia-se na tentativa de aproximar os percentis da distribuição de um estimador usando percentis gerados por "bootstrap". Existem na literatura vários tipos de intervalos percentis, sendo o mais simples deles aquele que substitui a estimativa do erro-padrão, pela estimativa "bootstrap". Manly (1997) ressalta que para intervalos percentis, é exigido número maior de amostras "bootstrap" em relação aos intervalos baseados na distribuição normal padronizada ou $t$, de forma que se obtenham estimativas acuradas dos pontos percentis da distribuição "bootstrap".

Efron \& Tibshirani (1986) propõem um procedimento para estabelecer um intervalo de confiança, com base em uma função monótona crescente $f$, tal que para $\varphi=f(\theta), \hat{\varphi}=f(\hat{\theta})$ e $\hat{\varphi}^{*}=f\left(\hat{\theta}^{*}\right)$ tem-se as quantidades pivotais Gaussianas $\hat{\varphi}-\varphi$ e $\hat{\varphi}^{*}-\hat{\varphi}$, ou seja:

$$
\hat{\varphi}^{*}-\hat{\varphi} \sim N\left(-z_{o} \sigma, \quad \sigma^{2}\right) \text { e } \hat{\varphi}-\varphi \sim N\left(-z_{o} \sigma, \sigma^{2}\right)
$$

para as constantes $z_{0}$ e $\sigma$. Portanto, $\hat{\varphi}-\varphi$ é uma quantidade pivotal Gaussiana sob $F$ e $\hat{F}$. Assim sendo, se $\hat{\theta}=\theta(\hat{F})$ então, $\hat{\varphi}=f(\hat{\theta})=f(\theta(\hat{F}))$. Sendo assim, o intervalo de confiança de nível $(1-\alpha)$ para $\varphi$, com base no pivô (13) é:

$$
P\left[\frac{\left|\hat{\varphi}-\varphi-\left(-z_{0} \sigma\right)\right|}{\sigma} \leq z_{\frac{\alpha}{2}}\right]=1-\alpha
$$

Como antes mencionado, o método mais simples para construir intervalos de confiança via "bootstrap" é o método percentil, Lavoranti (2003) apresenta ainda o esquema a seguir para melhor compreensão do mesmo: este método consiste em encontrar a distribuição $\hat{F}$ "bootstrap" (9) e calcular os percentis da distribuição $\hat{F}^{-1}\left(\frac{\alpha}{2}\right)$ e $\hat{F}^{-1}\left(1-\frac{\alpha}{2}\right)$, que correspondem aos limites inferiores $\left(L_{l}\right)$ e superiores $\left(L_{S}\right)$, respectivamente, do intervalo de confiança $(1-\alpha)$ 100\% (Efron \& Tibshirani, 1993). Na prática, esses intervalos $\left(L_{I}\right)$ e $\left(L_{S}\right)$, podem ser obtidos pelos valores relativos à 
parte inteira de $B \frac{\alpha}{2}$ e $B\left(1-\frac{\alpha}{2}\right)+1$, respectivamente, do ranqueamento das estatísticas "bootstrap" $T_{n}\left(X^{*}\right)$, obtidas em (10).

Um refinamento do método do percentil, denominado $B C_{a}$ "bias-corrected and accelerated" (Efron \& Tibshirani, 1993), apresenta alta acurácia na estimação dos intervalos de confiança para dados obtidos da distribuição "bootstrap" (Diciccio \& Efron, 1996). Esse método fixa os limites de confiança para o parâmetro $\theta$ em função dos percentis obtidos dos histogramas gerados pelas amostras "bootstrap". Os percentis são dados por:

$$
\hat{\theta}_{B C_{a}}[\alpha]=\hat{G}^{-1} \Phi\left(z_{0}+\frac{z_{0}+z^{\alpha}}{1-\alpha\left(z_{0}+z^{\alpha}\right)}\right)
$$

em que, $\hat{G}^{-1}$ é a inversa da função distribuição acumulada; $\Phi$ é a distribuição normal padronizada e $z^{\alpha}=\Phi^{-1}(\alpha)$.

Se $a$ e $z_{0}$ são nulos, então $\hat{\theta}_{B C_{a}}[\alpha]=\hat{G}^{-1}(\alpha)$ é o centésimo percentil 'bootstrap'. Assim, o intervalo de confiança fica determinado pelo $5^{\circ}$ e $95^{\circ}$ percentis "bootstrap". Se $G$ for uma distribuição perfeitamente normal, então $\hat{\theta}_{B C_{a}}=\hat{\theta}+z^{\alpha} \hat{\alpha}$, ou seja, um intervalo de confiança padrão com estimativas "bootstrap" (Diciccio \& Efron, 1996).

No caso de $a$ e $z_{0}$ serem diferentes de zero, excelentes estimativas para $a$ e $z_{0}$ são dadas por:

$$
\hat{\alpha}=\operatorname{Viés}_{\theta=\hat{\theta}} \frac{\left[l_{\theta}(\hat{\theta})\right]}{6},
$$

em que, $l_{\theta}(\hat{\theta})=\frac{\partial}{\partial \theta} \log \left\{g_{\theta}(\hat{\theta})\right\}$ e $g_{\theta}(\hat{\theta})$ é a densidade de $\frac{\partial G_{\theta}(\hat{\theta})}{\partial \hat{\theta}}$; 


$$
\hat{z}_{0}=\Phi^{-1}\left\{\frac{\#\left\{\hat{\theta}^{*}(b)<\hat{\theta}\right\}}{B}\right\} .
$$

Lavoranti (2003) mensiona o método "bootstrap-t" baseado na distribuição $t$ Student, como sendo bastante utilizado para determinar intervalos de confiança "bootstrap". Os limites de confiança são dados por:

$$
\left[T_{n}^{*}-t_{n-1}^{1-\alpha} s^{*}, T_{n}^{*}-t_{n-1}^{\alpha} s^{*}\right]
$$

em que, $T_{n}^{*}$ é definido na equação (11); $s^{*}$ é definido na equação (12) em que $t_{n-1}^{\alpha}$ é o valor de $t$, da tabela $t$-Student, ao nível de $(1-\alpha) 100 \%$, com n-1 graus de liberdade.

Incorporações ao método percentil foram propostas para construção de intervalos de confiança percentis corrigidos, como o intervalo de confiança percentil corrigido para viés "bias-corrected percentile confidence limits" e o intervalo de confiança percentil acelerado corrigido para o viés "accelerated bias-corrected percentile confidence limits". Estes foram desenvolvidos em função das distribuições de probabilidade; é importante mencionar que "bias-corrected percentile confidence limits", "accelerated bias-corrected percentile confidence limits" e bootstrap-t podem ser usados para a construção de intervalos de confiança não-paramétricos.

Métodos de reamostragem começam a se tornar ferramentas bastante úteis e importantes na construção de procedimentos inferenciais, evitando a obtenção de fórmulas via argumentos analíticos, tornando-se alternativas eficientes para os métodos estatísticos tradicionais (Lavoranti, 2003). 


\section{MATERIAL E MÉTODOS}

\subsection{Material experimental}

O material genético envolve três tipos de populações obtidas a partir de um dialelo parcial $4 \times 4$ desenvolvido com a finalidade de reunir os genes de tolerância/resistência a insetos presentes em quatro genitores (IAC-100, Crockett, Lamar e D72-9601-1), com genes para desempenho agronômico favorável (principalmente, produtividade de grãos e precocidade) presentes em quatro cultivares adaptadas (BR-6, IAS-5, Davis, Ocepar-4). Genótipos dos 16 cruzamentos do dialelo parcial foram avaliados em vários locais. Maiores informações sobre a geração $F_{2}$, método de condução das populações segregantes e avanço de gerações, podem ser obtidas no trabalho de Pinheiro (1998) e mais detalhes são mostrados a seguir.

Este estudo faz parte das linhas de pesquisa do Setor de Genética Aplicada às Espécies Autógamas do Departamento de Genética da ESALQ/USP. A diferenciação principal entre as três populações aconteceu na geração $F_{2}$, na qual foram empregados três procedimentos distintos de seleção de plantas individuais, conforme relatado a seguir:

- PCI (populações com controle de insetos): originadas da seleção para produtividade de grãos, a partir de 72 plantas $F_{2}$ de cada um dos 16 cruzamentos, em cultivo em covas na ESALQ; neste caso, aplicou-se inseticidas durante o ciclo total para o controle de insetos mastigadores e sugadores;

- PRIS (populaçòes selecionadas para resistência a insetos sugadores): obtidas pela seleção feita para tolerância a insetos sugadores entre 72 plantas $F_{2}$ de cada um dos 16 cruzamentos, em cultivo em covas em Mococa - SP (Estação Experimental do IAC); estas plantas receberam aplicaçòes de inseticidas apenas durante o ciclo vegetativo, com 
a finalidade de controlar insetos mastigadores; a partir do florescimento, nào foi feita nenhuma aplicaçào de inseticida, de maneira que os insetos sugadores pudessem desenvolver-se, multiplicar-se e atacar as vagens e gràos produzidos pelas plantas $F_{2}$;

- PRIM (populaçōes selecionadas para resistência a insetos mastigadores): sintetizadas após a seleçào para tolerância a insetos mastigadores (principalmente, lagartas) realizada entre 72 plantas $F_{2}$ de cada um dos 16 cruzamentos, em cultivo em covas em Campinas - SP (Centro Experimental do IAC); durante a fase vegetativa nào foi aplicado nenhum inseticida, de maneira que os insetos mastigadores tiveram condições para atacar as folhas das plantas; iniciou-se a aplicaçào de inseticidas após o florescimento, com a finalidade de controlar insetos sugadores.

A partir da geraçào $F_{3}$, os três tipos de populações foram conduzidas de maneira semelhante, através de experimentos realizados em locais diferentes, geralmente em cultivo atrasado (safrinha de outono - inverno), conforme esquematizado na Tabela 1. Em cada geraçào, promoveu-se seleçào principalmente para produtividade de gràos e tolerância ao fotoperíodo.

Os experimentos conduzidos em 1999/00 incluíram 120 linhagens experimentais, na geraçào $F_{10}$, sendo 40 linhagens de cada tipo de populaçào (PCI, PRIS e PRIM); os experimentos, conduzidos em 2000/01 envolveram um total de 60 linhagens $F_{11}$, sendo 20 linhagens selecionadas em cada uma das três populações, com base nos resultados obtidos no ano agrícola anterior.

Em todos os experimentos, as repetiçòes foram estratificadas em conjuntos experimentais, cada um deles com quatro testemunhas comuns: IAC-100, Ocepar-4, IAS-5 e Primavera. A cultivar Primavera foi eliminada nos experimentos do ano agrícola $2000 / 01$ 
Tabela 1. Resumo do avanço de endogamia com seleção dos três tipos de populaçooes sintetizadas, com a geração, número de progênies, local e época de semeadura. Soja

\begin{tabular}{|c|c|c|c|}
\hline Geração & \multicolumn{3}{|c|}{ Local/Época de Semeadura } \\
\hline $\mathrm{N}^{\circ}$ de Progênies & Populações PCI & Populações PRIS & Populaçōes PRIM \\
\hline$F_{3: 2}$ & ESALQ; 26/05/93 & $\begin{array}{c}\text { ESALQ; 08/93 a } \\
05 / 94\end{array}$ & Anhembi; 17/11/93 \\
\hline $\mathrm{N}$ & 1120 & (recuperação) & 1104 \\
\hline$F_{4: 2}$ & Anhembi; 08/06/94 & Anhembi; 08/06/94 & Anhembi; 02/02/95 \\
\hline $\mathrm{N}$ & 650 & 350 & 530 \\
\hline $\mathrm{F}_{5: 2}$ & $\begin{array}{l}\text { Anhembi; 18/10/95 } \\
\text { (recuperação) }\end{array}$ & $\begin{array}{c}\text { Anhembi; 18/10/95 } \\
\text { (recuperação) }\end{array}$ & $\begin{array}{c}\text { Anhembi; } 18 / 10 / 95 \\
293\end{array}$ \\
\hline $\mathrm{F}_{6: 2}$ & $\begin{array}{l}\text { Anhembi; } 09 / 07 / 96 \\
625\end{array}$ & $\begin{array}{l}\text { Anhembi; 09/07/96 } \\
575\end{array}$ & $\begin{array}{c}\text { Anhembi; } 09 / 07 / 96 \\
114\end{array}$ \\
\hline $\begin{array}{c}\mathrm{F}_{7: 2} \\
\mathrm{~N}\end{array}$ & $\begin{array}{c}\text { Anhembi; } 28 / 04 / 97 \\
100\end{array}$ & $\begin{array}{c}\text { Anhembi; } 28 / 04 / 97 \\
125\end{array}$ & $\begin{array}{c}\text { Anhembi; } 28 / 04 / 97 \\
73\end{array}$ \\
\hline$F_{8: 2}$ e $F_{8: 3}$ & $\begin{array}{c}\text { Anhembi e Areào } \\
20 / 01 / 98 \\
60\end{array}$ & $\begin{array}{c}\text { Anhembi e Areào } \\
20 / 01 / 98 \\
60\end{array}$ & $\begin{array}{c}\text { Anhembi e Areào } \\
20 / 01 / 98 \\
60\end{array}$ \\
\hline $\begin{array}{c}F_{9: 2} \text { e } F_{9: 3} \\
N\end{array}$ & $\begin{array}{c}\text { Anhembi e Areào } \\
11 / 98 \\
60\end{array}$ & $\begin{array}{c}\text { Anhembi e Areào } \\
11 / 98 \\
60\end{array}$ & $\begin{array}{c}\text { Anhembi e Areào } \\
11 / 98 \\
60\end{array}$ \\
\hline$F_{10: 2}$ e $F_{10: 3}$ & $\begin{array}{c}\text { Anhembi e Areào } \\
11 / 99 \\
40\end{array}$ & $\begin{array}{c}\text { Anhembi e Areào } \\
11 / 99 \\
40\end{array}$ & $\begin{array}{c}\text { Anhembi e Areào } \\
11 / 99 \\
40\end{array}$ \\
\hline$F_{11: 2}$ e $F_{11: 3}$ & $\begin{array}{c}\text { Anhembi e Areão } \\
11 / 00 \\
20\end{array}$ & $\begin{array}{c}\text { Anhembi e Areão } \\
11 / 00 \\
20\end{array}$ & $\begin{array}{c}\text { Anhembi e Areão } \\
11 / 00 \\
20\end{array}$ \\
\hline
\end{tabular}

\subsection{Instalação dos Experimentos}

Os 24 experimentos do presente estudo envolveram linhagens dos três tipos de população (PCI, PRIS e PRIM) e foram conduzidos em dois locais do município de Piracicaba, SP (Estação Experimental Anhembi e Fazenda Areão), durante dois anos agrícolas (1999/00,2000/01) e em dois sistemas de manejo (com controle intensivo de insetos e com controle ecológico de insetos). 
Nos experimentos com controle intensivo de insetos (CII), com base em monitoramento freqüente, promoveu-se a aplicação de inseticidas sempre que se detectaram insetos mastigadores e ou dois percevejos $/ \mathrm{m}^{2}$ de pano (método do pano de batida); este procedimento é recomendado para cultivos visando a produção de sementes e é um método de controle mais rigoroso do que aquele recomendado para cultivos comerciais de soja para produção de grãos, nos quais se aplicam inseticidas a partir de quatro percevejos $/ \mathrm{m}^{2}$ de pano.

Nos experimentos com controle ecológico de insetos (CEI), promoveu-se a aplicação de inseticidas apenas quando se observou a ocorrência de grande quantidade de danos nas folhas causadas por insetos mastigadores e ou quando a infestação natural atingiu quatro percevejos $/ \mathrm{m}^{2}$ de pano.

Todos os experimentos foram conduzidos no delineamento de blocos ao acaso, com as repetições estratificadas em conjuntos experimentais com testemunhas comuns. Inicialmente foram utilizados dois conjuntos por repetiçào, com 20 linhagens em cada um. Foram utilizadas 40 linhagens de cada tipo de população, totalizando 120 tratamentos; duas repetições por local, dois anos agrícolas e dois sistemas de manejo. Em cada população, local e ano agrícola, os dois experimentos correspondentes aos dois sistemas de manejo foram instalados em áreas contiguas (vizinhas) no campo.

Cada parcela foi composta por quatro fileiras de 5 metros de comprimento e espaçadas de 0,5 metros $\left(10 \mathrm{~m}^{2}\right)$, sendo que a área útil $\left(4 \mathrm{~m}^{2}\right)$ para a tomada dos dados compreendeu as duas fileiras centrais da parcela, sendo eliminados 0,5 metros de cada extremidade.

\subsection{Caráter Avaliado}

Em todos os 24 experimentos foi avaliado o caráter produtividade de grãos (PG) em gramas/parcela, através do peso dos grãos maduros colhidos na área útil de cada parcela, após um mínimo de três semanas de secagem em ambiente de laboratório para a padronizaçào da umidade. 


\subsection{Análises Estatísticas}

Antes de se proceder à análise de variância os dados foram transformados em $\mathrm{kg} / \mathrm{ha}$ e foi realizada a análise exploratória através da análise gráfica dos resíduos, conforme metodologia adotada por Carbonell (1995), Rocha (1998) e Soldini (1998). Essa análise detecta a existência ou nào de valores discrepantes (outliers), que interferem na normalidade dos resíduos, afetando por sua vez, uma das pressuposições importantes da análise de variância. Os valores atípicos foram substituídos pelos valores estimados pelo programa SAS. As análises de variância foram realizadas sem nenhuma transformação dos valores além daquela transformaçào para $\mathrm{kg} / \mathrm{ha}$.

\subsubsection{Análises de variância}

\subsubsection{Análise de variância para as testemunhas}

Com a finalidade de verificar a existência de diferenças entre conjuntos experimentais, inicialmente foram realizadas análises individuais de variância, seguidas de análise conjunta para os dois locais, para anos agrícolas, para cada tipo de populaçào e de sistema de manejo) e conjunta com desdobramentos de genótipos em linhagens e testemunhas comuns. Efeitos significativos para conjuntos experimentais e ou interaçào conjuntos $x$ testemunhas comuns indicariam a necessidade de se fazer ajustes das médias das linhagens em funçào das médias das testemunhas, dentro de cada conjunto experimental. Caso contrário (efeitos de conjuntos e interação conjuntos $x$ testemunhas nào significativos), não haveria necessidade de ajustes e a análise poderia ser feita em blocos ao acaso.

O modelo matemático adotado para a análise conjunta geral é apresentado conforme a equaçào 15 a seguir:

$Y_{i k l m}=\mu+t_{i}+a_{n}+l_{l}+(t l)_{i l}+(l a)_{n m}+c_{k(l m)}+(c t)_{k i}+(t l a)_{t l n}+\varepsilon_{i k l m}$ 
sendo:

$Y_{i k l m l}$ : observação referente à testemunha "i", no conjunto "k", no local "l”, no ano "m";

$\mu$ : média geral do caráter;

$t_{i}$ : $\quad$ efeito fixo da testemunha "i";

$a_{\mu}$ : efeito aleatório do ano "n"

li: $\quad$ efeito fixo do local "l";

$(t l)_{i l}$ : $\quad$ efeito fixo da interação entre a testemunha "i" e o local "l";

(la) $l_{n}$ : efeito aleatório da interação entre o local "l" e o ano "n";

$c_{k(I m)}: \quad$ efeito aleatório do conjunto "k", dentro do ano "m", dentro do local "l";

$(c t)_{k i}$ : efeito aleatório da interação entre o conjunto "k" e a testemunha "i";

$\left(\right.$ tla $_{\text {tlnn }}$ : efeito aleatório da interação tripla entre a testemunha "ị", o local "l" e o ano "n";

$\varepsilon_{i k l m}$ : efeito aleatório do erro experimental médio associado à parcela "iklm", admitido ser independente e com distribuição normal de média zero e variância $\sigma^{2}$.

\subsubsection{Análise de variância para as linhagens}

Os dados de produtividade de grãos, em kg/ha, foram submetidos a análises de variância individuais, dentro de cada tipo de população, manejo, local e ano agrícola; a seguir, foi testada a homogeneidade dos quadrados médios residuais, os quais foram considerados homogêneos sempre que a relação entre o maior e o menor foi inferior a sete (Pimentel Gomes, 1990).

O modelo adotado para a análise individual de variância foi o seguinte:

$$
Y_{l j k}=\mu+G_{i}+r_{j}+c_{k}(r)_{j}+\varepsilon_{i j k}
$$

sendo: 
$Y_{i j k}$ : observação do genótipo "i” na repetição “j”, no conjunto k;

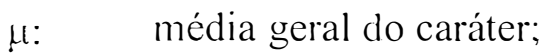

$\mathrm{G}_{\mathrm{i}}$ : efeito fixo da linhagem " $\mathrm{i}$ "; $i=1, \ldots, \mathrm{g}$;

$\mathrm{r}_{\mathrm{j}}$ : efeito aleatório da repetição “ $\mathrm{j}$ ”; $\mathrm{j}=1, \ldots, \mathrm{J}$;

$c_{k}(r)_{j}$ : efeito aleatório de conjunto " $k$ " dentro de repetição "j”; $k=1, \ldots, K$;

$\varepsilon_{\mathrm{ijk}}$ : $\quad$ erro experimental associado à parcela "ijk", admitido ser independente e com distribuição normal de média zero e variância $\sigma^{2}$.

Em seguida, foi realizada uma análise conjunta de variância para populações (POP), sistemas de manejos (M), locais ( $L$ ) e anos (A), tendo como principal objetivo estimar as possiveis interações entre linhagens, locais, anos e manejos. Nesta análise, foram considerados fixos os efeitos de populaçōes (linhagens - P1, P2,...,P20 e testemunhas comuns - T1, T2 e T3), visto que as mesmas se originaram de diferentes cruzamentos, não representando uma mesma população. O efeito de locais foram considerados fixos, uma vez que os mesmos foram escolhidos por serem contratantes em uma série de características como: tipo de solo, fertilidade e topografia; o efeito de manejos também foi considerado fixo por envolver diferenças eleitas à priori e poder ter sua condição reproduzida satisfatoriamente; conseqüentemente, as interações entre linhagens e locais $(\mathrm{PxL})$, linhagens e manejos (PxM), manejos e locais (MxL) e linhagens, manejos e locais (PxMxL) foram consideradas fixas. Os efeitos de repetições e anos, e as interações que envolvem estes efeitos, foram tratados de forma aleatória. $\mathrm{O}$ modelo matemático foi utilizado de acordo com a equação 17 a seguir:

$$
\begin{aligned}
& Y_{i k i m l n}=\mu+P_{p}+G_{i}(P)_{p}+M_{m}+(P M)_{p m n}+M G_{m g}(P)_{p}+A_{n}+(P A)_{p m}+A G_{m i}(P)_{p}+(M A)_{m n}+ \\
& (P M A)_{p m l n}+M A G_{m n l i}(P)+L_{l}+(P L)_{p l}+L G_{l i}(P)_{p}+(M L)_{m l}+(P M L)_{p m l}+M L G_{m l i}(P)_{p}+ \\
& (A L)_{n l}+(P A L)_{p m l}+A L G_{n l i}(P)_{p}+(M A L)_{m n l}+(P M A L)_{p m n l}+M A L G_{m n l i}(P)_{p}+R_{j} / M_{m l} / A_{n} / L_{l}+ \\
& C_{k} / M_{m} / A_{n} / L_{l} / R_{j}+\varepsilon_{i p j m l n k}
\end{aligned}
$$

em que: 


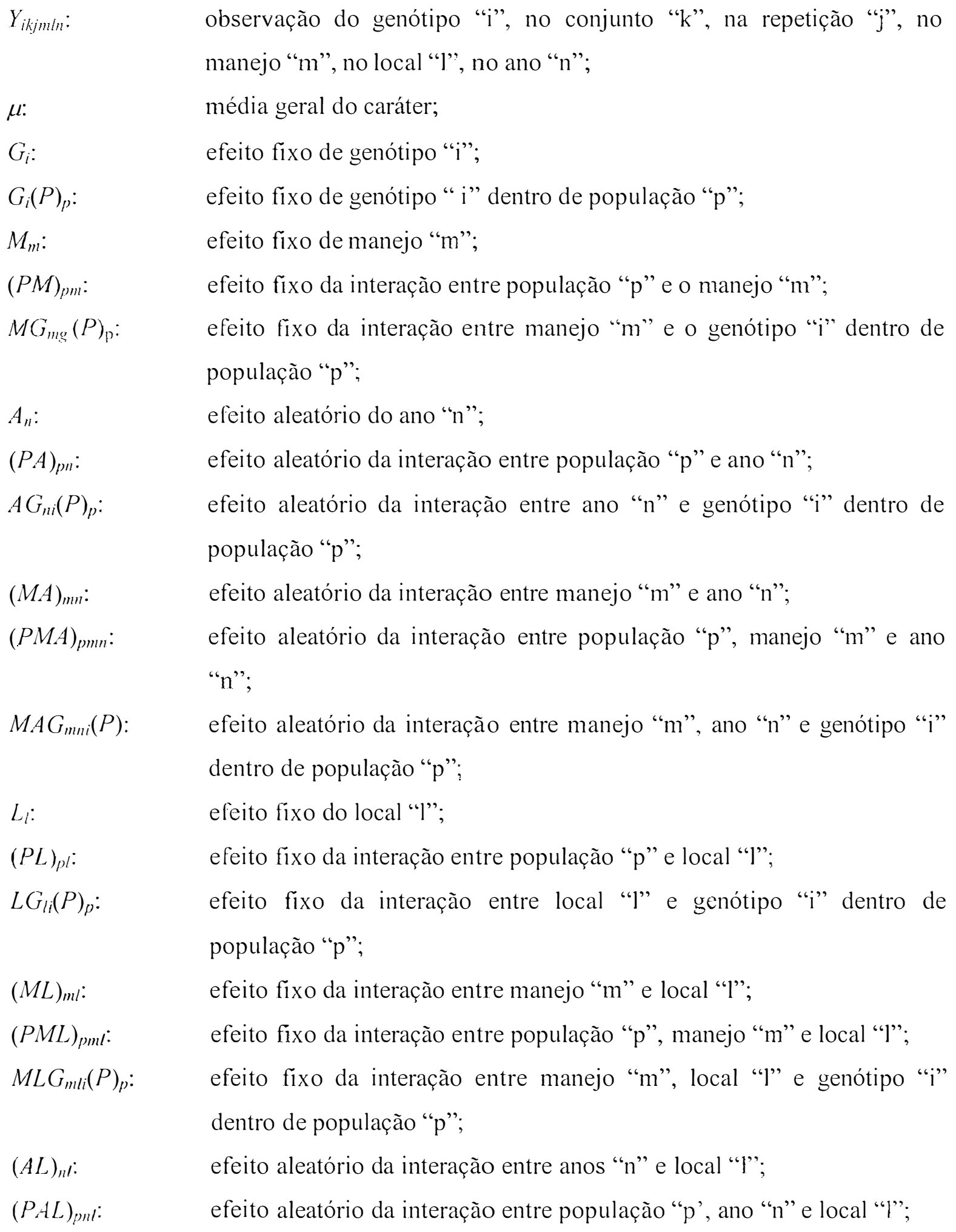


$A L G_{l l i}(P)_{p}: \quad$ efeito aleatório da interação entre ano "n", local "l" e genótipo "i" dentro de populaçào "p";

$(M A L)_{m u l}$ : $\quad$ efeito aleatório da interação entre manejo "m", ano "n" e local "l";

$(P M A L)_{\text {pmunl }}$ : efeito aleatório da interação entre população "p", manejo "m", ano "n" e local "l";

$\operatorname{MALG}_{\text {muli }}(P)_{p}:$ efeito aleatório da interaçào entre manejo "m", ano "n", local "l" e genótipo "i" dentro de população "p",

$R_{j} / M_{m l} / A_{n} / L_{l}: \quad$ efeito de repetiçào "j' dentro de manejo " $m$ " dentro de ano "n' dentro de local "l';

$C_{k} / M_{m l} / A_{n l} / L_{l} / R_{j}$ : efeito de conjunto "k" dentro de manejo " $m$ " dentro de ano " $\mathrm{n}$ ' dentro de local "l' dentro de repetição "j";

$\bar{\varepsilon}_{i j t m}$ : $\quad$ erro aleatório experimental médio associado à parcela "pijklnm", admitido ser independente e com distribuição normal de média zero e variância $\sigma^{2}$.

Todas as análises de variância foram realizadas utilizando-se o procedimento GLM do programa SAS (Statistical Analysis System) (Sas Institute, 1997).

\subsubsection{Análise de adaptabilidade e de estabilidade fenotípica}

\subsubsection{Via método AMMI}

Para a análise da adaptabilidade e de estabilidade fenotípica das linhagens, considerou-se como ambiente a combinação de ano, local e manejo. Assim, pela combinação dos dois locais (Anhembi e Areão) com os dois anos agrícolas (1999/00 e 2000/2001) e os dois sistemas de manejo (controle intensivo de insetos $=\mathrm{Cl}$ e controle ecológico de insetos $=\mathbf{C E I})$, obteve-se oito ambientes distintos $(\mathrm{E} 1, \mathrm{E} 2, \ldots, \mathrm{E} 8)$ para cada tipo de população (População 1 - PCI, Populaçào 2 - PRIS e População 3 - 
PRIM), quais sejam: [Anhembi-Cll-2000 (E1), Anhembi-CEI-2000 (E2), Areão-CII2000 (E3), Areão-CEI-2000 (E4), Anhembi-Cll-2001 (E5), Anhembi-CEI-2001 (E6), Areão-CII-2001 (E7) e Areão-CEI-2001 (E8)]. A análise foi realizada com as médias das duas repetições em cada ambiente e população.

As análises de estabilidade e adaptabilidade fenotípica foram realizadas pelos métodos: AMMI (Additive Main effects and Multiplicative Interaction) (Zobel et al. 1988); a técnica combina métodos univariados (análise de variância) para componentes principais e trata a interação multiplicativa destes fatores com base na análise multivariada por componentes principais e decomposição por valores singulares, equaçào (19). Foram empregados os testes $F_{\text {(iollol, e } F_{R}}$ (equaçào 21) propostos por Gollob (1968), Comelius et al. (1992) e Piepho (1995); foi feita a associaçào entre "bootstrap" e AMMI (Lavoranti, 2003), com base na reamostragem da matriz de resíduos, livres de ruídos, obtida dos valores estimados pelo método AMMI proposto por Gollob (1968). Nos dois casos, foram esquematizadas as análises de variância pelo quadro completo da análise conjunta, a partir das médias (Duarte \& Vencovsky, 1999) (Tabela 2). 
Tabela 2 Análise conjunta de variância, a partir de médias, usando os procedimentos de Gollob (1968), Comelius et al. (1992) e Piepho (1995), incluindo o desdobramento da interação $\mathrm{G}$ x E

\begin{tabular}{|c|c|c|c|c|}
\hline \multirow[b]{2}{*}{$\begin{array}{l}\text { Fontes de } \\
\text { Variaçào }\end{array}$} & \multicolumn{2}{|c|}{ Cornelius } & \multicolumn{2}{|c|}{ Gollob } \\
\hline & $\begin{array}{c}\text { Graus de Liberdade } \\
\text { (GL) }\end{array}$ & $\begin{array}{c}\text { Soma de Quadrados } \\
\qquad(S Q)\end{array}$ & $\begin{array}{c}\text { Graus de Liberdade } \\
\text { (GL) }\end{array}$ & Soma de Quadrados $(S Q)$ \\
\hline Genótipos (G) & - & - & $g-1$ & $S Q(G)$ \\
\hline Ambientes (E) & - & - & $e-1$ & $S Q(E)$ \\
\hline$(\mathrm{GxE})$ & - & - & $(g-1)(e-1)$ & $S Q(G X E)$ \\
\hline IPCAI & $(g-1-1)(e-1-1)$ & $\sum_{k=2} \lambda$ & $g+e+1-(2 \times 1)$ & $\lambda_{1}^{2}$ \\
\hline IPCA2 & $(g-1-2)(e-1-2)$ & & $g+e+1-(2 \times 2)$ & $\lambda_{2}^{2}$ \\
\hline IPCA3 & $(g-1-3)(e-1-3)$ & $\sum_{k=4} \lambda_{k}^{2}$ & $g+e+1-(2 \times 3)$ & $\lambda_{3}^{2}$ \\
\hline$\cdots$ & & & $\ldots$ & $\cdots$ \\
\hline IPCAn & & & $g+e+1-(2 x n)$ & $\lambda_{n}^{2}$ \\
\hline Erro Médio/r & & & ge $(n-1)$ & $S Q($ erro médio $)$ \\
\hline Total & & & ger - 1 & $S Q($ total $)$ \\
\hline
\end{tabular}

G: número de genótipos;

e: número de ambientes;

$\lambda$ : $\quad$ valor singular (escalar) da matriz de interação $\mathbf{G E} ; \mathrm{n}=$ mínimo (g-1, e-1);

IPCA: eixo da interação da análise de componentes principais.

A análise AMMI foi realizada em duas etapas seqüenciais: 1) os efeitos principais, na parte aditiva (média geral, efeitos de genótipos e ambientes), foram ajustados por análise de variância (ANAVA), resultando em un resíduo de não aditividade (interação GxE); 2) a interação (parte multiplicativa do modelo) foi analisada pela Análise de Componentes Principais (ACP). O modelo geral usado foi de acordo com aquele apresentado por Duarte \& Vencovsky (1999), segundo a equação 19 a seguir: 


$$
Y_{i j}=\mu+g_{i}+e_{i}+\sum_{k=1}^{p} \lambda_{k} \gamma_{i k} \boldsymbol{\alpha}_{i k}+\rho_{i j}+\bar{\varepsilon}_{i j}
$$

sendo:

$Y_{i j}$ : resposta média das repetiçōes do i-ésimo genótipo no j-ésimo ambiente;

$\mu$ : $\quad$ a média do i-ésimo genótipo em todos os ambiente (média geral);

$g_{i}$ : $\quad$ o efeito principal do genótipo “i”;

$e_{j}$ : o efeito principal do ambiente “ j”;

$\bar{\varepsilon}_{i j}: \quad$ erro experimental médio;

$i$ : $\quad$ variações de genótipos, $i=(1,2,3, \ldots, g)$;

$j: \quad$ variaçòes de ambientes, $j=(1,2,3, \ldots, \mathrm{e})$.

A interação (GxE) foi modelada de acordo com a equação 20:

$$
\sum_{k=1}^{p} \lambda_{k} \gamma_{i k} \alpha_{j k}+\rho_{i i}
$$

em que:

$\lambda_{k}: \quad$ é o valor singular do n-ésimo componente principal da interação (CPI) retido no modelo AMMI;

Yih: $\quad$ é o vetor singular do i-ésimo genótipo no n-ésimo CPI;

$\alpha_{j k}$ : é o vetor singular do j-ésimo ambiente no n-ésimo CPI;

$\rho_{i j}$ : $\quad$ o resíduo da interaçào G x E ou resíduo AMMI (ruído presente nos dados);

p: $\quad$ o número de CPI's retidos no modelo;

$k$ : raízes características nào nulas, $k=(1,2, \ldots, \min (g-1, e-1)$. 
Para definiçào do número de eixos a serem retidos afím de explicar o padrão relacionado à interaçào, foram adotados os critérios propostos por Gauch \& Zobel (1988), levando em consideração a proporção da soma de quadrados da interaçào $\left(S Q_{G X E}\right)$ acumulada até o n-ésimo eixo $\sum_{k=1}^{n} \lambda_{k}^{2} / Q M_{(G X E)}$. Dessa forma, o ponto de parada que determina a seleção do modelo de cada membro da família de modelos AMMI (AMMI0, AMMI1,..., AMMIn), foi obtido com base na significância dos testes $F_{\text {(jollob }}$ e $F_{R}$, para os sucessivos termos da interação. Sendo assim, o ruído AMMl, reunindo os demais termos da $\left(S Q_{\text {(ivE }}\right)$ (não retidos no modelo selecionado), também pode ser testado de maneira a assegurar o seu caráter desprezível, através da significância dos testes $F_{\text {Golloh }}$ e $F_{R}$ (Cornelius et al., 1992; Piepho, 1995), descrito pela equação 21 a seguir:

$$
F_{R, \|}=\left(S Q_{G, E}-\sum_{k=1}^{n} \lambda_{k}^{2}\right) /\left(f_{2} \cdot Q M_{\text {Firromédio }}\right)
$$

$$
\text { com: } f_{2}=(g-1-n)(a-1-n)
$$

em que:

$f_{2}$ : o número de graus de liberdade associados a cada parcela da interação GxE, com n termos multiplicativos incluídos no modelo definido por Gollob (1968).

O ponto forte da análise é sumarizar grande parte da interaçào (GxE) em apenas uns poucos eixos ( $S Q_{\text {GiVE }}$ Padrào), consumindo assim, poucos graus de liberdade e resultando num modelo reduzido e parcimonioso, que descarta um resíduo adicional ( $S Q_{\text {GixE }}$ Ruídos $)$ (Rocha, 2002). Segundo Gauch (1988), o procedimento AMMI faz a decomposiçào da soma de quadrados original $\left(S Q_{G, E}\right)$ em eixos singulares ortogonais, que podem ser separados em duas partes, padrão e ruído. Os primeiros eixos associados 
ao modelo AMMI detêm praticamente todo o padrão devido à interação, e os eixos de mais alto grau captam, praticamente, somente ruídos.

Sendo assim, o padrão possibilita a identificação de fatores genotípicos e ambientais mais associados à interação, e, o ruído, sem interesse agronômico é descartado, propiciando uma melhoria na capacidade preditiva das respostas fenotípicas (Lavoranti, 2003).

Assim sendo, após seleção feita através da significância do IPCA a $1 \%$ de probabilidade, de acordo com os níveis de significância do teste $F_{\text {Gollob }}$, puderam ser feitas as inferências sobre adaptabilidade e estabilidade fenotípica.

De acordo com Lavoranti (2003), as adaptabilidades como reflexo do nível de aproveitamento ao estímulo ambiental, mantendo sua alta média de produtividade, foram estimadas em função das respostas para cada combinação de genótipos e ambientes, sobre o modelo AMMI selecionado. As respostas esperadas dos genótipos i (i = $1,2,3, \ldots, \mathrm{g})$ nos ambientes $\mathrm{j}(\mathrm{j}=1,2,3, \ldots, \mathrm{e})$, ou seja, as $\left(\hat{Y}_{i j}\right)$, foram determinadas pela equaçào:

$$
\hat{Y}_{i j}=\bar{Y}_{i}+\bar{Y}_{j}-\bar{Y}_{. .}+\sum_{k-1}^{p} \lambda_{k} \gamma_{i k} \alpha_{j k}+\rho
$$

Sendo:

p: número de eixos significativos para a decomposição da interação ( $G x E)$; com $p \leq 7$;

$\bar{Y}_{i}$ : média do genótipo “i” no ambiente “j”, predita pelo modelo AMMIn selecionado;

$\bar{Y}_{i j}$ : média do ambiente "j" predita pelo modelo AMMIn selecionado;

$\bar{Y}$ : média geral predita pelo modelo AMMIn selecionado;

$\lambda_{k}$ : k-ésimo valor singular (escalar) da matriz de interaçào original (denotada por $\mathbf{G E}_{\mathrm{gre}}=|(\hat{g} e)|_{i j}, \operatorname{com} \hat{g} e_{i j}=\left(Y_{i j}-\bar{Y}_{i}-\bar{Y}_{. j}+\bar{Y}_{. .}\right)$;

$\gamma_{i k}$ : elemento correspondente ao i-ésimo genótipo no k-ésimo vetor singular coluna da 
matriz GE e;

$\alpha_{j k}$ : o elemento correspondente ao j-ésimo ambiente no $\mathrm{k}$-ésimo vetor singular linha da matriz GE. Os termos: $\lambda_{k}, \gamma_{k}$ e $\alpha_{j k}$ foram obtidos pela decomposição por valores singulares (DVS) da matriz de interação GE.

Os escores de genótipos $(\mathbf{G})$ e de ambientes $\left(\mathbf{H}^{\prime}\right)$ foram obtidos pela decomposição aproximada por n componentes:

$$
\begin{aligned}
\mathrm{GE} & =\mathrm{USV}^{\prime}=\mathrm{US}^{1 / 2} \mathrm{~S}^{1 / 2} V^{\prime} \\
\mathrm{G} & =\mathrm{US}^{1 / 2} \\
\mathrm{H}^{\prime} & =\mathrm{S}^{1 / 2} \mathrm{~V}^{\prime}
\end{aligned}
$$

Em que:

$\mathbf{U}$ é a matriz com vetores singulares-coluna $\gamma_{i k}$;

$\mathrm{S}$ é a matriz com os valores singulares $\lambda_{k} \mathrm{e}$, $V^{\prime}$ é a matriz com vetores singulares- linha $\alpha_{j k}^{\prime}$.

A matriz de interação GE é modelada por $\sum_{k=1}^{p} \lambda_{k} \gamma_{i h} \alpha_{i h}+\rho_{i j}$, sob as restrições de identificabilidade $\sum_{i=1}^{g} g_{i}=\sum_{j=1}^{i} e_{j}=\sum_{i=1}^{g}(g e)_{i j}=\sum_{j=1}^{e}(g e)_{i j}=0$. O termo GE (interação no modelo tradicional), na metodologia AMMI é representado pela soma de p parcelas, cada uma resultante da multiplicação de $\lambda_{k}$, expresso na mesma unidade de $Y_{i j}$, por um efeito genotípico $\left(\gamma_{i k}\right)$ e um efeito ambiental $\left(\alpha_{j k}\right)$, ambos adimensionais, ou seja, $\sum_{k=1}^{n} \lambda_{k} \gamma_{i k} \alpha_{j k}$ (n: termos da interação). O termo $\lambda_{k}$ traz uma informação relativa a k-ésima 
parcela da interação $\mathrm{G} \times \mathrm{E}$; os efeitos $\gamma_{i k}$ e $\alpha_{j k}$ representam os pesos do genótipo i e do ambiente j, naquela parcela da interação.

Os resultados da análise foram apresentados graficamente em biplot (Gabriel, 1971). A adaptabilidade, estimada via AMMI, foi interpretada através da exploração do efeito positivo da interação GxE. Sendo assim, foram observados os produtos entre os escores de genótipos e de ambientes, os quais forneceram as estimativas dos efeitos da interação. Os efeitos positivos desses produtos indicaram as situações favoráveis dos genótipos a aqueles ambientes. Estas relações adaptativas também foram verificadas pelos gráficos biplots AMMI selecionados, através das observações dos sinais dos escores para cada par de genótipos e ambientes. Indicações das adaptabilidades foram associadas aos genótipos e ambientes com escores de mesmo sinal, evidenciando um sinergismo adaptativo (Lavoranti, 2003). As relações adaptativas podem ser facilmente percebidas num biplot AMMI observando-se a magnitude e o sinal dos escores para cada par de genótipos e ambientes. Assim, genótipos e ambientes com escores de mesmo sinal $(-,-$ ou,++$)$ devem interagir positivamente. Já aqueles com sinais opostos $(+,-)$ devem interagir negativamente (Duarte \& Vencovsky, 1999). Tem-se observado em alguns trabalhos que nem sempre essa relação se mostra perfeitamente interpretável graficamente (Rocha, 2002).

Como lembra Duarte \& Vencovsky (1999), a interpretação de um biplot quanto à interação GxE é feita observando-se a magnitude e o sinal dos escores de genótipos e ambientes para o(s) eixo(s) que representa(m) a interação. Assim, os escores baixos (próximos de zero) são próprios de genótipos e ambientes que contribuem pouco para a interação, caracterizando-os como estáveis. Num biplot AMMI1, a estabilidade é avaliada inspecionando-se as ordenadas (CPI1). Logo, os pontos situados na faixa horizontal em torno de zero em relação ao CPIl correspondem aos genótipos e ambientes mais estáveis. Num biplot AMMI2, genótipos e ambientes estáveis são aqueles cujos pontos situam-se próximo à origem, ou seja, com escores praticamente nulos para os dois eixos da interação, que são próprios de genótipos e ambientes que contribuíram pouco ou quase nada para a interação (CPI1 e CPI2; Duarte \& Vencovsky, 1999). O que importa num diagrama de dispersão multivariado (biplot) são as posições 
relativas entre os genótipos, entre os ambientes e a comparação entre eles; as inferências devem ser tomadas avaliando-se distâncias, proximidades e projeções relativas (Duarte', 2003).

No presente estudo, como os ambientes representam um mesmo local em dois anos, valores baixos para o(s) eixo(s) de interação indicam que a classificação de genótipos de um ano para outro, neste local, é pouco variável, resultando numa classificação mais consistente. Uma maior repetibilidade da classificação, ao longo dos anos, está associada a uma maior confiabilidade na seleção de genótipos (Duarte \& Vencovsky, 1999).

A análise AMMI foi realizada utilizando os procedimentos GLM e IML do programa computacional SAS (SAS Institute, 1997), de acordo com o programa sugerido por Duarte \& Vencovsky (1999).

\subsubsection{Via método "bootstrap" AMMI}

A técnica via reamostragem "bootstrap", no modelo AMMI, em conjunto com representações gráficas de regiões de confiança para a estabilidade e gráficos de dispersões dos escores "bootstrap" em biplot foi apresentada por Lavoranti (2003) como um recurso estatístico que melhora a qualidade para predições das estabilidades fenotípicas, quando comparado ao método tradicional AMMI, com representação gráfica em diagrama de dispersão multivariado (biplot).

- comunicação pessoal do Professor Joào Batista Duarte, Universidade Federal de Goiás, Goiânia - GO, 2003. 
O desenvolvimento da metodologia "bootstrap" AMMI feita por Lavoranti (2003) consiste em se executar o método AMMI seguindo a proposta de Gollob (1968), a qual garante pelo menor rigor dos graus de liberdade, um número maior de fatores multiplicativos e, conseqüentemente, capta todo o padrão devido à interação GxE. A partir desse modelo, foram determinadas as estimativas dos genótipos $i$ nos ambientes $j\left(\hat{Y}_{i j}\right)$ livres de interferência de ruídos, conforme equação (22), e, a partir desse novo conjunto de dados, foram obtidas as matrizes de resíduos $\mid \hat{G} E_{G i t}=\left(\hat{g} e_{i j}\right)$ representadas por:

$$
\hat{G} E_{G i x:}=\left|\begin{array}{cccc}
\hat{g} e_{11} & \hat{g} e_{12} & \cdots & \hat{g} e_{1 c} \\
\hat{g} e_{21} & \hat{g} e_{22} & \cdots & \hat{g} e_{2 c} \\
\vdots & \vdots & \cdots & \vdots \\
\hat{g} e_{g 1} & \hat{g} e_{g 1} & \cdots & \hat{g} e_{g c}
\end{array}\right|
$$

com:

$$
\hat{g} e_{i j}=\hat{y}_{i j}-\hat{\bar{y}}_{i .}-\hat{\bar{y}}_{. j}+\hat{\bar{y}}
$$

sendo que:

$\hat{\bar{y}}_{i}$ : é a média dos valores estimados do genótipo $i$;

$\hat{\bar{y}}_{j}:$ é a média dos valores estimados do ambiente $j$;

$\hat{y}$ : é a média geral dos valores estimados.

Os resíduos também poderiam ser obtidos diretamente fazendo a soma de quadrados até p, dispensando assim a estimaçào dos mesmos (Duarte ${ }^{2}$, 2003).

2 - comunicação pessoal do Professor João Batista Duarte, Universidade Federal de Goiás, Goiânia - GO, 2003. 
Das matrizes $\hat{G} E_{G \vee E}$, foram reamostradas 200 matrizes "bootstrap" para genótipos $\left(G E_{g}^{*}\right)$, sendo o sorteio com reposiçào executado nas linhas; e também, foram reamostradas 200 matrizes "bootstrap" para ambientes $\left(G E_{c}^{*}\right)$, sendo o sorteio com reposição executado nas colunas. Assim, obteve-se:

$$
\hat{G} E_{k l}^{*}=\left|\begin{array}{cccc}
g e_{11}^{*} & g e_{12}^{*} & \cdots & g e_{12}^{*} \\
g e_{21}^{*} & g e_{22}^{*} & \cdots & g e_{2 c}^{*} \\
\vdots & \vdots & \cdots & \vdots \\
g e_{g 1}^{*} & g e_{g 2}^{*} & \cdots & g e_{g c}^{*}
\end{array}\right|
$$

com $: \mathrm{k}=\mathrm{g}$ ou $\mathrm{k}=\mathrm{e}$, para genótipos ou ambientes, respectivamente e $l=(1,2, \ldots, 200)$.

As matrizes "bootstrap" de residuos foram centradas em relaçào às médias de linhas, de coluna e geral, a fim de atender às restrições de identificabilidade da matriz de resíduos (W. I. Krzanowski em 2002, citado por Lavoranti, 2003).

Assim, de maneira esquemática, foram determinadas as matrizes $\left(\widetilde{G} E_{k l}^{*}\right)$, denominadas de matrizes "bootstrap" de residuos corrigidos:

$$
\widetilde{G} E_{k l}^{*}=\left|\begin{array}{cccc}
\widetilde{g} e_{11}^{*} & \widetilde{g} e_{12}^{*} & \cdots & \widetilde{g} e_{1 c}^{*} \\
\widetilde{g} e_{21}^{*} & \widetilde{g} e_{22}^{*} & \cdots & \widetilde{g} e_{2 c}^{*} \\
\vdots & \vdots & \cdots & \vdots \\
\widetilde{g} e_{g 1}^{*} & \widetilde{g} e_{g 2}^{*} & \cdots & \widetilde{g} e_{g c}^{*}
\end{array}\right|,
$$

em que:

$$
\begin{aligned}
\tilde{g} e_{i j}^{*} & =\hat{g} e_{i j}^{*}-\frac{1}{c} \sum_{j=1}^{g} \hat{g} e_{i j}^{*}-\frac{1}{g} \sum_{i=1}^{g} \hat{g} e_{i j}^{*}+\frac{1}{g e} \sum_{i=1}^{g} \sum_{j=1}^{c} \hat{g} e_{i j}^{*} \\
& =\hat{g} e_{i j}^{*}-\hat{g} e_{i .}^{*}-\hat{g} e_{j}^{*}+\hat{g} e^{*}
\end{aligned}
$$


A partir dessas matrizes foram determinados os efeitos "bootstrap" de genótipos $\left(\widetilde{G} E_{k l}^{*}\right)$ e efeitos "bootstrap" de ambientes $\widetilde{H}_{k l}^{* \prime}$, através da DVS. Nesse caso, a DVS foi aplicada em cada uma das 600 matrizes "bootstrap" de desvios corrigidos:

$$
\begin{aligned}
& \widetilde{G} E_{k l}^{*}=U_{k l} S_{k l} V_{k l}^{\prime}=U_{k l} S_{k l}^{\frac{1}{2}} S_{k l}^{\frac{1}{2}} V_{k l}^{\prime} \\
& \widetilde{G}_{k l}^{*}=U_{k l} S_{k l}^{\frac{1}{2}} \\
& \widetilde{H}_{k l}^{* \prime}=S_{k l}^{\frac{1}{2}} V_{k l}^{\prime}
\end{aligned}
$$

em que:

$U_{k l}$ : é a matriz com vetores "bootstrap" singulares-coluna $\gamma_{i k l}$;

$S_{k l}$ : é a matriz com valores "bootstrap" singulares $\lambda_{k l} \mathrm{e}$;

$V_{k l}^{\prime} \quad$ : é a matriz com vetores "bootstrap" singulares-linha $\alpha_{j k}^{\prime}$.

Dessa forma, foram obtidos para cada genótipo e ambiente, 200 escores associados a cada matriz "bootstrap", totalizando 15400 respostas, por eixo da interaçào GxE $\left(I P C A_{1}^{*}, I P C A_{2}^{*}\right)$. Esses resultados foram plotados seguindo o modelo $A M M_{2}$ $\mathrm{AMMl}_{2}$, isto é, em eixos cartesianos $I P C A_{1}^{*} \times I P C A_{2}^{*}$. A adoçào dessa representaçào gráfica foi ajustada pelo critério de avaliação "pos-dictiva" (Gauch \& Zobel, 1988) que visa a obtenção de um alto coeficiente de determinação.

A partir dos escores foram estabelecidas as regiões "bootstrap" de confiança, de $99 \%$ para $\bar{\theta}_{k}^{*}=\left\langle\overline{I P C}_{1 k}^{*}, \overline{I P C A}_{2 k}^{*}\right|$, ou seja, para os escores médios de cada genótipo e de cada ambiente, separadamente. As regiões de confiança foram obtidas a partir da estimativa não viesada da matriz de covariâncias $S_{\text {\%k }}^{*}$, para cada par de coordenadas $\bar{\theta}_{k l}^{*}=\left\lfloor I P C A_{\mid k l}^{*}, I P C A_{2 k l}^{*}\right\rfloor$, dada por Weinberg et al. (1984). 
A seguir é apresentado o esquema de Lavoranti (2003):

$$
\left(\bar{\theta}_{k}^{*}-\bar{\theta}_{k l}^{*}\right)^{\prime}\left(S_{\theta k}^{*}\right)^{-1}\left(\bar{\theta}_{k}^{*}-\bar{\theta}_{k l}^{*}\right) \leq \frac{2(B-1)}{B(B-2)} F_{(2, B-2)^{*}}
$$

em que:

$$
S_{0 k}^{*}=\left|\begin{array}{cc}
S_{1 k}^{2^{*}} & r_{k}^{*} S_{1 k}^{*} S_{2 k}^{*} \\
r_{k}^{*} S_{1 k}^{*} S_{2 k}^{*} & S_{2 k}^{2^{*}}
\end{array}\right|,
$$

$B$ : $\quad$ é o número de amostras "bootstrap" $(B=200)$;

$S_{1 k}^{2^{* *}}$ : é a variância "bootstrap" para os escores associados ao IPC $A_{1}^{*}$;

$S_{2 k}^{2^{*}}$ : é a variância "bootstrap" para os escores associados ao IPC $A_{2}^{*}$;

$r_{k}^{*}$ : é o coeficiente de correlação de Pearson para os escores "bootstrap" obtidos a partir de $\left(I P C A_{1}^{*} \times I P C A_{2}^{*}\right)$;

$k=\quad(\mathrm{g}, \mathrm{e})$ para "g" genótipos e "e" ambientes, $i=1,2, \ldots, \mathrm{g} ; j=1,2, \ldots, \mathrm{e}$

$l=1,2, \ldots, 200$

$g$ : $\quad$ é o número de genótipos;

$e: \quad$ é o número de ambientes.

Visando medir a precisão das estimativas de estabilidade, foram determinados os coeficientes "bootstrap" de estabilidade, denominados (CBE), através da razão entre o número de pontos $\left(I P C A_{1}^{*} \times I P C A_{2}^{*}\right)$ inclusos na região de predição para $\tilde{\theta}_{k}^{*}=[0,0]$ e o tamanho da amostra "bootstrap" $(B)$ :

$$
C B E=\#\left[\left(\tilde{\theta}_{k}^{*}-\tilde{\theta}_{k l}^{*}\right)^{\prime}\left(S_{\theta k}^{*}\right)^{-1}\left(\tilde{\theta}_{k}^{*}-\tilde{\theta}_{k l}^{*}\right) \leq \frac{2(B-1)}{B(B-2)} F_{(2 . B-2)^{k}}\right] B^{-1}
$$


A justificativa teórica para a utilizaçào dessa expressào, foi fundamentada na região de predição para uma única observaçào, nesse caso, o ponto nulo $(0,0)$. A distribuição $T^{2}$ de Hotelling foi baseada numa matriz X com distribuiçào normal pvariada, com vetor de médias zero e matriz de covariâncias $\sum$ e $\mathbf{Z}$, com distribuiçào de Wishart com $v$ graus de liberdade e parâmetro $\sum$. Entào $X^{\prime} Z^{-1} X$ tem uma distribuiçào $\frac{p}{v-p+1} F_{p, v-p+1}$. No caso das regiões de predição "bootstrap" para a origem, $\mathbf{X}$ é uma única estimativa "bootstrap". A matriz de covariâncias $\sum$ é calculada por $\mathrm{S}$, obtida de $B$ amostras "bootstrap", de forma que $(B-1)$ S substitui $\mathbf{Z} \operatorname{com} v=B-1$ e $p=2$. Substituindo esses valores, obtém-se o numerador da expressão (22).

Os genótipos e ambientes estáveis situam-se próximos à origem, isto é, com escores praticamente nulos para os dois eixos da interação GxE (IPCA, e IPCA2) (Duarte \& Vencovsky, 1999). Assim, para as interpretações das estabilidades via análise gráfica (regiōes "bootstrap" de confiança) e numérica (CBE), foram usadas os seguintes critérios, segundo Lavoranti (2003):

a) para os genótipos e ambientes cujas regiões de confiança "bootstrap" continham o ponto de coordenada nula $(0,0)$;

\begin{tabular}{|c|c|}
\hline Precisão das estimativas de estabilidade & Classificaçào da estabilidade \\
\hline $\mathrm{CBE} \geq \boldsymbol{Q} \mathbf{3}$ (terceiro quartil) & Muito Alta \\
\hline $\boldsymbol{Q 2}$ (segundo quartil) $\leq \mathrm{CBE}<\boldsymbol{Q 3}$ & Alta \\
\hline$Q 1$ (primeiro quartil) $\leq \mathrm{CBE}<Q 2$ & Média \\
\hline $\mathrm{CBE}<Q \mathbf{Q}$ & Baixa \\
\hline
\end{tabular}

b) os genótipos e ambientes, cujas regiões de confiança que não continham o ponto de coordenada nula, pertencentes a essa categoria foram considerados instáveis.

A adoçào dos quartis como medida de classificaçào de estabilidade, visou dividir a distribuiçào em quatro partes iguais, quanto ao número de elementos em cada uma. Os 
critérios de classificação foram baseados na amplitude de CBE, que pela equação (22) varia de zero a um $(-\mathrm{CBE}-1)$. Assim, quanto mais próximo de um for o $\mathrm{CBE}$, maior a classificação da estabilidade. A classificação como muito alta, significa que os genótipos e/ou ambientes, não sofrerão alteraçòes significativas em seus postos, quando submetidos novamente a esses ambientes (genótipos) ou no conjunto desses genótipos (ambientes). Quanto à classificação como de alta estabilidade, espera-se não haver alteraçòes significativas nos postos, porém caso ocorram, que sejam de pequena magnitude, isto é, um e no máximo dois níveis. Embora, a estabilidade estatística dê garantia de que os postos não sofrerão alteraçōes significativas, a qualidade dessa informação cai consideravelmente quando CBE aproxima-se de zero; assim, as classificaçòes das estabilidades como média e baixa, requerem uma avaliação mais cuidadosa, para recomendaçòes desses genótipos e desses locais. Nesses casos, deve-se ponderar os riscos de uma indicação mais produtiva em relação a de maior constância nos resultados (Lavoranti, 2003).

As adaptabilidades, via "bootstrap" AMMI, foram observadas através dos produtos entre os escores "bootstrap" de genótipos $\left(\mathbf{G}^{*}\right)$ e escores "bootstrap" de ambientes $\left(\mathbf{H}^{\text {"H }}\right)$, envolvendo apenas as duas primeiras colunas de $\mathbf{G}^{*}$ e as duas primeiras linhas de $\mathbf{H}^{* \mathrm{H}}$. Os resultados das somas desses produtos indicaram as situaçōes favoráveis para as respostas positivas e desfavoráveis para as respostas negativas (Lavoranti, 2003).

Vale ressaltar que as estabilidades de genótipos indicam boa adaptação aos ambientes de estudo. Assim, os sinais negativos para os produtos dos escores devem ser analisados com cautela, antes de serem descartados. O mesmo é válido para os genótipos instáveis que, apesar de sua adaptabilidade restrita, podem ser aproveitados vantajosamente na seleção e recomendação para um ambiente específico (Duarte \& Vencovsky, 1999).

Todas as análises e gráficos foram implementadas através do sistema estatístico SAS. 


\section{RESULTADOS E DISCUSSÃO}

As espécies que se reproduzem preferencialmente por autofecundações, como é o caso da soja que possui mecanismos como a cleistogamia, recurso este evolutivamente desenvolvido a fim de evitar cruzamentos e promover adaptaçào rápida, apresentam um aumento progressivo de homozigose genotipica com o avanço das geraçòes de endogamia, resultando na formaçào natural de linhagens puras. É esperado na estrutura genética das populaçòes obtidas através de cruzamentos biparentais (linhagens puras), uma proporçào alélica aproximada de $p=0,5$. Esta condiçào estabelece o estado de equilíbrio definido por Sewall Wright para as populaçòes de plantas autógamas, desde que nào estejam atuando açueles eventos genéticos que promovem perturbaçào nas freqüências alélicas desse sistema, como o é a reproduçào diferencial, por exemplo. A variância genética entre médias de linhagens avançadas é teoricamente máxima, com magnitudes até duas e quatro vezes respectivamente as porçòes das variâncias aditiva e epistática do tipo aditiva $x$ aditiva liberadas na geraçào $F_{2}$. O efeito conseqüente é observado como uma dissipaçào dentro das linhagens das variâncias de dominância e epistáticas do tipo dominante $x$ aditiva e dominante $x$ dominante ao longo do avanço de geraçòes, esperando-se que passem a ser despreziveis em $F \infty$. A prática da seleçào durante as geraçòes de endogamia deve diminuir a diferença entre as variâncias genéticas na geraçào inicial $\left(\mathrm{F}_{2}\right)$ e em uma geraçào avançada $(F \infty)$. Admite-se, que este limite é assintótico, sendo determinado quando o índice de fixaçào total ou coeficiente de endogamia tende para o valor 1.

É sabido que em populações continuamente submetidas à seleção, há um balanço dinâmico entre os componentes das variâncias genéticas. E a seleção será quão mais eficiente quanto maiores forem as variâncias aditiva e epistática aditiva $x$ aditiva responsáveis pela lixaçào do caráter de interesse. Seguramente, pode-se inferir que em se tratando de caráter quantitativo, evidentemente muito influenciado pela açào do ambiente, sua seleçào deve ser postergadla para geraçòes com niveis mais altos de endogamia. Se o interesse é explorar também 
a variaçào genética dentro das progênies, a seleçào pode ser feita nas gerações iniciais dos ciclos reprodutivos naturais; tal procedimento é comumente empregado para caracteres qualitativos.

\subsection{Análises Individuais e Conjuntas}

As análises de testemunhas comuns foram eficientes em detectar diferenças entre conjuntos dentro das repetições, tendo sido encontrados efeitos significativos para testemunhas e para interaçào testemunhas $\mathrm{x}$ conjuntos. Portanto, tornou-se necessário o ajustamento das médias das linhagens em funçào das médias das testemunhas comuns dentro de cada conjunto experimental nos dois anos de estudo.

Os quadros das análises individuais e conjuntas estão apresentados nas Tabelas 3 a 7. Os coeficientes de variaçào experimental (CV) encontrados para os experimentos (Expl, $\operatorname{Exp} 2, \ldots, \operatorname{Exp} 24)$, exceçào feita para o Exp21 (Anhembi/2001-CII), atestam boa precisào no controle das causas de variaçào de ordem sistemática dos ambientes experimentais, uma vez que a maioria deles esteve abaixo de $20 \%$. Resultado este que fornece segurança de coerência com o esperado para dados de produtividade de gràos, pois se trata cle caráter quantitativo.

Nas análises individuais (Tabelas 3 a 5), além dos resíduos, as fontes de variação mais relevantes compreendem os efeitos "linhagens/cruzamentos", "testemunhas comuns" e o contraste "testemunhas vs. linhagens", sobre as quais estào concentradas as discussões a seguir. Os ambientes (E1 a E8) foram identificados nas Tabelas 9 a 11 e 15. As linhagens (P1 a P20) de cada populaçào e testemunhas (T1 a T3) foram identificadas na Tabela 17.

Entre as testemunhas comuns foi detectada variaçào $(p<0,01)$ nos ambientes E4 e E6, e nos ambientes E1, E2 e E3 para $(p<0,05)$; sendo as testemunhas bem contrastantes, é inerente um maior grau de diferenças genéticas tanto para produtividade quanto para caracteres adaptativos. Apenas em E8 e nos ambientes E5 e E7 (ambos com controle intensivo de pragas) as testemunhas não diferiram significativamente entre si (Tabela 3 ).

Para as linhagens dentro de cruzamentos foram detectadas diferenças significativas $(\mathrm{p}<0,05)$ nos ambientes E3 e E4. A média das linhagens foi superior à média das testemunhas comuns nos ambientes E1, E2, E3, E4, E5 e E6, sendo semelhantes em magnitude nos ambientes E7 e E8. 
Médias de produtividade altas e relativamente semelhantes entre as linhagens podem ser conseqüiencia do progresso genético acumulado com a prática de seleção durante as sucessivas gerações de endogamia na população $\mathrm{PCl}$ (controle total de insetos em $\mathrm{F}_{2}$ ).

Tabela 3. Quadrados médios para o caráter produtividade de grãos ( $\mathrm{kg} / \mathrm{ha}$ ) obtidos na análise individual em blocos ao acaso com repetições subdivididas em conjuntos experimentais com testemunhas comuns, em oito ambientes ( $\mathrm{El}$ a E8, combinando os anos 1999/00 e 2000/01, os locais Anhembi e Areão, os manejos controle de intensivo de insetos ou CII e controle ecológico de insetos ou CEI), para a PCI (População formada a partir de plantas $\mathrm{F}_{2}$ obtidas com Controle Total de Insetos)

\begin{tabular}{|c|c|c|c|c|c|c|c|c|c|c|}
\hline \multirow{3}{*}{$\mathrm{PCl}$} & & \multicolumn{4}{|c|}{$1999 / 00$} & \multicolumn{5}{|c|}{$2000 / 01$} \\
\hline & & \multicolumn{2}{|c|}{ ANHEMBI } & \multicolumn{2}{|c|}{ AREÃO } & \multicolumn{3}{|c|}{ ANIEMBI } & \multicolumn{2}{|c|}{ AREÃO } \\
\hline & & $\begin{array}{l}\mathrm{Cll} \\
(\mathrm{E} I)\end{array}$ & $\begin{array}{l}\mathrm{CE} 1 \\
(\mathrm{E} 2)\end{array}$ & $\begin{array}{l}\text { CII } \\
\text { (E3) }\end{array}$ & $\begin{array}{l}\text { CEI } \\
(\mathrm{E} 4)\end{array}$ & & $\begin{array}{l}\mathrm{CII} \\
(\mathrm{E} 5 \mathrm{5})\end{array}$ & $\begin{array}{l}\text { CEI } \\
\text { (EO) }\end{array}$ & $\begin{array}{l}\mathrm{CII} \\
\text { (E7) }\end{array}$ & $\begin{array}{l}\text { CEI } \\
(\mathrm{E} S)\end{array}$ \\
\hline $\begin{array}{l}\text { FONTES DE } \\
\text { VARIACÁA }\end{array}$ & $\mathrm{GL}$ & QM & QM & QM & QM & GL & QM & QM & QM & QM \\
\hline Repetiçoes (R) & 1 & $9902^{115}$ & $109181^{\mathrm{ns}}$ & $63375^{115}$ & $163874^{*}$ & 1 & $22069^{\mathrm{ns}}$ & $214531^{\text {ns }}$ & $189004^{\mathrm{ns}}$ & $311550^{155}$ \\
\hline Conjuntos/R & 2 & $15658^{115}$ & $117345^{\mathrm{ns}}$ & $604288^{*}$ & $49185^{\mathrm{ns}}$ & 2 & $154573^{\mathrm{ns}}$ & $890851^{*}$ & $117633^{\mathrm{ns}}$ & $513187^{\text {ns }}$ \\
\hline Tratamentos & 43 & $273268^{*}$ & $234086^{\mathrm{ns}}$ & $335657^{*}$ & $163874^{*}$ & 22 & $373863^{1 \mathrm{Is}}$ & $912233^{* *}$ & $185076^{\mathrm{ns}}$ & $230186^{\mathrm{ns}}$ \\
\hline ...Testemunhas( $\mathrm{T}$ ) & 3 & $4828 S 1^{*}$ & $484979^{*}$ & $581360^{*}$ & $499708^{* * *}$ & 2 & $401108^{n s}$ & $4332008^{* *}$ & $232825^{\mathrm{ns}}$ & $388144^{\mathrm{ns}}$ \\
\hline ...T us linhagens & 1 & $987814^{*}$ & $435457^{\mathrm{ns}}$ & $42941^{115}$ & $87733^{115}$ & 1 & $2329548^{*}$ & $5122162^{* *}$ & $10907^{\mathrm{ns}}$ & $54197^{\text {in }}$ \\
\hline ... Linhagens $(P)$ & 39) & $238822^{11 s}$ & $209624^{\text {ns }}$ & $324263^{*}$ & $139993^{\mathrm{ns}}$ & 19 & $268064^{115}$ & $330682^{\text {ns }}$ & $189217^{\mathrm{ns}}$ & $222821^{\mathrm{ns}}$ \\
\hline ......Cruzamentos $(\mathrm{C})$ & 9 & $440136^{*}$ & $394456^{*}$ & $221771^{\text {is }}$ & $52845^{\text {ns }}$ & 6 & $188297^{\mathrm{ns}}$ & $479012^{*}$ & $265338^{*}$ & $135190^{115}$ \\
\hline$\ldots \ldots P / C$ & 30 & $178428^{\mathrm{ns}}$ & $154174^{n s}$ & $355101^{*}$ & $166137^{*}$ & 13 & $339854^{n s}$ & $262222^{\mathrm{ns}}$ & $154084^{n s}$ & $263267^{115}$ \\
\hline Residuo & 49 & 161487 & 163429 & 170707 & 91784 & 26 & 357092 & 184483 & 96472 & 204185 \\
\hline Total & 95 & 19704600 & 18417634 & 24760233 & 12174794 & 51 & 17477541 & 26861931 & 7004217 & 11710817 \\
\hline Mèdia Geral (MCi) & & 3501 & 2917 & 2057 & 1438 & & 3141 & 3054 & 1744 & 2224 \\
\hline MG Testemunhas & & 3274 & 3068 & 2009 & 1370 & & 2756 & 2481 & 1770 & 2283 \\
\hline MCi linhagens & & 3546 & 2887 & 2066 & 1451 & & 3260 & 3226 & 1736 & 2206 \\
\hline$C V(\%)$ & & 11.48 & 13,87 & 20,09 & 21.08 & & 19,02 & 14,06 & 17,81 & 20,32 \\
\hline
\end{tabular}

${ }^{* * *}$ : significativo ao nivel de $5 \%$ e $1 \%$ de probabilidade, respectivamente, pelo teste $F$; ns: nào signiticativo pelo teste $\mathrm{F}$;

GL : graus de liberdade;

QM : quadrados médios

Na Tabela 4 encontram-se os resultados da análise individual para a população PRIS (seleção em $\mathrm{F}_{2}$ para tolerância a insetos sugadores). Em relaçào à populaçào anterior (PCI, Tabela 3), observa-se um número maior de ambientes (E3, E4, E7 e E8), todos envolvendo o local Areão (nos dois anos agrícolas e nos dois sistemas de manejo), com diferenças significativas entre linhagens dentro de cruzamentos. As testemunhas também se mostraram 
mais contrastantes entre si, pois foram detectadas diferenças significativas entre elas em sete ambientes contra cinco ambientes na Tabela 3.

Tabela 4. Quadrados médios para o caráter produtividade de grãos ( $\mathrm{kg} / \mathrm{ha}$ ) obtidos na análise individual em blocos ao acaso com repetições subdivididas em conjuntos experimentais com testemunhas comuns, em oito ambientes (El a E8 combinando os anos 1999/00 e 2000/01, os locais Anhembi e Areão, os manejos controle de intensivo de insetos ou CII e controle ecológico de insetos ou CEI), para a PRIS (População formada a partir de plantas $F_{2}$ selecionadas para Resistência a insetos Sugadores)

\begin{tabular}{|c|c|c|c|c|c|c|c|c|c|c|}
\hline \multirow{3}{*}{ PRIS } & & \multicolumn{4}{|c|}{$1999 /(0)$} & \multicolumn{5}{|c|}{$2(0)(0 /() 1$} \\
\hline & & \multicolumn{2}{|c|}{ ANHEMBI } & \multicolumn{2}{|c|}{ AREÀO } & \multicolumn{3}{|c|}{ ANHEMBI } & \multicolumn{2}{|c|}{ AREÃO } \\
\hline & & $\begin{array}{l}\text { CII } \\
(\mathrm{E} 1)\end{array}$ & $\begin{array}{l}\text { CEI } \\
\text { (E2) }\end{array}$ & $\begin{array}{l}\mathrm{CII} \\
(\mathrm{E} 3)\end{array}$ & $\begin{array}{l}\text { CEI } \\
(\mathrm{E} 4)\end{array}$ & & $\begin{array}{l}\mathrm{CII} \\
(\mathrm{E} 5)\end{array}$ & $\begin{array}{l}\text { CEI } \\
\text { (EO) }\end{array}$ & $\begin{array}{l}\mathrm{Cll} \\
(\mathrm{E} 7)\end{array}$ & $\begin{array}{l}\text { CEI } \\
(\mathrm{ES})\end{array}$ \\
\hline $\begin{array}{l}\text { FONTES DE } \\
\text { VARIACÄO }\end{array}$ & GL & QM & QM & QM & QM & GL & QM & QM & QNl & QM \\
\hline Repetiçóes (R) & I & $158844^{\mathrm{ns}}$ & $10626^{115}$ & $1051063^{* *}$ & $2098 S 15^{*}$ & I & 7() $892^{\mathrm{ns}}$ & $|\delta 2 \delta|^{115}$ & $12462^{1 \mathrm{ss}}$ & $2538 S 1^{115}$ \\
\hline Comjuntos/R & 2 & $78 S 3^{\mathrm{ns}}$ & $159345^{\mathrm{ms}}$ & $28 S 41^{\mathrm{ns}}$ & $154338^{\mathrm{ns}}$ & 2 & $01267^{\mathrm{ns}}$ & 7608() $3^{\mathrm{ns}}$ & $63963^{\mathrm{ns}}$ & $182730^{\mathrm{ns}}$ \\
\hline Tratamentos & 43 & $296830^{* *}$ & $4(0316)^{* *}$ & $362589^{* *}$ & 305() $84^{* *}$ & 22 & $345881^{\text {ns }}$ & $1372288^{* *}$ & $289\left(094^{* *}\right.$ & $32(0)(0) 0)^{* *}$ \\
\hline ... Testemunhas(T) & 3 & $1534652^{\text {*** }}$ & $1822321^{* *}$ & $438433^{\circ}$ & $890622^{* *}$ & 2 & 34664()$^{n 15}$ & $40\left(05619^{* * *}\right.$ & $1028519^{* *}$ & $417579^{*}$ \\
\hline ...T vs linhagens & 1 & $335228^{*}$ & $\left(05195()^{*}\right.$ & 218() $3^{\mathrm{ns}}$ & $1284^{\mathrm{ns}}$ & 1 & $1861623^{* *}$ & $16531505^{* *}$ & $477750^{* * *}$ & $175135^{\mathrm{ns}}$ \\
\hline ... inhagens $(P)$ & 39) & $200628^{\text {ns }}$ & $287624^{*}$ & $365493^{* *}$ & $267832^{* * *}$ & 1) & $260(1) 25^{\mathrm{ns}}$ & $297242^{115}$ & 2() $1331^{* *}$ & $317457^{* *}$ \\
\hline ......Cruamentos(C) & 9 & $286714^{115}$ & $49\left(9197^{* * *}\right.$ & $64\left(0417^{* *}\right.$ & $596\left(695^{* *}\right.$ & 6 & $194895^{\text {ns }}$ & $573466^{n \mathrm{~ns}}$ & 29) $2365^{* * *}$ & $527793^{* * *}$ \\
\hline A...PC & 30 & $181797^{115}$ & $243312^{115}$ & $305353^{* *}$ & $195893^{* * *}$ & 13 & 29) $8855^{\mathrm{ms}}$ & $169753^{\mathrm{ns}}$ & $159315^{* * *}$ & 22() 379 * \\
\hline Residuo & 49 & 131521 & 152283 & 11284() & 91298 & 26 & 182981 & 239430 & 50559 & 75245 \\
\hline Tiotal & 95 & 19382800 & 25127424 & 222292() & 19917099 & 51 & $1256(0317$ & 37967401 & 7814994 & 9533338 \\
\hline Media (ieral (MC) & & 3293 & 2834 & 1942 & 1716 & & 3107 & 3186 & 1529) & 2176 \\
\hline MGi Testemunhas & & 3425 & $3(19$ & $19(1) 9$ & 1724 & & 2762 & 2156 & 17() 4 & $22 S S$ \\
\hline MGi Linhagens & & 3260 & 2798 & 1949) & 1714 & & 3211 & 3495 & 1470 & 2145 \\
\hline$C V(\%)$ & & $11,() 1$ & 13,77 & 17.29 & 17,61 & & 13,77 & 15,36 & 14,71 & 12,61 \\
\hline
\end{tabular}

${ }^{* * *}$ : significativo ao nível de $5 \%$ e $1 \%$ de probabilidade, respectivamente, pelo teste $\mathrm{F}$;

ns: não significativo pelo teste $\mathrm{F}$;

GL : graus de liberdade;

QM : quadrados médios

De acordo com a Tabela 5 , em relação à população formada a partir de plantas $F_{2}$ selecionadas para tolerância a insetos mastigadores (PRIM), as linhagens/cruzamentos foram significativamente variáveis $(p<0,01)$ apenas nos ambientes El e E3. Estes resultados são mais parecidos com aqueles da população PCI (Tabela 3) do que com os resultados de PRIS (Tabela 
4). Os ambientes E5 e E6, ambos no local Anhembi em 2000/01, não apresentaram níveis de variaçào para nenhuma fonte analisada; no caso particular de E5, o valor de CV $(26,15 \%)$ mais elevado dentre os 24 experimentos, pode ter sido responsável pela não detecçào de efeitos significativos para todas as fontes de variaçào.

Quanto às testemunhas comuns, foram observadas diferenças significativas ao nivel de 1\% de probabilidade para os ambientes E1, E2, E3 e E7, e ao nível de 5\% para o ambiente E4 (Tabela 5). Os resultados obtidos para as testemunhas nos experimentos da Tabela 5 também foram mais próximos àqueles obtidos na Tabela 3 do que os da Tabela 4 . Este fato pode ser interpretado como uma evidência de que existem diferenças ambientais entre as três séries de oito experimentos, além de possíveis diferenças genéticas inicialmente estabelecidas entre os três tipos de populações, conseqüiência principalmente do tipo de seleção praticada entre plantas $\mathrm{F}_{2}$.

Na população PRIM, a pressão de seleção mais forte em $F_{2}$ foi feita para a caracteristica resistência/tolerância a insetos mastigadores, avaliada com base em atribuiçào de notas (1: ataque estimado em () a 33\%; 2: 34 a 66\% e 3: 64 a 100\%. Este critério é subjetivo e questionável visto que o caráter é quantitativo e, portanto, idealmente maior número de classes (notas) seria requerido para melhor representar sua variação contínua; além disso, a subjetividade poderia ser minimizada pelo uso de médias de vários avaliações independentes feitas por pesquisadores distintos.

Quanto às médias das linhagens da populaçào PRIM, em relaçào às testemunhas comuns, foi constatado comportamento semelhante ao observado na população PRIS (Tabela 4), sendo que em apenas três ambientes as linhagens superaram a média das testemunhas (Tabela $5)$.

É bem conhecido na literatura que materiais genéticos selecionados para resistência/tolerância comumente apresentam menor produtividade, na ausência de pragas. Geralmente, genes para resistência a insetos são mais freqüentemente encontrados em materiais exóticos, comumente ligados a outros genes desfavoráveis do ponto de vista de caracteres adaptativos e agronômicos. Isso obriga o uso de várias gerações adicionais, geralmente através de retrocruzamentos, para quebrar as mencionadas ligações genéticas, fato que desestimula o uso de materiais exóticos nos programas de melhoramento, principalmente em instituições 
privadas que convivem com a rotina de lançar cultivares em espaço de tempo relativamente curto. Portanto, com o fim de melhorar o desempenho destes materiais, pode ser feito um prémelhoramento (pré - breeding; Nass, 2001) nestes genótipos, no sentido de preencher a lacuna existente entre os recursos genéticos e os programas de melhoramento, visando estimular os melhoristas a usarem mais freqüentemente estes materiais detentores de genes para controle de insetos.

Também, é possivel comparar os 24 experimentos (Tabelas 3, 4 e 5) para o efeito "testemunhas vs. linhagens", juntamente com os contrastes entre médias de testemunhas e de linhagens. Observa-se um empate relativo entre os dois grupos (testemunhas e linhagens), pois em 12 experimentos (seis com contrastes significativos) as testemunhas foram mais produtivas, enquanto que nos outros 12 experimentos (também seis com contrastes significativos) as linhagens foram mais produtivas que as testemunhas. 
Tabela 5. Quadrados médios para o caráter produtividade de grãos ( $\mathrm{kg} / \mathrm{ha}$ ) obtidos na análise individual em blocos ao acaso com repetições subdivididas em conjuntos experimentais com testemunhas comuns, em oito ambientes (E1 a E8 combinando os anos 1999/00 e 2000/01, os locais Anhembi e Areào, os manejos controle de intensivo de insetos ou CII e controle ecológico de insetos ou CEI), para a PRIM (Populaçào formada a partir de plantas $F_{2}$ selecionadas para Resistência a insetos Mastigadores)

\begin{tabular}{|c|c|c|c|c|c|c|c|c|c|c|}
\hline \multirow{3}{*}{ PRIM } & & \multicolumn{4}{|c|}{$1999 /(0)$} & \multicolumn{5}{|c|}{$200(0)(01$} \\
\hline & & \multicolumn{2}{|c|}{ ANHEMBI } & \multicolumn{2}{|c|}{ AREÃO } & \multicolumn{3}{|c|}{ ANHEMBI } & \multicolumn{2}{|c|}{ AREÃO } \\
\hline & & $\begin{array}{l}\mathrm{CII} \\
(\mathrm{EI})\end{array}$ & $\begin{array}{l}\text { CEI } \\
(\mathrm{E} 2)\end{array}$ & $\begin{array}{c}\mathrm{CII} \\
(\mathrm{E} 3)\end{array}$ & $\begin{array}{l}\text { CEI } \\
(\mathrm{E} 4) \\
\end{array}$ & & $\begin{array}{l}\mathrm{CII} \\
(\mathrm{ES})\end{array}$ & $\begin{array}{l}\text { CEI } \\
(\mathrm{E}())\end{array}$ & $\begin{array}{l}\mathrm{ClI} \\
\text { (E7) }\end{array}$ & $\begin{array}{l}\text { CEI } \\
\text { (ES) }\end{array}$ \\
\hline $\begin{array}{l}\text { FONTES DE } \\
\text { VARIAÇÃO }\end{array}$ & GL & QM & QM & QM & QM & GL & QM & QM & QM & QM \\
\hline Repetições (R) & 1 & $30817^{\mathrm{ns}}$ & $1733438^{* \%}$ & $12950)^{n s}$ & $449819^{115}$ & I & $128405^{115}$ & $821274^{115}$ & $1731^{\mathrm{ns}}$ & $455732^{115}$ \\
\hline Conjuntos/R & 2 & $493953^{* *}$ & $101514^{\mathrm{ns}}$ & $15492^{115}$ & $297222^{\mathrm{ns}}$ & 2 & $27948^{115}$ & $297124^{\mathrm{ns}}$ & $11665^{115}$ & $708918^{*}$ \\
\hline Tratamentos & 43 & $282606^{* *}$ & $307175^{*}$ & $286220^{* *}$ & $207237^{*}$ & 22 & $417461^{115}$ & $456389^{\mathrm{ns}}$ & $356(05)^{* * *}$ & $272187^{115}$ \\
\hline ...Testemunhas( $(\Gamma)$ & 3 & $1126771^{* * *}$ & $1304102^{* *}$ & $1099743^{* *}$ & $527135^{*}$ & 2 & $961.040^{\mathrm{ns}}$ & $474502^{n s}$ & $905077^{* *}$ & $77964^{1 \mathrm{~ns}}$ \\
\hline ...T vs linhagens & 1 & $1077000^{\mathrm{ns}}$ & $1719610^{* * *}$ & $166321^{\mathrm{ns}}$ & $806(0) 41^{*}$ & 1 & $541895^{115}$ & $1013115^{\mathrm{ms}}$ & $725201^{*}$ & $74710^{\mathrm{ns}}$ \\
\hline$\ldots$ linhagens $(P)$ & 39) & $222155^{* *}$ & 194272 $1 \mathrm{ss}$ & $226716^{* * *}$ & $167275^{\mathrm{ns}}$ & 19) & $353693^{\text {ns }}$ & $425181^{115}$ & $278839^{* *}$ & $3(030) 25^{\mathrm{ns}}$ \\
\hline ...... Cruzamentos(C) & 9 & $136098^{115}$ & $153484^{115}$ & $2914\left(14^{* *}\right.$ & $76438^{135}$ & 6 & $144204^{115}$ & $383382^{\mathrm{ns}}$ & $527738^{* * *}$ & $459291^{*}$ \\
\hline$\ldots . . P C$ & 30) & $247972^{* *}$ & $20\left(3509^{115}\right.$ & $207310^{* n}$ & $194527^{115}$ & 13 & $450380^{\mathrm{ns}}$ & $4628000^{115}$ & $54829^{n s}$ & $1623844^{\mathrm{ns}}$ \\
\hline Residuo & 49 & 97318 & 167574 & 89223 & 125455 & 26 & 594115 & 330774 & 101477 & 156825 \\
\hline Tolal & 95 & 17939374 & 23356133 & 16723318 & 15957115 & 51 & 24815420 & 20056201 & 10496748 & $118(12873$ \\
\hline Media (ieral (MCi) & & 3411 & 2852 & 1975 & 1809 & & 2948 & 3071 & 1670 & 2317 \\
\hline MG Testemumhas & & 3486 & 3151 & 2068 & 1604 & & 2762 & 2816 & 1885 & 2244 \\
\hline MG tinhagens & & 3396 & 2792 & 1956 & 1850 & & 30() 4 & 3147 & 1605 & 2337 \\
\hline $\mathrm{CV}(\%)$ & & 9.14 & 14.36 & 15,13 & 19,58 & & 26,15 & 18.73 & 19,08 & $17,(19)$ \\
\hline
\end{tabular}

*** : significativo ao nível de 5\% e 1\% de probabilidade, respectivamente, pelo teste F;

ns : nào significativo pelo teste $\mathrm{F}$;

GL : graus de liberdade;

QM : quadrados médios

Em comparaçào à análise individual de variâncias (Tabelas 3 a 5), a análise feita conjuntamente é mais arrojada em detectar efeitos significativos, em razào do maior número de graus de liberdade para o resíduo, além de permitir se testar interações entre fontes de variaçào e contrastes de interesse do ponto de vista do melhoramento genético.

$\mathrm{Na}$ análise conjunta de variâncias (Tabela 6 e 7), a fonte de variaçào populaçòes (POP) nào apresentou variabilidade genética significativa entre si. Este fato evidencia que a seleçào praticada entre plantas $\mathrm{F}_{2}$ para tolerância a insetos mastigadores (população PRIM) e insetos sugadores (populaçào PRIS) nào alterou a produtividade de grãos das plantas, relativamente à populaçào padrào, ou seja, com controle total de insetos em $\mathrm{F}_{2}$ (PCI). Três possíveis explicaçòes 
podem ser consideradas. Em primeiro lugar, a seleçào para tolerância a insetos entre plantas $F_{2}$ pode nào ter sido efíciente; esta hipótese nào deve ter ocorrido, pois foram verificadas diferenças significativas entre populaçòes para reaçào a insetos sugadores, cujos dados nào sào apresentados nessa pesquisa. Em segundo lugar, não ocorreu ligaçòes fortes entre os genes para tolerância a insetos e os genes que controlam a produtividade de grãos. Em terceiro lugar, a prática de seleção para produtividade de grãos e tolerância a fotoperíodo durante as diversas geraçòes de endogamia $\left(F_{3}\right.$ a $\left.F_{10}\right)$ pode ter anulado as diferenças entre populaçòes para produtividade de grãos, possivelmente estabelecidas em $\mathrm{F}_{2}$.

A existência de variabilidade genética entre linhagens foi constatada tanto nas análises individuais (1999/Areào/CII e 1999/Areào/CEI para a populaçào PCI, Tabela 3; 1999/Areào/CIl, 1999/Areão/CEI, 2000/Areão/CII e 2000/Areão/CEI para a populaçào PRIS, Tabela 4; 1999/Anhembi/CIl e 1999/Areào/CII para a populaçào PRIM, Tabela 5) quanto na análise conjunta (entre linhagens dentro de populaçòes, Tabela 7). Este fato indica que existe variabilidade remanescente dentro das populaçòes, a qual poderá ser explorada em futuros ciclos de seleção. Além disso, esta variabilidade evidencia que as populaçòes ainda nào estào homogêneas o que certamente dificulta a detecção de variabilidade significativa entre populaçòes, conforme anteriormente relatado.

Além de linhagens dentro de populaçòes, o exame associado das Tabelas 6 e 7 revela que a análise conjunta das três populaçòes detectou como significativos os efeitos principais entre os dois sistemas de manejo (controle intensivo de insetos vs. controle ecológico de insetos) e entre os dois locais (Anhembi e Areão). Portanto, em termos de magnitudes relativa dos quadrados médios, os efeitos de locais e de manejos foram mais importantes que o efeito de anos agricolas. Todavia, Vencovsky \& Torres (1988) enfatizam que, para o agricultor é mais importante que uma cultivar seja estável ao longo dos anos. As Tabelas 6 e 7 também mostram a existência de interaçōes de primeira ordem, ou seja, entre os efeitos principais combinados dois a dois, com destaque para: populaçòes x manejos, anos x linhagens dentro de populaçòes, manejos $\mathrm{x}$ anos, manejos $\mathrm{x}$ locais e anos x locais. Observa-se que todas estas cinco interaçòes significativas envolvem no mínimo um efeito principal significativo, fato este relativamente bem conhecido da literatura. Também foram detectadas interaçòes significativas de ordem mais elevada, envolvendo três ou quatro efeitos principais: populaçòes x manejos x locais, manejos x 
locais x linhagens dentro de populações, populações x anos x locais, anos x locais x linhagens dentro de populaçòes, manejos x anos x locais, manejos x anos x locais x linhagens dentro de populações. É interessante notar a importância de manejos (controle intensivo de insetos vs. controle ecológico de insetos) que se mostrou significativo na análise conjunta (tabelas 6 e 7), além de interagir de forma também significativa $\mathrm{com}$ a maioria dos efeitos principais. Este fato abre a possibilidade de se utilizar o manejo diferenciado como um novo representante de ambientes nos experimentos dos programas de melhoramento de soja, além dos representantes tradicionais (locais, anos agrícolas, épocas de cultivo). A significância das interaçòes de primeira, segunda e terceira ordens apontam para a importância de se considerar os efeitos principais envolvidos no detalhamento do estudo da interação GxE, por exemplo, através das metodologias AMMI e "bootstrap". 
Tabela 6. Quadrados médios para o caráter produtividade de gràos $(\mathrm{kg} / \mathrm{ha})$ obtidos na análise conjunta de três populaçòes de soja (PCI, PRIS e PRIM) sem desdobramento (genótipos incluem linhagens e testemunhas comuns) em blocos ao acaso com repetiçòes subdivididas em conjuntos experimentais com testemunhas comuns

\begin{tabular}{|c|c|c|}
\hline FONTES DE VARIAÇÃO & GL & QM \\
\hline POPULAÇÕES (POP) & 2 & $299451^{\text {ns }}$ \\
\hline GENÓTIPOS(G)/POP & 129 & $515867^{* * *}$ \\
\hline MANEJOS(M) & 1 & $797605^{*}$ \\
\hline POP $\times$ M & 2 & $1270539^{* *}$ \\
\hline $\mathrm{M} \times \mathrm{G} / \mathrm{POP}$ & 129 & $215855^{*}$ \\
\hline ANOS(A) & 1 & $937^{\mathrm{ns}}$ \\
\hline POP $\times \mathrm{A}$ & 2 & $227554^{\text {ns }}$ \\
\hline$A \times G / P O P$ & 66 & $552559^{* *}$ \\
\hline $\mathrm{M} \times \mathrm{A}$ & 1 & $46638843^{* * *}$ \\
\hline $\mathrm{POP} \times \mathrm{M} \times \mathrm{A}$ & 2 & $171692^{\mathrm{ns}}$ \\
\hline $\mathrm{M} \times \mathrm{A} \times \mathrm{G} / \mathrm{POP}$ & 66 & $208446^{\mathrm{ns}}$ \\
\hline LOCAIS (L) & 1 & $553816368^{* *}$ \\
\hline POP $\times \mathrm{L}$ & 2 & $497113^{\text {ns }}$ \\
\hline$L \times G / P O P$ & 129 & $248435^{* *}$ \\
\hline$M \times L$ & 1 & $14244798^{* *}$ \\
\hline POP $\times M \times L$ & 2 & $1189294^{* * *}$ \\
\hline $\mathrm{M} \times \mathrm{L} \times \mathrm{G} / \mathrm{POP}$ & 129 & $241139^{* *}$ \\
\hline$A \times L$ & 1 & $761327^{*}$ \\
\hline POP $\times A \times L$ & 2 & $1622544^{* *}$ \\
\hline$A \times L \times G / P O P$ & 66 & $565353^{* *}$ \\
\hline$M \times A \times L$ & 1 & $3037683^{* *}$ \\
\hline POP $\times M \times A \times L$ & 2 & $79435^{\mathrm{ns}}$ \\
\hline$M \times A \times L \times G / P O P$ & 66 & $278802^{* *}$ \\
\hline REPETIÇÕES(R)/ M / A / L & 8 & $289257^{\mathrm{ns}}$ \\
\hline CONJUNTOS/M / A / L / R & 16 & $220199^{1 \mathrm{~s}}$ \\
\hline RESÍDUO MÉDIO & 942 & 167287 \\
\hline CV $(\%)$ & & 16,4 \\
\hline
\end{tabular}

"**: significativo ao nivel de $5 \%$ e $1 \%$ de probabilidade, respectivamente, pelo teste F;

ns : nào significativo pelo teste $\mathrm{F}$;

GL : graus de liberdade;

QM : quadrados médios 
Tabela 7. Quadro simplificado de quadrados médios para o caráter produtividade de grãos ( $\mathrm{kg} / \mathrm{ha}$ ), obtidos na análise conjunta de três populações de soja (PCI, PRIS e PRIM) com desdobramento considerando apenas as linhagens (P), em blocos ao acaso com repetiçòes subdivididas em conjuntos experimentais com testemunhas comuns

\begin{tabular}{|c|c|c|}
\hline FONTES DE VARIAÇÃO & GL & QM \\
\hline POPULACÕ̇ES (POP) & 2 & $299451^{\text {ns }}$ \\
\hline LINHAGENS(P)/POP & 117 & $421227^{* *}$ \\
\hline MANEJOS(M) & 1 & $797605^{*}$ \\
\hline POP $\times M$ & 2 & $1270539^{* *}$ \\
\hline$\ldots \mathrm{M} \times \mathrm{P} / \mathrm{POP}$ & 117 & $199564^{\text {ns }}$ \\
\hline $\operatorname{ANOS}(\mathrm{A})$ & 1 & $937^{\mathrm{ns}}$ \\
\hline POP $\times A$ & 2 & $227554^{\mathrm{ns}}$ \\
\hline$\ldots \mathrm{A} \times \mathrm{P} / \mathrm{POP}$ & 55 & $286608^{* *}$ \\
\hline $\mathrm{M} \times \mathrm{A}$ & 1 & $46638843^{* * *}$ \\
\hline $\mathrm{POP} \times \mathrm{M} \times \mathrm{A}$ & 2 & $171692^{\mathrm{ns}}$ \\
\hline$\ldots \mathrm{M} \times \mathrm{A} \times \mathrm{P} / \mathrm{POP}$ & 55 & $155736^{\mathrm{ns}}$ \\
\hline LOCAIS (L) & 1 & $553816368^{* * *}$ \\
\hline POP $\times L$ & 2 & $497113^{\mathrm{ns}}$ \\
\hline$\ldots \mathrm{L} \times \mathrm{P} / \mathrm{POP}$ & 117 & $190765^{\mathrm{ns}}$ \\
\hline $\mathrm{M} \times \mathrm{L}$ & 1 & $14244798^{* *}$ \\
\hline POP $\times M \times L$ & 2 & $1189294^{* * *}$ \\
\hline$\ldots \mathrm{M} \times \mathrm{L} \times \mathrm{P} / \mathrm{POP}$ & 117 & $223054^{*}$ \\
\hline$A \times L$ & 1 & $761327^{*}$ \\
\hline POP $\times A \times L$ & 2 & $1622544^{* *}$ \\
\hline$\ldots \mathrm{A} \times \mathrm{L} \times \mathrm{P} / \mathrm{POP}$ & 55 & $256856^{* *}$ \\
\hline$M \times A \times L$ & 1 & $3037683^{* *}$ \\
\hline POP $\times M \times A \times L$ & 2 & $79435^{\text {ns }}$ \\
\hline$\ldots \mathrm{M} \times \mathrm{A} \times \mathrm{L} \times \mathrm{P} / \mathrm{POP}$ & 55 & $241798^{*}$ \\
\hline REPETICCÕES(R)/ M / A / L & 8 & $289257^{\mathrm{ns}}$ \\
\hline CONJUNTOS/M / A / L / R & 16 & $220199^{\mathrm{ns}}$ \\
\hline RESÍDUO MÉDIO & 942 & 167287 \\
\hline CV $(\%)$ & & 16,4 \\
\hline
\end{tabular}

${ }^{*}{ }^{* *}$ : significativo ao nível de $5 \%$ e $1 \%$ de probabilidade, respectivamente, pelo teste $\mathrm{F}$;

ns : não significativo pelo teste $\mathrm{F}$;

GL : graus de liberdade;

QM : quadrados médios 
Tabela 8. Autovalor $\left(\lambda_{k}{ }^{2}\right)$ e porcentagem da soma de quadrados acumulada (PA) por eixo singular. Análise conjunta de variância, incluindo o desdobramento da interaçào G x E para dados de produtividade de gràos $(\mathrm{kg} / \mathrm{ha})$

\begin{tabular}{|c|c|c|c|c|c|c|c|}
\hline \multirow[b]{2}{*}{$\begin{array}{c}\text { Eixos } \\
\text { Singulares }\end{array}$} & \multirow[b]{2}{*}{$\lambda_{k}^{2}$} & \multirow[b]{2}{*}{$\mathrm{PA}$} & \multirow[b]{2}{*}{ F.V. } & \multicolumn{2}{|c|}{ Comelius } & \multicolumn{2}{|c|}{ Gollob } \\
\hline & & & & $\mathrm{GL}$ & FR & GL & $\mathrm{F}$ \\
\hline & & & Genótipos (G) & 68 & $1,82 * *$ & 68 & $1,82 * *$ \\
\hline & & & Ambientes (E) & 7 & $231,86 * *$ & 7 & $231,86 * *$ \\
\hline & & & GxE & 476 & $70,52 * *$ & 476 & $70,52 * *$ \\
\hline 1 & 2883,74 & 39,85 & IPCAI & 402 & $1,03 *$ & 74 & $3,69 * *$ \\
\hline 2 & 1023,05 & 53,98 & IPCA2 & 330 & $0,96^{\mathrm{ms}}$ & 72 & $1,35 *$ \\
\hline 3 & 928,65 & 66,82 & IPCA3 & 260 & $0,87^{\mathrm{ns}}$ & 70 & $1,26^{\mathrm{ns}}$ \\
\hline 4 & 798,80 & 77,85 & IPCA4 & 192 & $0,79^{\mathrm{ns}}$ & 68 & $1,11^{\mathrm{ns}}$ \\
\hline 5 & 745,22 & 88,15 & IPCA5 & 126 & $0,64^{11 \mathrm{~s}}$ & 66 & $1,07^{\mathrm{Is}}$ \\
\hline 6 & 548,10 & 95,73 & IPCA6 & 62 & $0,47^{11 \mathrm{~s}}$ & 64 & $0,81^{\mathrm{ns}}$ \\
\hline 7 & 309,31 & 100,00 & IPCA7 & 0 & & 62 & $0,47^{11 \mathrm{~s}}$ \\
\hline & & & Erro Médio & 693 & & & \\
\hline
\end{tabular}

$F_{\text {(iolloh) }}:$ teste F de Gollob (1968);

$F_{R} \quad:$ teste $F_{R}$ de Cornelius et al. (1992) e Piepho (1995);

** : significativo ao nível de probabilidade, $p<0,01$;

* : significativo ao nível de probabilidade, $p<0,05$ e

ns : não significativo

\subsection{Análise AMMI}

Na Tabela 8 , a fonte de variação genótipos compreendeu vinte linhagens mais três testemunhas comuns para cada populaçào (PCI, PRIS e PRIM), totalizando 69 genótipos e 68 graus de liberdade para este fator principal.

A Tabela 8 mostra que o efeito significativo da interaçào (GxE), condição ideal para se efetuar a análise AMMI, foi detectado pelo teste F (Cochran, 1954). Obteve-se resposta significativa ao nível de $1 \%$ de probabilidade para os efeitos principais de genótipos $(G)$, ambientes (E) e interação cruzada desses fatores (GxE). O efeito de ambientes (E), seguido pelo 
efeito da interação resultou em maior contribuição para a variação dos tratamentos; o efeito de genótipos $(\mathrm{G})$, foi responsável pela menor parte dessa variação.

Esta situação era esperada, uma vez que os ambientes foram escolhidos por serem bem contrastantes, enquanto que os genótipos pesquisados são os remanescentes da seleção praticada entre plantas $F_{2}$ para tolerância a insetos e entre progênies $F_{3}$ a $F_{10}$ para produtividade de gràos.

As três populações consideradas nesse estudo foram geradas através de cruzamentos entre genitores divergentes para adaptabilidade, incluindo-se materiais bem adaptados às condiçōes ambientais brasileiras e um grupo de materiais exóticos ou semi-exóticos comprovadamente detentores de genes para resistência/tolerância a insetos. Vello (1985) comenta que, apesar do efeito negativo que os materiais exóticos possam exercer na média da população resultante de cruzamentos mistos (adaptados x exóticos), é possível obter genótipos superiores mesmo nestes cruzamentos, desde que o genitor exótico apresente boa adaptação ao ambiente de cultivo e caracteres de valor agronômico. Isto ocorre em razào da introduçào nos materiais adaptados de genes "novos" presentes nos genitores exóticos, fato que aumenta significativamente a variabilidade genética da populaçào obtida de cruzamentos mistos dentro da espécie cultivada. É necessário selecionar os genitores exóticos para eliminar os genótipos que apresentam genes responsáveis por fenótipos indesejáveis ligados aos genes de interesse; outra justificativa seria o aumento da freqüência dos genes favoráveis na populaçào, principalmente poligenes que controlam caracteres quantitativos como a produtividade de grãos e, dessa maneira, aumentar a probabilidade de obtenção de linhagens superiores no final do programa (Rocha, 20()2). Provavelmente, as linhagens avaliadas nesta pesquisa devem ter concentrado maior número de genes para adaptação oriundos dos genitores adaptados, uma vez que as populações foram submetidas à seleçào para produtividade e outros caracteres agronômicos ao longo da condução das gerações de endogamia.

Usualmente, emprega-se o índice ambiental para classificar os ambientes, que é uma medida da qualidade ambiental, sendo classificados como favoráveis ou desfavoráveis em função do ordenamento das médias relativamente à média geral da experimentação. Diversos métodos que visam identificar a estabilidade e adaptabilidade dos genótipos via análise de regressão fazem uso desse índice ambiental. A crítica mais forte à utilização deste critério diz 
respeito à associação do índice ambiental (variável independente na regressão) com a variável dependente, razão pela qual esta pesquisa sobre o efeito da interação foi efetuada pelo modelo AMMI (Additive Main effects and Multiplicative Interaction Analysis), visando-se a identificação de genótipos com desempenhos superiores e bem adaptados às condiçōes ambientais. Cruz \& Regazzi (1994) informam que, quando se observa significância da interação GxE, é necessário que a seleçào de genótipos superiores seja efetuada para ambientes específicos, ou grupos afins, podendo nesse processo identificar quais genótipos que apresentam menor variação.

De acordo com Duarte (2001), a análise AMMI representa um dos potenciais instrumentos para que se possa aprofundar na compreensão dos fatores realmente envolvidos na manifestação da interação (GxE). Para tanto, o método estima o efeito multiplicativo da interação GxE através da análise multivariada (análise de componentes principais - ACP e decomposição por valores singulares - DVS) para descrever o padrão subjacente aos dados de uma matriz de interação $(\mathrm{GxE})$, fazendo a decomposição da soma de quadrados da interação GxE (SQGX) em eixos ou componentes principais da interação (IPCA), sendo adotado aqui o critério "pos-dictivo" pelos testes $F_{\text {ciollob }}$ e $F_{R}$ apresentado por Cornelius et al. (1992) e Piepho (1995), para seleção de modelos AMMI mais preditivos e parcimoniosos (Tabela 8).

O primeiro eixo singular da análise AMMI retém a maior porcentagem de padrão e, com acumulação subseqüente das dimensões dos eixos, há uma diminuição na porcentagem de padrão e um aumento de ruídos (Gauch, 1988). Idealmente, espera-se capturar grande parte do padrão estrutural da SQGe nos primeiros componentes. O estudo da interação cruzada foi realizado pela ACP; a SQGx: foi desmembrada em sete eixos ou IPCAs, apresentando significância ao nivel de $1 \%$ pelo teste $F_{\text {Gollob }}$ para o primeiro eixo (IPC $A_{1}$ ); este componente singular explica 39,85\% daquela soma de quadrados, podendo ser considerado satisfatório por se tratar da variável produtividade de grãos, que sabidamente é bastante influenciada por fatores aleatórios externos. Os demais eixos são incluídos no resíduo AMMI do último IPCA significativo, acumulando uma variação da $\mathrm{SQ}_{\mathrm{Gxl}}$ : predominantemente rica em variação não controlada (ruido). Assim, pelo critério de Gollob (1968), o modelo $\mathrm{AMMI}$, foi selecionado como aquele que melhor descreve o padrão inerente à interação GxE. Cabe salientar que o teste $F_{\text {Ciollol }}$ é mais liberal que o teste $F_{R}$ de Comelius et al. (1992), como alerta Mandel (1971), 
critério este que pode aumentar a probabilidade de selecionar número maior de eixos, aumentando assim, a ocorrência do erro tipo I. Contudo, de acordo com Oliveira et al. (2003), sobre a escolha do nível cle significância do teste adotado, com a utilizaçào de $1 \%$ em vez de $5 \%$, reduz-se a probabilidade de ocorrer o erro tipo I, isto é, de aceitar um modelo AMMI com maior número de eixos, quando na verdade o modelo é menos parametrizado. Por outro lado, aumenta-se a probabilidade de ocorrer o erro tipo II, isto é, de aceitar um modelo AMMI com menor número de eixos, quando o modelo correto é mais parametrizado. Além disso, um modelo preditivo, geralmente tem menor número de termos do que o número julgado significativo por um teste. Assim, uma estratégia no sentido de selecionar um modelo preditivo é aumentar o rigor dos testes, reduzindo o seu nivel de significância. Portanto, em virtude da utilização do modelo de Gollob (1968), conhecidamente menos rigoroso na seleção de modelos AMMI, empregou-se o nível de $1 \%$ de probabilidade, o que implicou na utilizaçào do modelo $\mathrm{AMMl}_{1}$.

De acordo com Lavoranti (2003), a escolha de um teste mais rigoroso para a seleçào do modelo AMMI, implica, conseqüentemente, na diminuiçào do número de eixos utilizados para explicar as somas de quadrados dos efeitos multiplicativos, podendo levar a uma menor porcentagem da soma de quadrados dos efeitos multiplicativos, explicada por esses eixos. Entretanto, diferentemente da maneira convencional, em que se busca uma explicaçào máxima dessa soma de quadrados, no modelo AMMI busca-se absorver apenas o padrào devido à

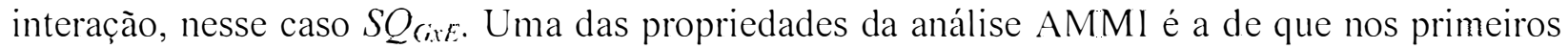
eixos concentram-se as maiores porcentagens de padrão, mesmo que esses eixos expliquem a menor porcentagem das somas de quadrados da interaçào GxE. Contudo, para Gauch \& Zobel (1996), as baixas proporçōes das somas de quadrados explicadas pelos primeiros eixos indicam uma contaminação da matriz de interações por ruídos que não foram controlados pela experimentação, muito provavelmente, devidos a fatores imprevisiveis ou previsíveis, porém nào controlados. Esses ruídos inflacionam a matriz de interaçòes originais depreciando a qualidade de suas estimativas. Dessa forma, todos os métodos que se utilizam dessas estimativas para fazer as inferências sobre o material, sem eliminar esses ruídos, fornecem informações de baixa consistência. Enfatiza, ainda, que a inclusão excessiva de termos multiplicativos no modelo AMMI pode reduzir seriamente a qualidade e a acurácia da análise. 
Apesar da porção relativamente pequena $(39,85 \%)$ de $S Q_{G x t}$ explicada pelo primeiro eixo, espera-se capturar todo o padrão estrutural devido à interação GxE. Dessa forma, os escores de genótipos e de ambientes (Tabela 8) foram plotados, seguindo o modelo $\mathrm{AMMI}_{2}$ (Figura 2). Assim sendo, estão acumulados 53,98\% do padrão estrutural dos dados de produtividade de grãos, porcentagem significativa em se tratando desse caráter.

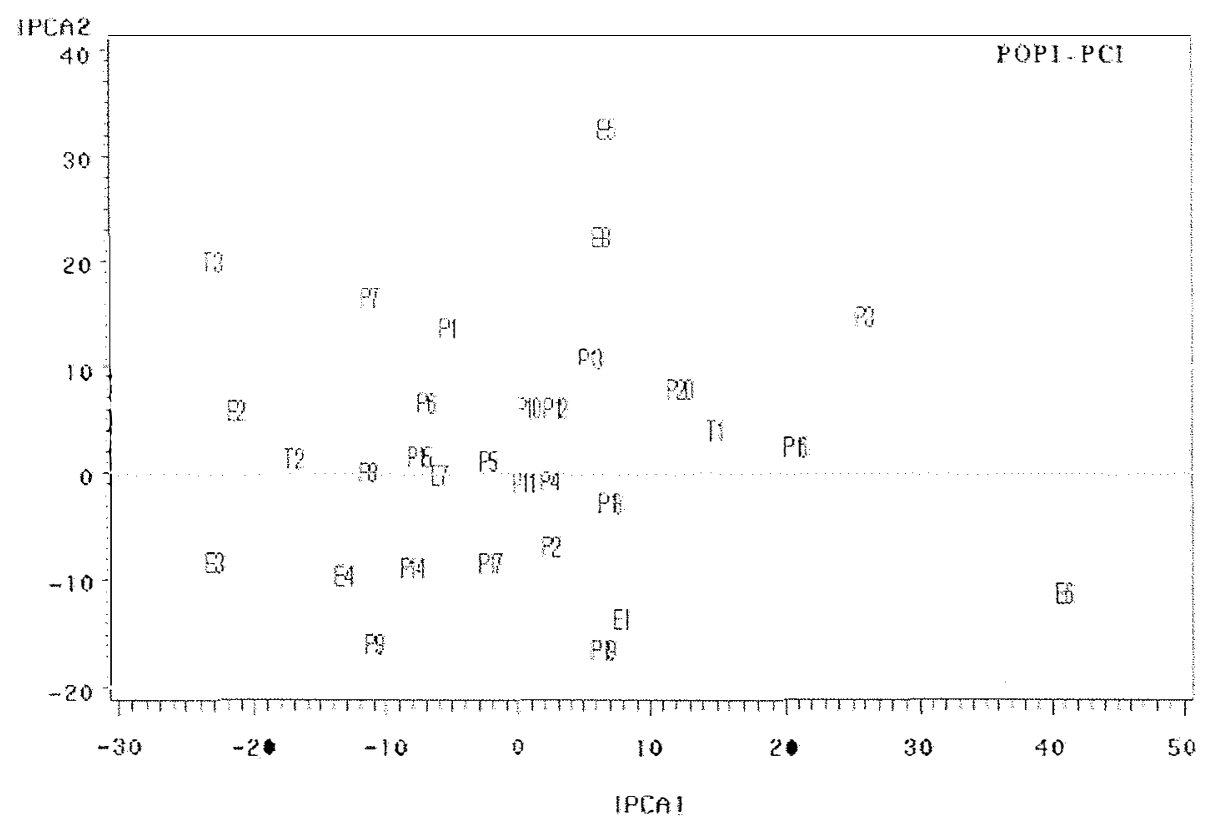

Figura 2 - Escores (ICPA 1 e 2) de componentes principais do modelo AMMI, para produtividade de grãos $(\mathrm{kg} / \mathrm{ha})$, de 20 linhagens ( $\mathrm{Pl}$ a $\mathrm{P} 20$ ) da população $\mathrm{PCI}$ (População com Controle Total de Insetos), três testemunhas (T1 a T3) de soja e oito ambientes (EI a E\&)

Num biplot $\mathrm{AMMI}_{2}$, é esperado que genótipos e ambientes estáveis são aqueles cujos pontos situam-se próximos à origem, ou seja, com escores praticamente nulos para os dois componentes principais da interação (IPCA1 e IPCA2) (Duarte \& Vencovsky, 1999). À medida que seus escores se distanciam da origem, os genótipos e ambientes são reconhecidos como aqueles que mais contribuem para a interação cruzada.

Úma discriminação da interação pode ser feita através da estimativa da adaptabilidade e da estabilidade fenotípica quando se avalia respectivamente, o nivel de resposta ao estímulo ambiental e a previsibilidade, isto é, a manutenção da produtividade frente a ambientes diversos. 
Conforme os critérios adotados, e de acordo com a figura 2, pode-se considerar como de alta estabilidade fenotípica para a população PCI, as linhagens P5, P11, P10, P4, P12 e P15, em ordem decrescente. Estas linhagens também apresentaram maior estabilidade que as testemunhas comuns; entre estas, T1 seguida de T2 mostraram-se mais estáveis. Um segundo grupo de linhagens ainda pode ser identificado por apresentar um nível de estabilidade intermediária; assim, as linhagens com presivisibilidade média em ordem decrescente de estabilidade foram P6, P2, P18, P17, P8, P13, P1 e P20. O primeiro e segundo grupos de linhagens diagnosticadas como estáveis somam 14 linhagens ou $70 \%$ da população PCI. Destacaram-se como instáveis, as linhagens P3, P9, P7, P19, P16 e P14.

As estabilidades ambientais informam sobre a confiabilidade das posições dos genótipos (postos) em cada ambiente, em relação à classificação para a média dos ambientes testados (Lavoranti, 2003).

A Figura 2 também mostra que os ambientes E1, E2, E4, E7 e E8, nessa ordem foram os que menos influenciaram a magnitude da interação cruzada. Por outro lado, os ambientes com mais alta instabilidade foram E6, E5 e E3, em ordem decrescente.

As relações adaptativas podem ser facilmente percebidas num biplot AMMI observando-se os sinais dos escores para cada par de genótipos e ambientes. Assim, genótipos e ambientes com escores de mesmo sinal $(-,-$ ou,++$)$ devem interagir positivamente. Já aqueles com sinais opostos (+, -) devem interagir negativamente (Duarte \& Vencovsky, 1999). Contudo, tem-se verificado que nem sempre essas relações se mostram perfeitamente interpretáveis graficamente. Sendo assim, para maior segurança, confirmou-se tal associação adaptativa através de tabelas auxiliares para médias e escores de genótipos e de ambientes (Tabelas 9, 10 e $11)$.

Com respeito às adaptabilidades fenotípicas, dentre aqueles grupos de genótipos e ambientes com estabilidade mais acentuada incluem-se aqui os dois primeiros grupos. De acordo com a Figura 2 e a Tabela 9, as linhagens P 5 (IPCA1 $=-2,0334$ e IPCA2 $=-1,2933$ ) e P15 $(\mathrm{IPCA} 1=-7,3498$ e $\mathrm{IPCA} 2=-0,6194)$ mostraram interação positiva com os ambientes $\mathrm{E7}$ $(\operatorname{IPCA} 1=-5,7876$ e $\operatorname{IPCA} 2=-2,2765)$ e $\mathrm{E} 4(\mathrm{IPCA} 1=-13,0673$ e $\mathrm{IPCA} 2=-11,7764)$; as linhagens P11 e P4 foram as que apresentaram maior adaptabilidade frente à influência 
ambiental EI; as linhagens PI0 e P12 mostraram capacidade de aproveitar bem a condição ambiental de E8. A segunda testemunha comum mais estável T2 adaptou-se bem aos ambientes E7 e E4. No conjunto de linhagens que apresentaram estabilidade média, observou-se comportamento responsivo de P1 e P6 no ambiente E2, as linhagens P2 e P18, tiveram capacidade de explorar positivamente o efeito interativo do ambiente E1 e P17, e P8 o fez junto aos ambientes E7 e E4, a linhagem P13 apresenta bom comportamento adaptativo com E8. 
Tabela 9. Médias e escores (IPCA 1 e 2) de componentes principais do modelo AMMI para 20 linhagens ( $\mathrm{Pl}$ a $\mathrm{P} 20)$ da populaçào com controle total de insetos (PCI), três testemunhas (Tl. a T3) e oito ambientes (El a E8), para produtividade de gràos $(\mathrm{kg} / \mathrm{ha})$

\begin{tabular}{crrr}
\hline $\begin{array}{c}\text { GENOTIPOS } \\
\text { IAMBIENTES }\end{array}$ & MÉDIAS & \multicolumn{1}{l}{ IPCAI } & \multicolumn{1}{c}{ IPCA2 } \\
\hline P1 & 2805,99 & $-5,0827$ & 11,3147 \\
P2 & 2667,87 & 2,5502 & $-9,1479$ \\
P3 & 2750,76 & 26,1101 & 12,4604 \\
P4 & 2580,76 & 2,6380 & $-3,0360$ \\
P5 & 2689,20 & $-2,0334$ & $-1,2933$ \\
P6 & 2523,07 & $-6,7245$ & 4,4131 \\
P7 & 2405,49 & $-11,0902$ & 14,3652 \\
P8 & 2456,43 & $-11,1406$ & $-2,1335$ \\
P9 & 2308,07 & $-10,7191$ & $-18,2289$ \\
P10 & 2727,01 & 0,8513 & 3,9668 \\
P11 & 2505,68 & 0,5455 & $-3,1758$ \\
P12 & 2623,38 & 2,9601 & 3,8788 \\
P13 & 2476,31 & 5,7026 & 8,4741 \\
P14 & 2322,68 & $-7,9656$ & $-11,0641$ \\
P15 & 2411,82 & $-7,3498$ & $-0,6194$ \\
P16 & 2753,18 & 21,0260 & 0,3336 \\
P17 & 2270,88 & $-2,0674$ & $-10,7099$ \\
P18 & 2386,74 & 7,2585 & $-5,1312$ \\
P19 & 2744,01 & 6,5912 & $-18,8168$ \\
P20 & 2888,26 & 12,4168 & 5,7328 \\
T1 - Ocepar-4 & 2189,97 & 15,0993 & 1,6609 \\
T2 - IAS-5 & 2526,41 & $-16,7809$ & $-0,9338$ \\
T3 - IAC-100 & 2381,56 & $-22,7954$ & 17,6902 \\
E1 - Anhembi-CII-00 & 3514,21 & 8,0122 & $-15,8038$ \\
E2 - Anhembi-CEI-00 & 3046,41 & $-21,1341$ & 3,6666 \\
E3 - Areão-CII-00 & 2187,61 & $-22,7853$ & $-10,7010$ \\
E4 - Areão-CEI-00 & 1506,41 & $-13,0673$ & $-11,7764$ \\
E5 - Anhembi-CII-01 & 2972,27 & 7,0428 & 30,2752 \\
E6 - Anhembi-CEI-01 & 3128,59 & 41,1169 & $-13,4344$ \\
E7 - Areão-CII-01 & 1740,11 & $-5,7876$ & $-2,2765$ \\
E8 - Areão-CEI-01 & 2215,87 & 6,6025 & 20,0503 \\
\hline
\end{tabular}

Para a população formada a partir de plantas $F_{2}$ selecionadas para tolerância a insetos sugadores (PRIS), o grupo de materiais genéticos que menos contribuíram para a interaçào 
cruzada, inclui os seguintes genótipos, em ordem decrescente de estabilidade fenotípica, P7, P10, P5, P9, P11, P20 e P3. No segundo grupo de linhagens com estabilidade mediana estào P2, P18, P13, P15, P19 e Pl4 representando 65\% do conjunto de linhagens que compõe a população PRIS. A testemunha comum com mais alto nível de estabilidade foi, T1. Num outro grupo, contendo os genótipos mais instáveis sob os estímulos dos ambientes considerados, encontramse as linhagens P16, P6, P8, P17, P12, P4 e P1 e as testemunhas comuns, nesta ordem T2 e T3 (Figura 3).

O grupo de ambientes com estabilidade fenotípica mais pronunciada envolve E4, E5, El, E7 e E8 citados em ordem decrescente de estabilidade fenotípica. Já dentre os que mais inflacionaram a interaçào GxE aparecem E6, E2 e E3, nessa ordem de maior para menor instabilidade (Figura 3 e Tabela 10).

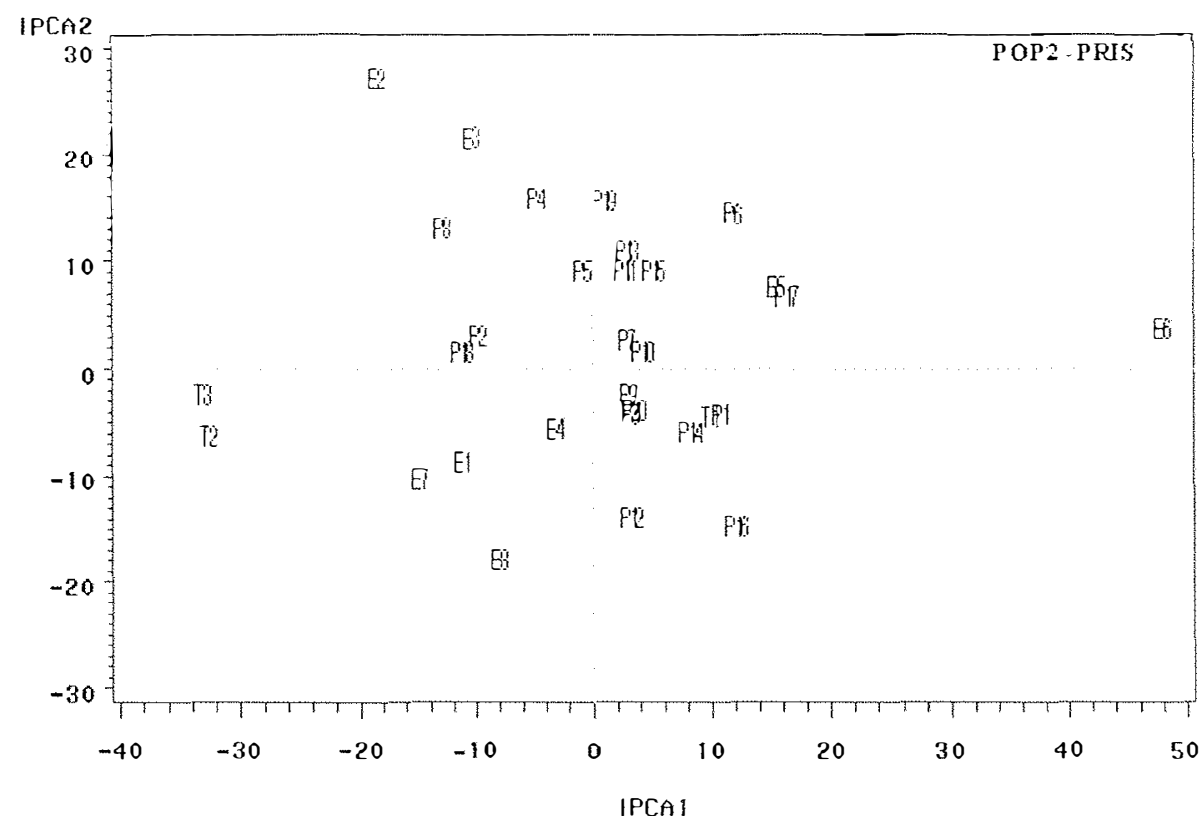

Figura 3 -... Escores (IPCA 1 e 2) de componentes principais do modelo AMMI, para 20 linhagens (PI a P20) população PRIS, três testemunhas (T1 a T3) de soja e oito ambientes (EI a ES), para produtividade de gràos ( $\mathrm{kg} / \mathrm{ha})$

No que concerne às adaptações fenotípicas, as linhagens P7 e P11 indicaram sinergismo adaptativo na condiçào do ambiente E5. Já as linhagens de presivibilidade média P13, P15 e P19 mostram adaptaçào específica ao ambiente E5, enquanto que a linhagem P18 combinou-se 
bem com os ambientes E4, El e E7. Quanto à testemunha comum mais estável T1 não se encontrou combinação adaptativa a nenhum ambiente (Figura 3). Estas combinações adaptativas podem ser mais facilmente visualizadas através da Tabela 10.

Tabela 10. Médias e escores (IPCA 1 e 2) de componentes principais do modelo AMM1 para 20 linhagens (P1 a P20) população PRIS, três testemunhas (T1 a T3) de soja e oito ambientes (E1 a E8), para produtividade de grãos ( $\mathrm{kg} / \mathrm{ha})$

\begin{tabular}{crrr}
\hline $\begin{array}{c}\text { GENÓTIPOS / } \\
\text { AMBIENTES }\end{array}$ & MEDIAS & \multicolumn{1}{l}{ IPCA1 } & \multicolumn{1}{l}{ IPCA2 } \\
\hline P1 & 2691,42 & 10,9989 & $-6,4358$ \\
P2 & 2767,33 & $-9,6215$ & 0,9022 \\
P3 & 2390,01 & 3,3315 & $-6,4578$ \\
P4 & 2668,27 & $-4,6329$ & 13,7421 \\
P5 & 2377,83 & $-0,6023$ & 6,8183 \\
P6 & 2387,98 & 12,0922 & 12,1138 \\
P7 & 2891,39 & 2,9089 & 0,5735 \\
P8 & 2645,46 & $-12,7848$ & 10,9648 \\
P9 & 2808,89 & 3,1423 & $-4,5492$ \\
P10 & 2597,33 & 4,3045 & $-0,6882$ \\
P11 & 2651,08 & 2,7815 & 6,8870 \\
P12 & 2788,58 & 3,4346 & $-16,1758$ \\
P13 & 2752,33 & 3,0250 & 8,6928 \\
P14 & 2229,86 & 8,4442 & $-8,0416$ \\
P15 & 2298,92 & 5,3706 & 6,9758 \\
P16 & 2369,39 & 12,3721 & $-16,9308$ \\
P17 & 2388,76 & 16,5498 & 4,4813 \\
P18 & 2567,02 & $-10,9554$ & $-0,5523$ \\
P19 & 2397,67 & 1,1350 & 13,4184 \\
P20 & 2380,79 & 3,6835 & $-6,0665$ \\
T1 - Ocepar-4 & 2080,63 & 10,1629 & $-6,6679$ \\
T2 - IAS-5 & 2594,22 & $-32,3582$ & $-8,4246$ \\
T3 - IAC-10 & 2283,09 & $-32,7824$ & $-4,5793$ \\
\hline E1 - Anhembi-CII-00 & 3342,09 & $-11,0036$ & $-10,9307$ \\
E2 - Anhembi-CEI-00 & 2913,97 & $-18,2781$ & 24,8697 \\
E3 - Areão-CII-00 & 2013,86 & $-10,0250$ & 19,3622 \\
E4 - Areão-CEI-00 & 1762,96 & $-2,9703$ & $-7,7568$ \\
E5 - Anhembi-CII-01 & 3152,18 & 15,7321 & 5,4449 \\
E6 - Anhembi-CEI-01 & 3319,94 & 49,1615 & 1,5907 \\
E7 - Areão-CII-01 & 1505,92 & $-14,7809$ & $-12,4129$ \\
E8 - Areão-CEI-01 & 2165,85 & $-7,8358$ & $-20,1671$ \\
\hline
\end{tabular}


$\mathrm{Na}$ populaçào formada a partir de plantas $\mathrm{F}_{2}$ selecionadas para tolerância a insetos mastigadores (PRIM), dentre as linhagens do primeiro grupo com estabilidade fenotípica mais alta, apresentando manutençào da produtividade frente a ambientes diversos, isto é, com previsibilidade de comportamento destacam-se em ordem decrescente P14, P7, P20, P15, P11 e P17. No grupo de magnitude média para previsibilidade aparecem P12, P19, P5, P16 e P4. Neste caso, $55 \%$ de linhagens da populaçào PRIM mostrou estabilidade fenotípica apreciável. As mais instáveis foram P18, P8, P13, P2, P10, P3, P6, P9 e P1, também nessa ordem. As testemunhas comuns T1 e T2 sào os genótipos com maior nível de estabilidade fenotípica (Figura 4).

O grupo de ambientes com menor variaçào foram agrupados em ordem decrescente de estabilidade fenotípica em: E4, E1, E7 e E8. Por outro lado, foram mais instáveis, também nessa ordem, os ambientes E5, E6 e E2 (Figura 4).

Cumpre enfatizar que o ambiente E6 nas três populações pesquisadas através do procedimento AMMI tradicional foi comum ao grupo de ambientes que manifestou maior influência para a parcela da interaçào, o valor de seu escore está fora dos limites estabelecidos, o que atestou sua instabilidade. Os ambientes menos variáveis, ou seja, os que menos contribuiram para a interaçào, no conjunto de populações foram E4, E1, E7 e E8.

A testemunha comum $\mathrm{Tl}$ apresentou maior previsibilidade de comportamento nas três populações estudadas (PCI, PRIS e PRIM). 


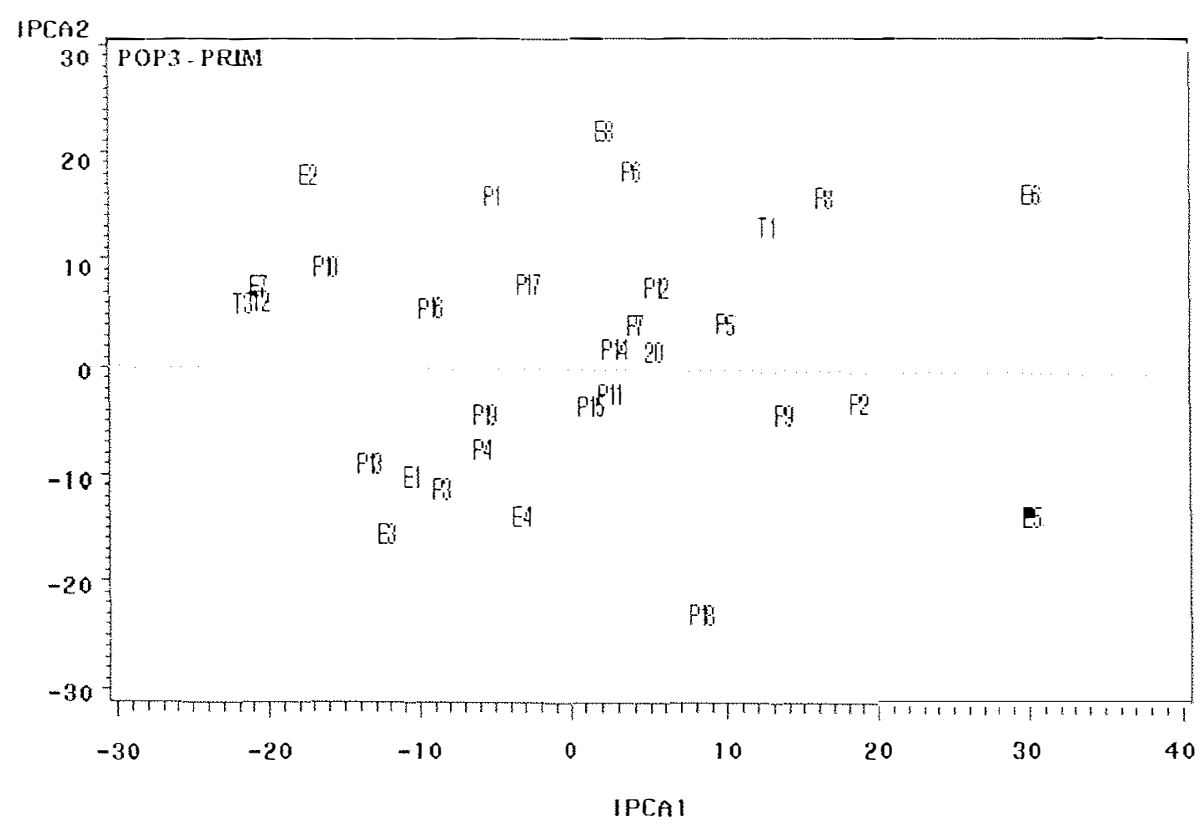

Figura 4 - Escores (IPCA 1 e 2) de componentes principais do modelo AMMI, para 20) linhagens (Pl a P20) da populaçào PRIM, três testemunhas (T1 a T3) de soja e oito ambientes (El a E8), para produtividade de grãos ( $\mathrm{kg} / \mathrm{ha})$

Sobre a adaptabilidade fenotípica como reflexo melhor aproveitamento por parte das linhagens dos efeitos previsíveis e imprevisiveis dos ambientes, isto é, relações responsivas favoráveis frente às flutuações ambientais prevalecentes. Referindo-se ao grupo de genótipos e ambientes da população PRIM, com alta estabilidade fenotípica, aponta-se a linhagem P7 e a testemunha $\mathrm{Tl}$ com boa performance adaptativa frente ao ambiente E8. A linhagem P17 e a testemunha comum T2 mostrou bom comportamento em combinação com o ambiente E7. No segundo grupo de linhagens, com estabilidade fenotípica média tem-se P12 e P5 com relações de respostas positivas frente ao ambiente E8; P19 e P4 foram bem associadas com E4 e E1; a linhagem P16 tirou proveito do estímulo ambiental de E7 como pode ser identificado na Figura 4 e Tabela 11.

Entre as três populações, a $\mathrm{PCl}$ foi a que apresentou maior número de linhagens com associações adaptativas; este resultado indica que foi nesta população que ocorreu uma concentraçào mais alta de genes para adaptabilidade fenotípica combinados com os genes para 
produtividade mais acentuada. Aparentemente, está sendo evidenciada novamente uma certa associação negativa entre genes para tolerância a insetos e genes para produtividade e adaptaçào, uma vez que as outras duas populações (PRIS e PRIM) possivelmente têm freqüências maiores de genes para tolerância a insetos em razào da seleçào praticada entre plantas $F_{2}$. 
Tabela 11. Médias e escores (IPCA1 e 2) de componentes principais do modelo AMM1 para 20 linhagens (P1 a P20) da PRIM (População com seleção para Resistência a Insetos Mastigadores em $\mathrm{F}_{2}$ ), três testemunhas ( $\mathrm{T} 1$ a T3) de soja e oito ambientes (El a E8), para produtividade de grãos $(\mathrm{kg} / \mathrm{ha})$

\begin{tabular}{crrr}
\hline $\begin{array}{c}\text { GENOTIP@S } \\
\text { AMBIENTES }\end{array}$ & MÉDIAS & \multicolumn{1}{l}{ IPCA1 } & \multicolumn{1}{l}{ IPCA2 } \\
\hline P1 & 2503,24 & $-5,0538$ & 14,0640 \\
P2 & 2609,73 & 18,9772 & $-5,5780$ \\
P3 & 2546,37 & $-8,3674$ & $-13,4866$ \\
P4 & 2875,66 & $-5,7470$ & $-9,7649$ \\
P5 & 2528,79 & 10,0699 & 1,9336 \\
P6 & 2616,06 & 4,1222 & 16,3740 \\
P7 & 2607,31 & 4,2578 & 1,8965 \\
P8 & 2548,40 & 16,6199 & 13,8804 \\
P9 & 2541,52 & 13,9139 & $-6,5587$ \\
P10 & 2781,91 & $-16,1000$ & 7,4461 \\
P11 & 2465,27 & 2,6882 & $-4,5881$ \\
P12 & 2419,41 & 5,6610 & 5,3511 \\
P13 & 2518,79 & $-13,2540$ & $-10,9961$ \\
P14 & 2379,81 & 2,9918 & $-0,4125$ \\
P15 & 2528,63 & 1,4926 & $-5,7505$ \\
P16 & 2798,09 & $-9,0974$ & 3,6563 \\
P17 & 2681,13 & $-2,6199$ & 5,8312 \\
P18 & 2639,96 & 8,4884 & $-25,3401$ \\
P19 & 2476,76 & $-5,5194$ & $-6,3832$ \\
P20 & 2694,18 & 5,4759 & $-0,6912$ \\
T1 - Ocepar-4 & 2156,41 & 12,8261 & 11,0076 \\
T2 - IAS-5 & 2680,24 & $-20,2928$ & 4,1191 \\
T3 - IAC-100 & 2576,71 & $-21,5331$ & 3,9901 \\
\hline E1- Anhembi-CII-00 & 3529,78 & $-10,3929$ & $-12,2924$ \\
E2 - Anhembi-CEI-00 & 2894,54 & $-17,2008$ & 16,0855 \\
E3 - Areão-CII-00 & 2048,01 & $-12,1564$ & $-17,6823$ \\
E4 - Areão-CEI-00 & 1850,03 & $-3,0963$ & $-15,9554$ \\
E5 - Anhembi-CII-01 & 3185,38 & 30,4393 & $-16,2361$ \\
E6 - Anhembi-CEI-01 & 3103,91 & 30,4829 & 14,1759 \\
E7 - Areão-CII-01 & 1641,68 & $-20,4863$ & 5,6881 \\
E8 - Areão-CEI-01 & 2329,05 & 2,4105 & 26,2169 \\
\hline
\end{tabular}

Uma outra abordagem que pode ser implementada via biplot AMMIl é da maior importância para pesquisar a produtividade dos genótipos como resultado de seus componentes primários e secundários; caracteres agronômicos tais como resistência/tolerância a insetos estão 
incluidos neste contexto. O enfoque complementar às características de adaptabilidade e estabilidade fenotípica como o é a produtividade média dos materiais genéticos sào imprescindiveis para recomendações de uma nova cultivar, que em última instancia é o que mais interessa ao agricultor.

Nota-se pelo biplot AMMIl (Figura 5), que das vinte linhagens da populaçào PCI, 17 (85\%) mostraram média de produtividade superior à média das testemunhas comuns (MT = $2366 \mathrm{~kg} / \mathrm{ha}$ ). Dentre as linhagens que formam esse grupo mais produtivo, destacam-se com interações relativamente baixas com os ambientes 13 linhagens (65\%), a saber: P20, P1, P10, P5, P2, P12, P4, P6, P11, P13, P8, P15 e P18, em ordem decrescente de produtividade (Tabela $9)$.

Os ambientes E1 e E2 sobressaíram-se quanto à produtividade e, ao mesmo tempo, mostraram estabilidade fenotípica (Figura 5 e Tabela 9).

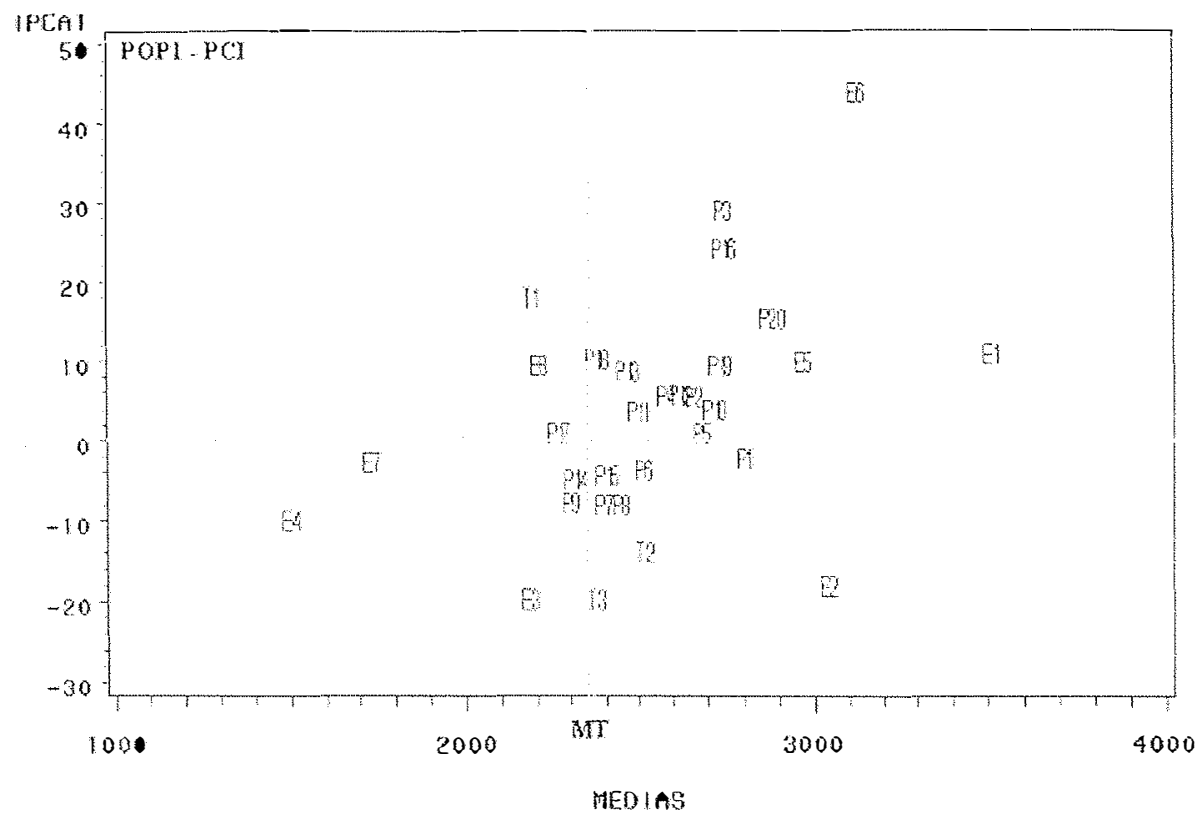

Figura 5 - Biplot AMMI1 segundo os escores de componente principal- IPCA1 x médias de produtividade de grãos (kg/ha), para 20 linhagens (Pl a P20) da PCI (Populaçào com Controle Total de Insetos em $F_{2}$ ), três testemunhas ( $\mathrm{T} 1$ a $\mathrm{T} 3$ ) de soja e oito ambientes (El a E8) 
Na populaçào PRIS (Figura 6 e Tabela 10), formada a partir de plantas $F_{2}$ selecionadas para resistência a insetos sugadores, com produtividade média superior à média das testemunhas comuns $(\mathrm{MT}=2373 \mathrm{~kg} / \mathrm{ha})$, também ocorreram 17 linhagens. Considerando as linhagens que agregam as características desejáveis de estabilidade fenotípica e alta produtividade, apresentase em ordem decrescente de desempenho produtivo P7, P9, P2, P13, P11, P1 • P18, P19, P3, P20 e P5, constituindo 55\% das linhagens da populaçào PRIS.

Os ambientes E1 e E5 conciliaram altas produtividades e estabilidade fenotípica (Figura 6 e Tabela 10 ).

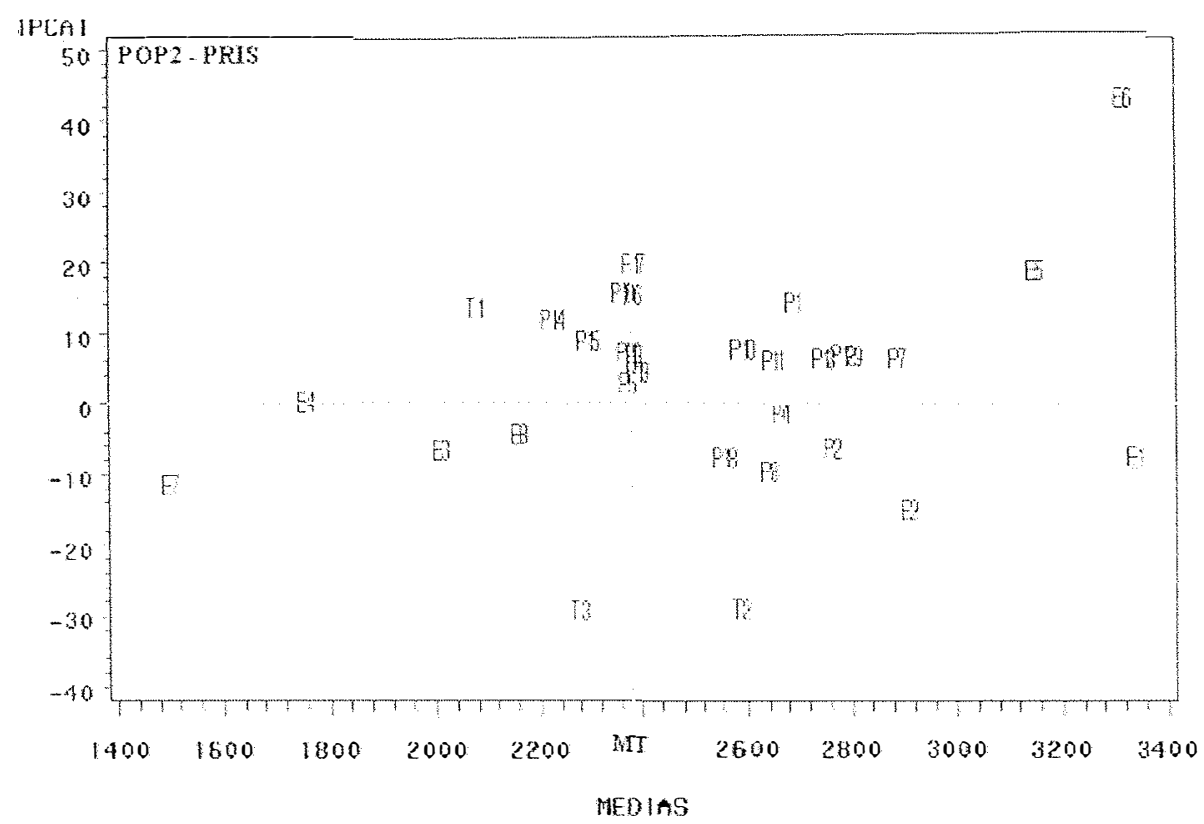

Figura 6 - Biplot AMMI1 segundo os escores de componente principal - IPCA1 x médias de produtividade de grãos (kg/ha), para 21 linhagens (P1 a P20) da PRIS (Populaçào com seleção para Resistência a Insetos Sugadores em $\mathrm{F}_{2}$ ), três testemunhas (T1 a T3) de soja e oito ambientes (E1 a E8)

Quanto à produtividade média dos materiais genéticos que compòem a populaçào formada a partir de plantas $F_{2}$ selecionadas para tolerância a insetos mastigadores (PRIM), encontram-se 16 linhagens (80\%), com valor superior à média das testemunhas comuns (MT $=$ $2502 \mathrm{~kg} / \mathrm{ha}$ ), reportando aos grupos com alta e média magnitude de estabilidade fenotípica, tem- 
se em ordem decrescente de performance produtiva as linhagens P4, P16, P20, P17, P7, P5, P15 (Figura 7 e Tabela 11 ).

Para os ambientes estáveis, a populaçào PRIM apresentou maior produtividade no ambiente El (Figura 7 e Tabela 11 ), representando apenas 35\% das linhagens da população.

Entre as três populações, a PCI seguida da PRIS foram as que apresentaram maior número de linhagens com associações favoráveis de estabilidade fenotípica e produtividade de gràos.

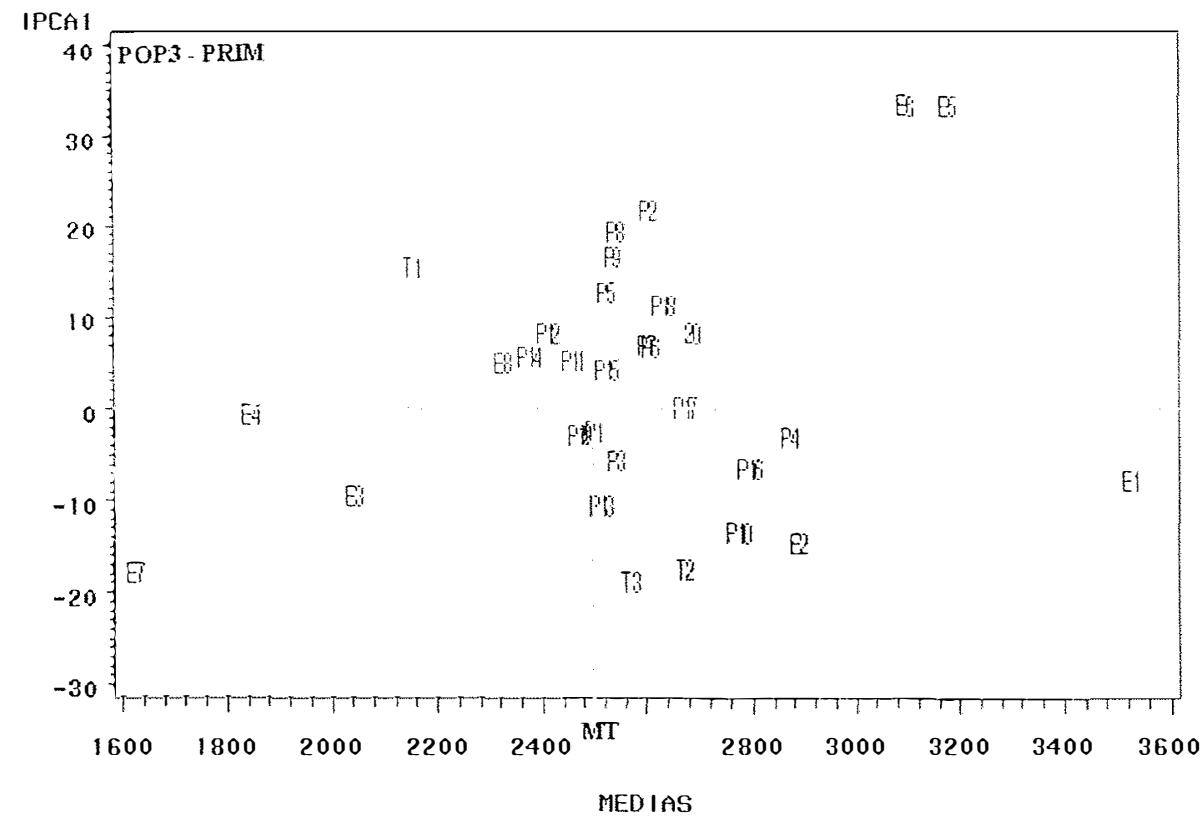

Figura 7 - Biplot AMMII segundo os escores de componente principal - IPCAI x média de produtividade de grãos (kg/ha), para 20 linhagens (PI a P20) da PRIM (Populaçào com seleçào para a Resistência a Insetos Mastigadores em $F_{2}$ ), três testemunhas (TI a T3) de soja e oito ambientes (EI a E8) 


\subsection{Análise AMM1 com reamostragem "bootstrap"}

Os escores AMMI têm distribuiçào de probabilidade desconhecida, fato que dificulta a obtençào de fórmulas via argumentos analíticos. Para medir a precisão desses escores, Lavoranti (2003), apresentou uma metodologia complementar para avaliar a precisão dos escores de genótipos e de ambientes, através de técnicas refinadas de reamostragem "bootstrap", permitindo uma melhoria na qualidade das inferências sobre as adaptabilidades e estabilidades fenotípicas estimadas pelo modelo AMMI.

Como os coeficientes dos escores de genótipos e ambientes são obtidos a partir da matriz de resíduos, procurou-se de acordo com Lavoranti (2003), associar a ferramenta estatística "bootstrap" às necessidades da análise AMMI. Em concordância com o modelo AMMI, que permite a estimação dos genótipos associados aos ambientes livres de ruídos, optou-se pela reamostragem na matriz de resíduos, obtida dos valores estimados. Dessa forma, foram desenvolvidos procedimentos estatísticos que possibilitaram as análises gráficas e numéricas das adaptabilidades e estabilidades fenotípicas dos genótipos e dos ambientes envolvidos neste estudo.

Os resultados da análise da estabilidade via AMMI "bootstrap" de genótipos da populaçào PCI (Figura 8) permitiram identificar como estáveis os genótipos que continham o ponto de coordenadas nulas $(0,0)$ incluidas na regiào de confiança para o vetor "bootstrap" de médias. Todos os genótipos apresentaram estabilidade fenotípica, sendo separados em quatro categorias distintas e citados a seguir em ordem decrescente de estabilidade, com base na magnitude dos coeficientes "bootstrap" apresentados na Tabela 12. No grupo de genótipos com estabilidade muito alta destacaram-se P3, P17, P16, P1, P6 e T3; no grupo de alta estabilidade ficaram P5, T1, P7, T2, P4, P8, P18 e P11; um terceiro grupo incluiu os seguintes genótipos com estabilidade média P13, P14, P20 e P2; finalmente, um quarto grupo de genótipos classificados como de estabilidade baixa foi formado por P10, P19, P9, P15 e P12. 

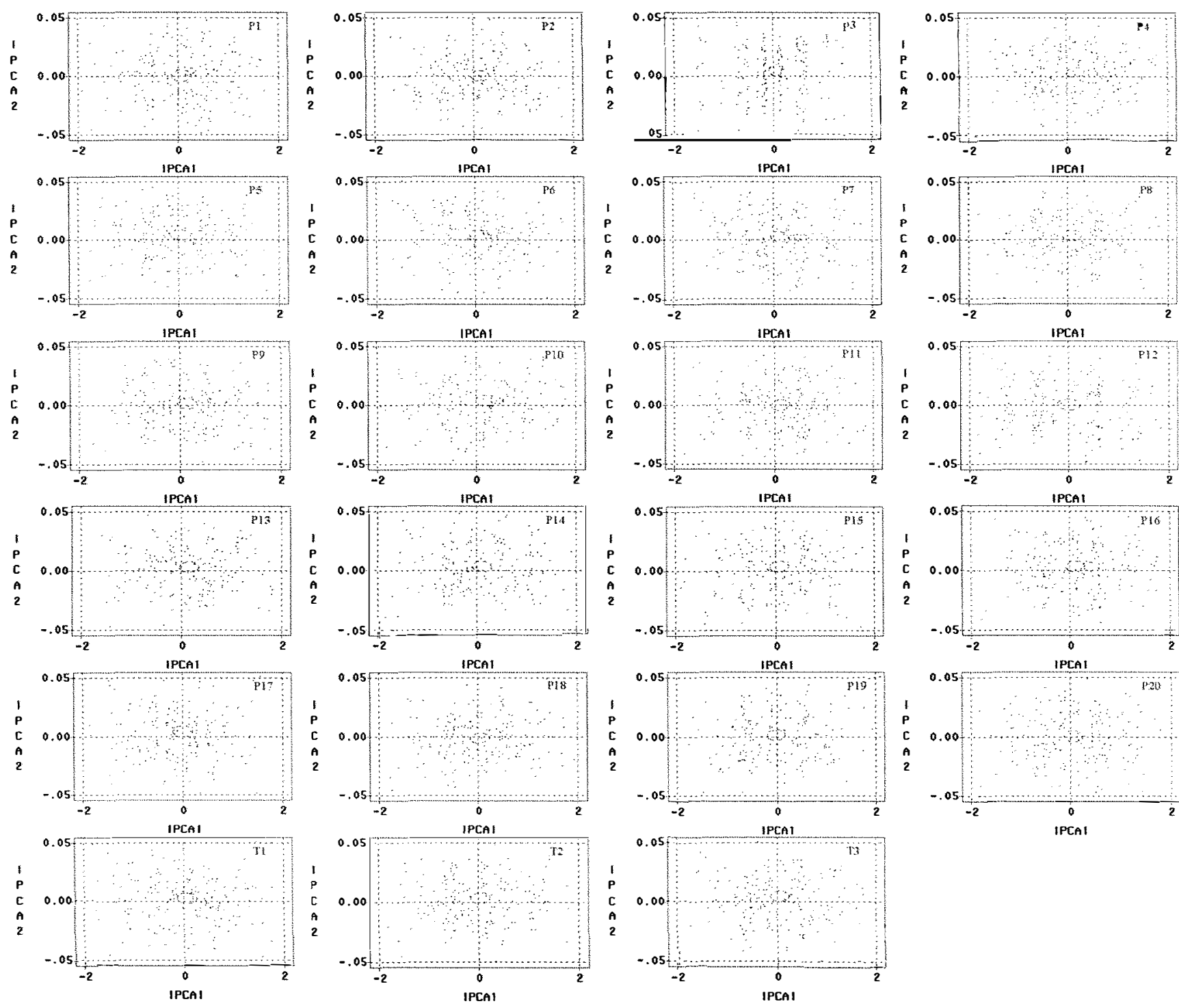

Figura 8 - Gráficos de dispersão e regiões de confiança de $99 \%$ para os escores "bootstrap" de 20 linhagens (P1 a P20) da PCI (população com Controle Total de Insetos em F $F_{2}$ e três testemunhas ( $\mathrm{T} 1$ a $\mathrm{T} 3$ ) de soja, para produtividade de grãos $(\mathrm{kg} / \mathrm{ha})$ em oito ambientes 
Tabela 12. Classificaçào através de coeficiente "bootstrap" de estabilidade (CBE), de 20 linhagens ( $\mathrm{P} 1$ a P20) da $\mathrm{PCl}$ (Populaçào com Controle Total de Insetos em $\mathrm{F}_{2}$ ) e três testemunhas comuns ( $\mathrm{Tl}$ a $\mathrm{T} 3$ ), para produtividade de gràos $(\mathrm{kg} / \mathrm{ha})$, em oito ambientes

\begin{tabular}{ccccc}
\hline Genótipos & $\mathrm{N}^{\mathrm{a}}$ & $\mathrm{CBE}$ & \multicolumn{2}{c}{ Classificaçào } \\
\hline P1 & 115 & 0,425 & Estável & Muito Alta \\
P2 & 123 & 0,385 & Estável & Média \\
P3 & 101 & 0,495 & Estável & Muito alta \\
P4 & 120 & 0,400 & Estável & Alta \\
P5 & 117 & 0,415 & Estável & Alta \\
P6 & 115 & 0,425 & Estável & Muito alta \\
P7 & 118 & 0,410 & Estável & Alta \\
P8 & 120 & 0,400 & Estável & Alta \\
P9 & 127 & 0,365 & Estável & Baixa \\
P10 & 124 & 0,380 & Estável & Baixa \\
P11 & 119 & 0,405 & Estável & Alta \\
P12 & 143 & 0,285 & Estável & Baixa \\
P13 & 121 & 0,395 & Estável & Média \\
P14 & 121 & 0,395 & Estável & Média \\
P15 & 128 & 0,360 & Estável & Baixa \\
P16 & 113 & 0,435 & Estável & Muito alta \\
P17 & 112 & 0,440 & Estável & Muito alta \\
P18 & 120 & 0,400 & Estável & Alta \\
P19 & 126 & 0,370 & Estável & Baixa \\
P20 & 122 & 0,390 & Estável & Média \\
\hline T1 & 117 & 0,415 & Estável & Alta \\
T2 & 118 & 0,410 & Estável & Alta \\
T3 & 116 & 0,420 & Estável & Muito alta \\
\hline
\end{tabular}

${ }^{a}$ : N é o número de pontos externos à regiào de prediçào para o vetor nulo

Para a populaçào formada a partir de plantas $F_{2}$ selecionadas para tolerância a insetos sugadores (PRIS), os resultados obtidos via construçào da regiào de confiança "bootstrap" sào mostrados na Figura 9. Todos os genótipos foram classificados como estáveis, sendo separados em quatro grupos com diferentes níveis de estabilidade, os quais estào a seguir relacionados em ordem decrescente de estabilidade (Tabela 13). O grupo com estabilidade muito alta envolveu os seguintes genótipos P10, P16, P9, P2, T2 e P5; entre as linhagens e testemunhas de alta presivibilidade ficaram P7, P8, P14, T3, P6 e P11; genótipos medianamente estáveis 
compreenderam as linhagens P3, P13, P15, P17, P18, P1 e P12; já o grupo de baixa estabilidade incluiu os genótipos: P19, T1, P4 e P20.
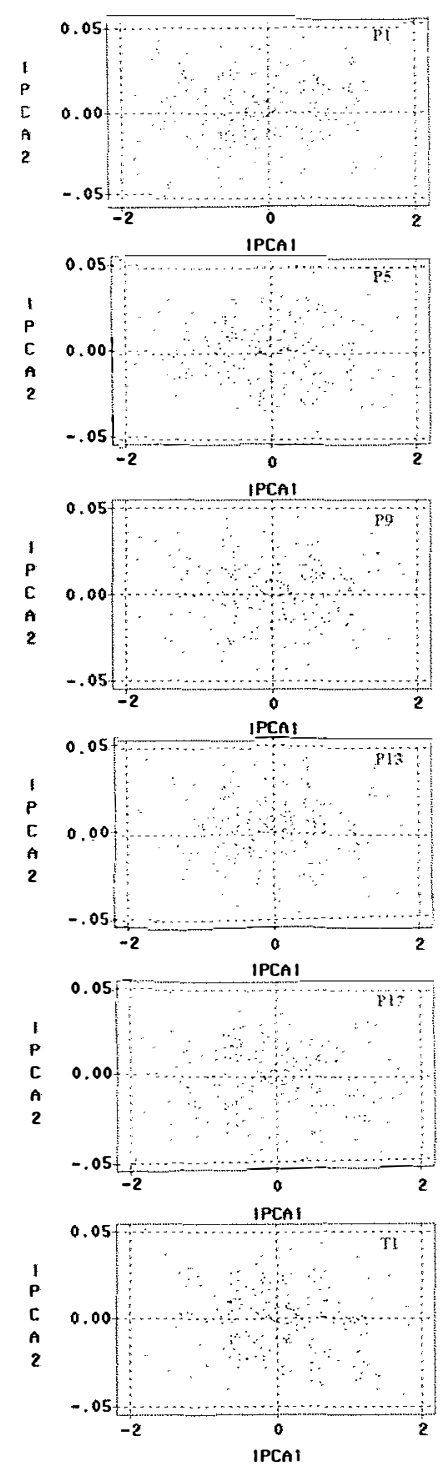
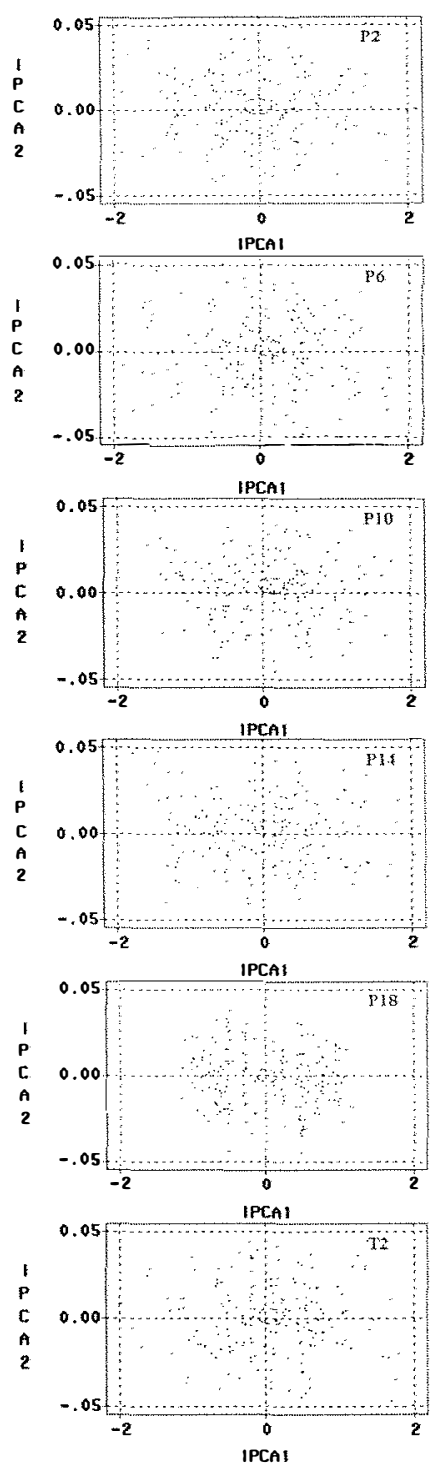
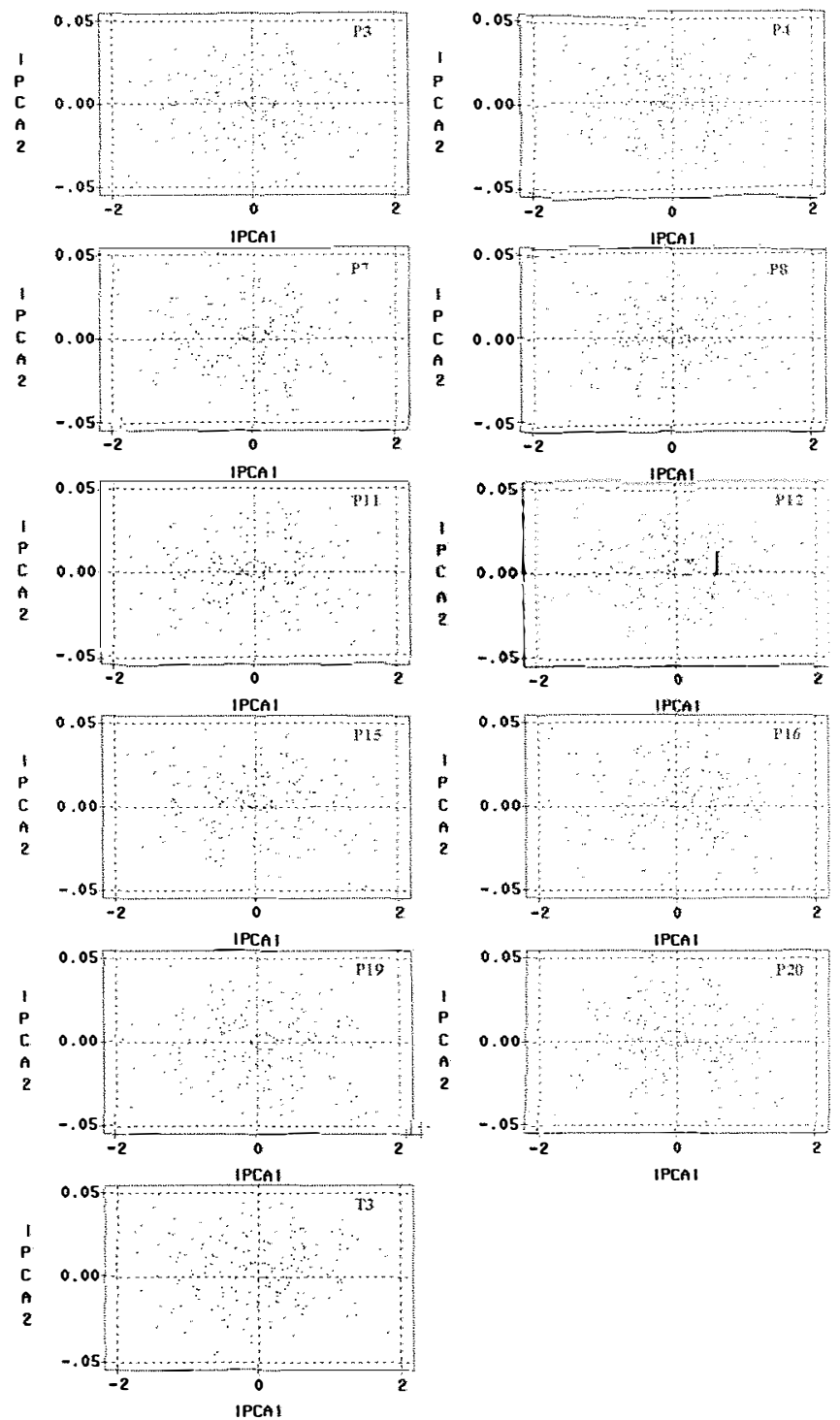

Figura 9 - Gráficos de dispersão e regiões de confiança de $99 \%$ para os escores "bootstrap" de 20 linhagens (P1 a P20) da PRIS (População com seleção para Resistência a Insetos Sugadores em $\mathrm{F}_{2}$ ) e três testemunhas ( $\mathrm{T} 1 \mathrm{a}$ T3) de soja, para produtividade de grãos, ( $\mathrm{kg} / \mathrm{ha})$ em oito ambientes 
Tabela 13. Classificação através de coeficiente "bootstrap" de estabilidade (CBE), de 20 linhagens (P1 a P20) da PRIS (Populaçào com seleçào para Resistência a Insetos Sugadores em $\mathrm{F}_{2}$ ) e três testemunhas comuns ( $\mathrm{T} 1$ a $\mathrm{T} 3$ ) de soja, para produtividade de gràos $(\mathrm{kg} / \mathrm{ha})$ em oito ambientes

\begin{tabular}{ccccc}
\hline Genótipos & $N^{\mathrm{a}}$ & CBE & \multicolumn{2}{c}{ Classificação } \\
\hline P1 & 123 & 0,385 & Estável & Média \\
P2 & 115 & 0,425 & Estável & Muito alta \\
P3 & 121 & 0,395 & Estável & Média \\
P4 & 129 & 0,355 & Estável & Baixa \\
P5 & 116 & 0,420 & Estável & Muito alta \\
P6 & 119 & 0,405 & Estável & Alta \\
P7 & 117 & 0,415 & Estável & Alta \\
P8 & 118 & 0,410 & Estável & Alta \\
P9 & 114 & 0,430 & Estável & Muito alta \\
P10 & 112 & 0,440 & Estável & Muito alta \\
P11 & 120 & 0,400 & Estável & Alta \\
P12 & 123 & 0,385 & Estável & Média \\
P13 & 121 & 0,395 & Estável & Média \\
P14 & 118 & 0,410 & Estável & Alta \\
P15 & 121 & 0,395 & Estável & Média \\
P16 & 113 & 0,435 & Estável & Muito alta \\
P17 & 121 & 0,395 & Estável & Média \\
P18 & 122 & 0,390 & Estável & Média \\
P19 & 124 & 0,380 & Estável & Baixa \\
P20 & 130 & 0,350 & Estável & Baixa \\
T1 & 126 & 0,370 & Estável & Baixa \\
T2 & 115 & 0,425 & Estável & Muito alta \\
T3 & 118 & 0,410 & Estável & Alta \\
\hline
\end{tabular}

": N é o número de pontos externos à regiào de predição para o vetor nulo

Todos os genótipos da populaçào PRIM apresentaram o ponto de coordenadas nulas $(0,0)$ incluído na regiào de confiança para o vetor "bootstrap" de médias (Figura 10). A classificação da variável estabilidade fenotípica pode ser visualizada com auxílio da Tabela 13. na qual os genótipos foram classificados em quatro grupos distintos para o nível de estabilidade, estando relacionados a seguir em ordem decrescente de estabilidade. O grupo com estabilidade muito alta incluiu os genótipos P16, P10, P8, P7, P5 e T2; os genótipos P2, P4, P11, P19, P9 e T3 ficaram no grupo com alta presivibilidade; diagnosticou-se P1 8, P3, P6, P20, T1 e P15 como 
edianamente estáveis; o grupo com baixa estabilidade envolveu as linhagens P1, P17, P14, P12 e P13.
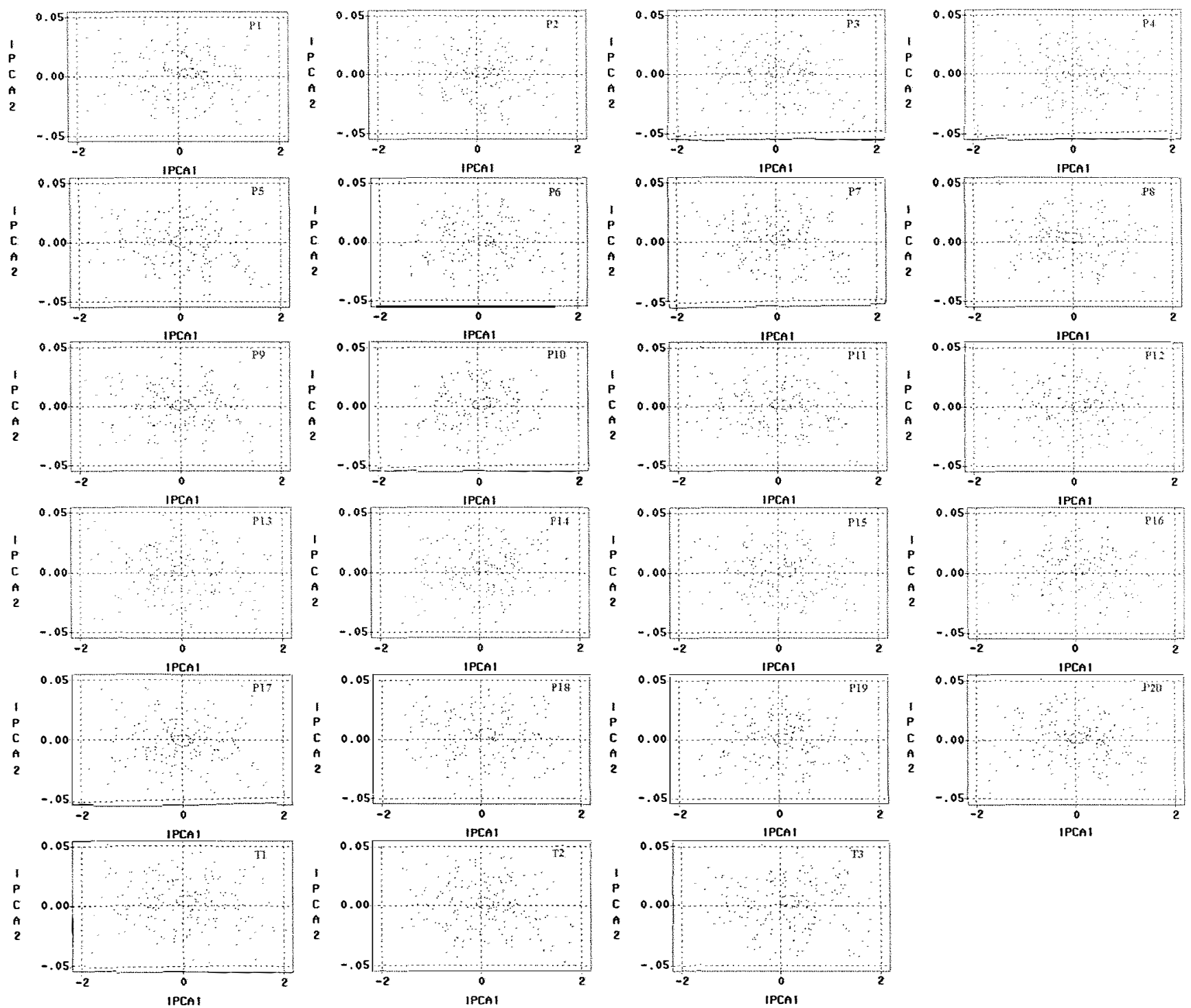

Figura 10 - Gráficos de dispersão e regiões de confiança de $99 \%$ para os escores "bootstrap" de 20 linhagens (Pl a P20) da PRIM (População com seleção para Resistência a Insetos Mastigadores em $\mathrm{F}_{2}$ ) e três testemunhas ( $\mathrm{T} 1$ a $\mathrm{T} 3$ ) de soja para produtividade de grãos $(\mathrm{kg} / \mathrm{ha})$ em oito ambientes 
Tabela 14. Classificação através de coefíciente "bootstrap" de estabilidade (CBE), de 20 linhagens (Pl a P20) da PRIM (População com seleção para Resistência a Insetos Mastigadores em $F_{2}$ ) e três testemunhas ( $\mathrm{Tl}$ a $\mathrm{T} 3$ ) de soja para produtividade de grãos ( $\mathrm{kg} / \mathrm{ha}$ ) em oito ambientes

\begin{tabular}{ccccc}
\hline Genótipos & $\mathrm{N}^{\mathrm{a}}$ & CBE & \multicolumn{2}{c}{ Classificação } \\
\hline P1 & 124 & 0,38 & Estável & Baixa \\
P2 & 117 & 0,415 & Estável & Alta \\
P3 & 122 & 0,39 & Estável & Média \\
P4 & 119 & 0,405 & Estável & Alta \\
P5 & 116 & 0,42 & Estável & Muito alta \\
P6 & 122 & 0,39 & Estável & Média \\
P7 & 115 & 0,425 & Estável & Muito alta \\
P8 & 111 & 0,445 & Estável & Muito alta \\
P9 & 120 & 0,4 & Estável & Alta \\
P10 & 110 & 0,45 & Estável & Muito alta \\
P11 & 119 & 0,405 & Estável & Alta \\
P12 & 128 & 0,36 & Estável & Baixa \\
P13 & 128 & 0,36 & Estável & Baixa \\
P14 & 127 & 0,365 & Estável & Baixa \\
P15 & 123 & 0,385 & Estável & Média \\
P16 & 108 & 0,46 & Estável & Muito alta \\
P17 & 124 & 0,38 & Estável & Baixa \\
P18 & 121 & 0,395 & Estável & Média \\
P19 & 119 & 0,405 & Estável & Alta \\
P20 & 122 & 0,39 & Estável & Média \\
T1 & 122 & 0,39 & Estável & Média \\
T2 & 116 & 0,42 & Estável & Muito alta \\
T3 & 120 & 0,4 & Estável & Alta \\
\hline \hline
\end{tabular}

a: N é o número de pontos externos à região de predição para o vetor nulo

Resultado semelhante ao observado no procedimento AMMI foi encontrado no "bootstrap" AMMI, considerando os dois primeiros grupos de materiais genéticos com característica de muito alta e alta estabilidade fenotípica, a população $\mathrm{PCI}$, também, apresentou maior número de genótipos $(60,87 \%)$ em comparação as populações PRIS e PRIM, ambas representando $52,17 \%$ de linhagens e testemunhas comuns constituindo esses dois grupos. 
Os resultados da análise da estabilidade via AMMI "bootstrap" de ambientes permitiram identificar como estáveis os ambientes que continham o ponto de coordenadas nulas $(0,0)$ incluído na região de confiança para o vetor "bootstrap" de médias. Os ambientes com alta estabilidade são aqueles que participaram em menor grau da interação de genótipos com ambientes, como foi evidenciado na Figura 11. De acordo com a Tabela 15, os oito ambientes foram classificados em quatro grupos distintos em ordem decrescente de estabilidade. O ambiente E8 (Areão-CEI-01) apresentou menor dispersão de escores, sendo classificado como de estabilidade muito alta; em seqüência agrupam-se E7 (Areão-CII-01) e E4 (Areão-CEI-00) com alta estabilidade; com estabilidade baixa têm-se os ambientes E2 (Anhembi-CEI-00), E6 (Anhembi-CEI-01) e E5 (Anhembi-CII-01); um quarto grupo, representado pelos ambientes El (Anhembi-CII-00) e E3 (Areão-CII-00) foi classificado como instável; estes últimos ambientes não tiveram seus pontos de coordenadas nulos, redundando no aumento da variância da interação GxE.
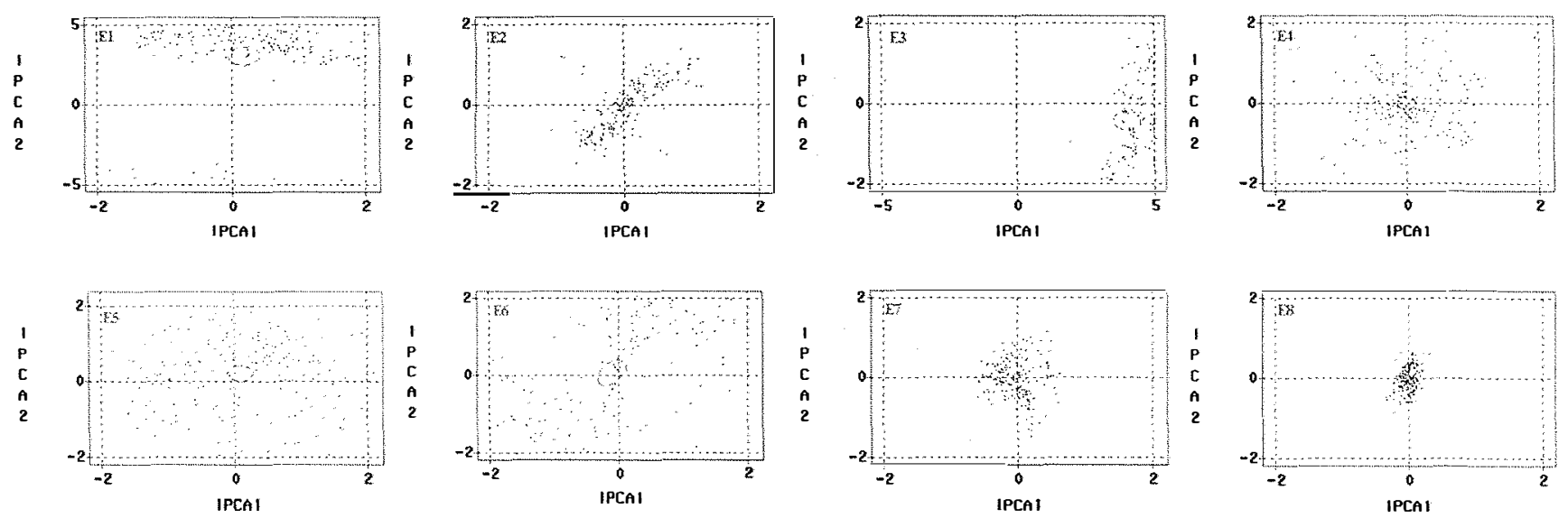

Figura 11 - Gráficos de dispersão e regiões de confiança de $99 \%$ para os escores "bootstrap" de ambientes (E1 a E8), para produtividade de grãos ( $\mathrm{kg} / \mathrm{ha})$, de três populações ( $\mathrm{PCI}$, PRIS e PRIM) de soja 
Tabela 15. Classificação através de coeficiente "bootstrap" de estabilidade (CBE), de ambientes (El a E8), para produtividade de grãos (kg/ha) de populações (PCI, PRIS e PRIM) de soja

\begin{tabular}{ccclc}
\hline \hline Ambientes & $\mathrm{N}^{\mathrm{a}}$ & CBE & \multicolumn{2}{c}{ Classificação } \\
\hline El-Anhembi-CII-00 & 200 & 0 & Instável & \\
E2 - Anhembi-CEI-00 & 131 & 0,345 & Estável & Baixa \\
E3 - Areão-CII-00 & 200 & 0 & Instável & \\
E4 - Areão-CEI-00 & 128 & 0,360 & Estável & Alta \\
E5 - Anhembi-CII-01 & 191 & 0,045 & Estável & Baixa \\
E6-Anhembi-CEI-01 & 188 & 0,060 & Estável & Baixa \\
E7 - Areão-CII-01 & 68 & 0,660 & Estável & Alta \\
E8 - Areão-CEI-01 & 21 & 0,895 & Estável & Muito alta \\
\hline \hline
\end{tabular}

a: N é o número de pontos externos à região de predição para o vetor nulo

Na análise de estabilidade através do procedimento AMMI tradicional com representação gráfica em biplot, apenas apresentam falta de estabilidade fenotípica aqueles genótipos e/ou ambientes que tiveram as duas coordenadas (IPCAI e IPCA2) distanciadas do zero ou muito distantes do IPCA1 (Lavoranti, 2003). Em relação à maior influência do IPCA1, isso pode ser explicado em função da análise multivariada por componentes principais reter a maior porcentagem da variância explicada no primeiro eixo principal (Johnson \& Wichern, 1998). Assim, a maior concentração do padrão de variação devido à interação, está concentrada no IPCAl (Gauch, 1988).

Houve uma tendência geral das regiòes de confiança para estabilidade com níveis diferentes de inclusão do vetor nulo, mas nào o suficiente para atestar possiveis instabilidades. Visando melhorar a classificação das estabilidades, foram determinadas as regiões "bootstrap" de prediçào para o vetor nulo, e, a partir dos valores ordenados dos coeficientes "bootstrap" para a estabilidade, implementou-se as classificaçòes das estabilidades fenotípicas de genótipos e ambientes via valores ordenados dos coeficientes "bootstrap" de acordo com análise numérica (Tabelas 12, 13, 14 e 15).

Apesar da versatilidade do modelo "bootstrap" AMMI, mais pesquisas devem ser conduzidas visando o pleno entendimento desse fenômeno, tão intrigante nos programas de 
melhoramento, que é a interação GxE. Um dos pontos que merece estudos mais detalhados é a definição dos níveis de estabilidade, via região de predição para o vetor nulo, como por exemplo, a análise gráfica da dispersão dos escores "bootstrap" (Lavoranti, 2003).

Um outro aspecto de maior relevância, representando um recurso adicional para melhor discernimento da metodologia aplicada, refere-se à avaliação dos gráficos da dispersão dos escores "bootstrap" de genótipos (Figuras 8, 9 e 10) e de ambientes (Figura 11). Aparentemente, neste processo, a exemplo do que foi constatado nos biplots AMMI2, suspeitase que o IPCAI tem maior influência na classificação da estabilidade dos materiais, como pode ser evidenciado no gráfico das linhagens P12 (Figura 8) e P20 (Figura 9) e do ambiente E3 (Figura 11 ) identificados como genótipos de baixa estabilidade e ambiente instável, para os quais percebe que a dispersão da nuvem de pontos ocorreu ao longo do eixo IPCA2. Aquilatouse, também, uma certa uniformidade para esses pontos de dispersão de escores entre os grupos de genótipos de muito alta, alta, média e baixa estabilidade, fato este que não se repetiu para os ambientes. Portanto, pode-se inferir com base nesse critério, que o descarte de genótipos considerados de baixa estabilidade via região de predição para os escores dos genótipos merece ser repensado. Cabe salientar que estas regiões de predição foram geradas com alto nível de confiança $(99 \%)$ e que o caráter produtividade de grãos, por ser muito abalado por condições extrínsecas não controláveis, pode exercer influência a ser considerada quanto à escollha do nível de confiança fixado.

O padrão relativamente homogêneo de dispersão de escores entre os quatro grupos de genótipos estáveis tendeu a se repetir para as três populações, o que remete a proceder com cuidado sobre os critérios de eliminação de genótipos classificados aqui com baixa constância de comportamento frente às variações ambientais.

Uma outra constatação que pode ser tirada situa-se no tamanho e forma da região de confiança, estando esta correlacionada com a nuvem de dispersão dos pontos dos escores, delineada predominantemente no tipo elíptico, com diâmetro maior na horizontal quando prevalece concentração dos pontos dos escores no sentido do IPCAl; todavia, quando esta nuvem de pontos está mais concentrada ao longo do IPCA2, o desenho elíptico tem maior diâmetro vertical; se houver uma distribuição de pontos que contemple simultaneamente os dois eixos de forma semelhante, será plotado no gráfico um círculo. Essa associaçào é definida 
também através dos valores de desvio padrão para cada eixo, sendo que o diâmetro será maior quanto maior for o desvio padrão do eixo respectivo, isto é, o diâmetro da região de confiança "bootstrap" acompanha a tendência da magnitude do desvio padrão. Quando a elipse é do tipo horizontal entende-se que o IPCAl dominou, isto é, maior porção da variação foi retida neste eixo, como o esperado. Quanto menor o tamanho dessas regiões e mais próximos estiverem do ponto de coordenadas $(0,0)$ que inclui o vetor nulo, espera-se manifestação mais alta de estabilidade dos materiais avaliados. Esse deslocamento da região de confiança ditado pelo padrão da nuvem de pontos é facilmente identificado na Figura 11. Nessa avaliaçào, observouse que os genótipos apresentaram menor oscilação do que os ambientes, confirmando as magnitudes dos testes $\mathrm{F}$ para esse efeito.

Como salienta Lavoranti (2003), uma questão que deve ser melhor explorada diz respeito ao número de eixos que definem o padrão da interação, pela análise AMMI. Uma vez que o padrão explicado pelos eixos singulares da análise AMMI, via Cornelius et al. (1992), não foi suliciente para captar toda a estrutura da interação GxE, pois, ao se utilizar do processo "bootstrap", contendo supostamente todo o padrão (Gollob, 1968), as interpretações das estabilidades foram diferentes.

A soma de quadrados da interação GxE (SQ $\left.\mathrm{SQxE}_{\mathrm{E}}\right)$ é importante para explicar o padrão adjacente à interação GxE. Assim, quando se cometeu o erro tipo Il ao aceitar um modelo AMMI com menor número de eixos, cujo modelo correto, seja de fato mais parametrizado, foi excluído parte da $\mathrm{SQ}_{\mathrm{GxE}}$, que contém variações devidas aos padrões de interação GxE, que são de interesse agronômico. Dessa forma, as interpretações de estabilidade ficam comprometidas. Para evitar os riscos desse tipo de erro, recomenda-se utilizar outras técnicas mais acuradas para a definição do modelo, como as apresentadas por Dias \& Krzanowski (2003), combinando-se essas técnicas (seleção de modelos "exatos" e "bootstrap" AMMI).

Lavoranti et al. (2001a), encontrou resultados de estabilidade fenotípica pelos testes de Eberhart \& Russel (1966) e de Wrike (1962) mais coerentes com os verificados pela análise "bootstrap" AMMI. No presente estudo, também não houve convergência notável entre os resultados gerados pelos métodos AMMl e AMMI "bootstrap".

O procedimento AMMI "bootstrap" teve caráter de refinamento para análises de estabilidade fenotípica, mostrando grande potencial complementar à análise AMMI, 
apresentando recursos adicionais para ajudar na seleção mais criteriosa de genótipos e ambientes para estabilidade fenotípica.

Tabela 16. Identificação das linhagens e cruzamentos de maior destaque em cada população

\begin{tabular}{|c|c|c|c|}
\hline Populações & $\begin{array}{c}\text { Símbolo } \\
\text { das } \\
\text { Linhagens }\end{array}$ & $\begin{array}{l}\text { Número dos } \\
\text { cruzamentos }\end{array}$ & Genitores \\
\hline \multirow{7}{*}{$\mathrm{PCI}$} & P20 & $08-07$ & IAS-5 x IAC- 100 \\
\hline & PI & $08-01$ & BR-6 x Crockett \\
\hline & P10 & $08-03$ & BR-6 x IAC-100 \\
\hline & P5 & $08-03$ & BR-6 $\times$ IAC- 100 \\
\hline & $\mathrm{P} 2$ & $08-01$ & BR-6 x Crockett \\
\hline & $\mathrm{P} 12$ & $08-04$ & BR-6 x D72-9601-1 \\
\hline & P 4 & $08-02$ & BR-6 x Lamar \\
\hline \multirow{7}{*}{ PRIS } & P7 & $08-07$ & IAS-5 x [AC- 100 \\
\hline & P9 & $08-07$ & IAS-5 x IAC- 100 \\
\hline & $\mathrm{P} 2$ & $08-07$ & IAS-5 x IAC-100 \\
\hline & $\mathrm{P} 13$ & $08-11$ & Davis $x$ IAC -100 \\
\hline & P11 & 08-09 & Davis $x$ Crockett \\
\hline & PIO & $08-08$ & IAS-5 x D72-9601-1 \\
\hline & P18 & $08-11$ & Davis $\times$ IAC- 100 \\
\hline \multirow{7}{*}{ PRIM } & P4 & $08-12$ & Davis $x$ D72-9601-1 \\
\hline & P 16 & $08-15$ & OCEPAR-4 x IAC-100 \\
\hline & P20 & $08-16$ & OCEPAR-4 x D72-9601-1 \\
\hline & $\mathrm{P} 17$ & $08-15$ & OCEPAR-4 x IAC- 100 \\
\hline & P7 & $08-12$ & Davis x D72-9601-1 \\
\hline & P5 & $08-12$ & Davis $x$ D72-9601-1 \\
\hline & PI5 & $08-15$ & OCEPAR-4 x IAC- 100 \\
\hline
\end{tabular}


Tabela 17. Identificação das linhagens (P1 a P20) das populações PCI (formada a partir de plantas $\mathrm{F}_{2}$ obtidas com controle total de insetos), PRIS (formada a partir de plantas $\mathrm{F}_{2}$ selecionadas para tolerância a insetos sugadores) e PRIM (formada a partir de plantas $F_{2}$ selecionadas para tolerância a insetos mastigadores) e testemunhas

\begin{tabular}{|c|c|c|c|c|c|c|}
\hline Simbolo & $\begin{array}{l}\text { Código } \\
\text { PCI }\end{array}$ & $\begin{array}{c}\mathrm{N}^{\circ} \\
\text { Cruzame } \\
\text { nto }\end{array}$ & Código PRIS & $\begin{array}{c}\mathrm{N}^{\circ} \\
\text { Cruzamento }\end{array}$ & Código PRIS & $\begin{array}{c}\mathrm{N}^{\bullet} \\
\text { Cruzamento }\end{array}$ \\
\hline P1 & P-1-97-8001 & $08-01$ & P-2-97-8085 & $08-07$ & P-3-97-8195 & $08-11$ \\
\hline P2 & P-3-97-8146 & 08-01 & P-2-97-8088 & 08-07 & P-3-97-8175 & $08-11$ \\
\hline P3 & P-2-97-8063 & 08-02 & P-2-97-8091 & $08-07$ & P-3-97-8178 & $08-11$ \\
\hline P4 & P-2-97-8064 & 08-02 & P-2-97-8093 & $08-07$ & P-2-97-81 14 & $08-12$ \\
\hline P5 & P-1-97-8004 & $08-03$ & P-2-97-8095 & $08-07$ & P-2-97-8118 & $08-12$ \\
\hline P6 & P-1-97-8007 & $08-03$ & P-2-97-8096 & $08-07$ & P-2-97-8119 & $08-12$ \\
\hline P7 & P-1-97-8009 & $08-03$ & P-3-97-8121 & 08-07 & P-3-97-8147 & $08-12$ \\
\hline P8 & P-2-97-8067 & $08-03$ & P-3-97-8035 & $08-07$ & P-1-97-8033 & $08-13$ \\
\hline P9 & P-2-97-8068 & $08-03$ & P-3-97-8149 & 08-07 & P-3-97-8176 & $08-13$ \\
\hline $\mathrm{P} 10$ & P-3-97-8172 & $08-03$ & P-1-97-8024 & 08-08 & P-1-97-8039 & $08-15$ \\
\hline P11 & P-2-97-8072 & 08-04 & P-2-97-8100 & 08-09 & P-1-97-8043 & $08-15$ \\
\hline $\mathrm{P} 12$ & P-2-97-8073 & 08-04 & P-3-97-8173 & 08-09 & P-1-97-8051 & $08-15$ \\
\hline P13 & P-3-97-8165 & $08-05$ & P-1-97-8026 & $08-11$ & P-1-97-8054 & $08-15$ \\
\hline P14 & P-1-97-8010 & $08-07$ & P-2-97-8105 & $08-11$ & P-1-97-8055 & $08-15$ \\
\hline P15 & P-1-97-8012 & $08-07$ & P-2-97-8108 & $08-11$ & P-2-97-8056 & $08-15$ \\
\hline P16 & P-1-97-8014 & 08-07 & P-2-97-8009 & $08-11$ & P-1-97-8057 & $08-15$ \\
\hline P17 & P-1-97-8016 & $08-07$ & P-3-97-8132 & $08-11$ & P-3-97-8122 & $08-15$ \\
\hline P18 & P-1-97-8019 & 08-07 & P-3-97-8142 & $08-11$ & P-3-97-8137 & $08-15$ \\
\hline P19 & P-1-97-8022 & $08-07$ & P-3-97-8151 & $08-11$ & P-3-97-8158 & $08-15$ \\
\hline P20 & P-2-97-8080 & $08-07$ & P-3-97-8154 & $08-11$ & P-3-97-8136 & $08-16$ \\
\hline \multicolumn{2}{|r|}{$\mathrm{N}^{\circ}$ Cruzamento } & \multicolumn{2}{|c|}{ Genitores } & $\begin{array}{c}\mathrm{N}^{\circ} \\
\text { Cruzamento }\end{array}$ & \multicolumn{2}{|c|}{ Genitores } \\
\hline & $08-01$ & BR-6 & Crockett & 08-09 & Davis & Crockett \\
\hline & 08-02 & BR-6 & Lamar & $08-10$ & Davis & Lamar \\
\hline & $08-03$ & BR-6 & IAC-100 & $08-11$ & Davis & IAC-100 \\
\hline & 08-04 & BR-6 & x D72-9601-1 & $08-12$ & Davis & $x$ D72-9601-1 \\
\hline & $08-05$ & IAS-5 & Crockett & $08-13$ & OCEPAR-4 & Crockett \\
\hline & $08-06$ & IAS-5 & Lamar & $08-14$ & OCEPAR-4 & Lamar \\
\hline & $08-07$ & IAS-5 & $x \quad$ IAC -100 & $08-15$ & OCEPAR-4 & $x \quad$ IAC -100 \\
\hline & $08-08$ & IAS-5 & x D72-9601-1 & $08-16$ & OCEPAR-4 & $x$ D72-9601-1 \\
\hline $\begin{array}{c}\text { Testemu } \\
\text { nhas }\end{array}$ & \multicolumn{2}{|c|}{ T1 (Ocepar-4) } & \multicolumn{2}{|c|}{ T2 $($ IAC -100$)$} & \multicolumn{2}{|c|}{ T3 (IAS-5) } \\
\hline
\end{tabular}


As Tabelas 16 e 17 mostram que três dos 16 cruzamentos nào contribuiram com linhagens $F_{11}$ com alta produtividade de gràos e estabilidade fenotípica, em nenhuma das três populações: 08-06 (IAS-5 x Lamar), 08-10 (Davis x Lamar) e 08-14 (OCEPAR-4 x Lamar). Por outro lado, cinco cruzamentos destacaram-se com um número mais expressivo de linhagens $F_{11}$ selecionadas: 08-07 (IAS-5 x IAC-100) com 16 linhagens, sendo sete linhagens na PCI e nove linhagens na PRIS; 08-11 (Davis x IAC-100) com 11 linhagens, sendo oito na PRIS e três na PRIM; 08-15 (OCEPAR-4 x IAC-100), com dez linhagens, todas na PRIM; 08-03 (BR-6 x IAC-100) com seis linhagens na PCI; 08-12 (Davis x D72-9601-1) com quatro linhagens na PRI. Certamente, estes cinco cruzamentos têm tendência para capacidade específica de combinação mais alta.

Pela Tabela 16, pode-se observar que alguns genitores destacaram-se com participações mais expressivas nos cruzamentos que originaram as sete linhagens $(p=35 \%) F_{11}$ superiores de cada populaçào. Em primeiro lugar, como maior destaque, classificou-se o genitor IAC-100 com 11 participações, sendo cinco em PRIS, três em PRIM e três em PCI. Em segundo lugar, classificaram-se os genitores D72-9601-1, BR6 e Davis, com seis participações cada um; o genitor D72-9601-1 teve quatro participações em PRIM, uma em PRIS e uma em PCI; o genitor BR-6, teve todas as seis participaçōes em PCI; e o genitor Davis mostrou três participações em PRIM e três em PRIS. Em terceiro lugar, classificou-se o genitor IAS-5, com cinco participações, sendo quatro em PRIS e uma em PCI. Em quarto lugar, colocou-se o genitor OCEPAR-4, com quatro participações, todas em PRIM. Em quinto lugar, tem-se o genitor Crockett, com três participações, sendo duas em PCI e uma em PRIS. Finalmente, em sexto lugar, classificou-se o genitor Lamar, com uma única participaçào, sendo esta na PCl. Esta classificaçào relativa dos genitores reflete a capacidade geral de combinaçào dos mesmos. É muito encorajador o fato de todos os quatro genitores com resistência/tolerância a insetos terem sido incluídos entre os maiores destaques, em ordem decrescente de participações: IAC-1 00, D72-9601-1, Crockett e Lamar. 


\section{CONCLUSÕES}

As seguintes conclusões foram obtidas, com base na produtividade de grãos:

a) nas três populações existe variabilidade genética remanescente entre linhagens $F_{11}$;

b) o manejo diferenciado (CII ou controle de intensivo de insetos vs. CEI ou controle ecológico de insetos) mostrou ser um representante eficiente de ambientes diversos;

c) a variação fenotípica foi explicada em ordem decrescente pelos efeitos: entre ambientes, da interação de genótipos com ambientes e entre genótipos;

d) o método AMMI evidenciou como linhagens $F_{11}$ estáveis e produtivas $70 \%$ da PCI (População com Controle Total de Insetos em $\mathrm{F}_{2}$ ), 65\% da PRIS (População com Seleção para Resistência a Insetos Sugadores em F2) e 55\% da PRIM (População com Seleção para Resistência a Insetos Mastigadores em F2);

e) o local Anhembi destacou-se como de alta produtividade em todas as situações (três populações, dois anos e dois manejos); para as três populações, dentre os ambientes mais produtivos, o método AMMI destacou El (Anhembi, 1999/00, CII) como de máxima estabilidade e E6 (Anhembi, 2000/01, CEI) como de máxima instabilidade;

f) o método AMMI com reamostragem (bootstrap) mostrou resultados diferentes daqueles observados somente com o método AMMI; todos os genótipos (20 linhagens de cada população e três testemunhas) foram classificadas como estáveis; 
para as três populações, foram formados quatro grupos de genótipos com diferentes níveis de estabilidade, tendo a soma dos dois grupos de estabilidade mais elevada incluído pelo menos $50 \%$ das linhagens de cada população e duas das três testemunhas; os dois métodos diferiram principalmente na classificação da estabilidade dos ambientes; o método AMMI com reamostragem, destacou o ambiente E8 (Areão, 2000/01, CEI) como de estabilidade máxima e os ambientes E1 (Anhembi, 1999/00, CII) e E3 (Areào, 1999/00, CII) como ambientes instáveis;

g) para a capacidade de gerar linhagens superiores em adaptabilidade e estabilidade, sobressaíram-se os genitores IAC-100, D72-9601-1, BR-6, Davis e IAC-5; destaques especiais envolveram os cruzamentos do genitor IAC-100 com os genitores IAC-5, Davis, OCEPAR-4 e BR-6. 


\section{REFERÊNCIAS BIBLIOGRÁFICAS}

ALL, J.; BOERMA, W.; PARROTT, C. N.; STEWART, Jr.; RAYMER, B.; RECTOR, S., RAMACHANDRAN, D.; WALKER, D.; TREACY, M. Interactions in entomology: utilization and management of new genetic techniques for insect control in southern field crops. Journal of Entomology Science, v.34, p.2-7, 1999a.

ALLIPRANDINI, L.F. Estudo dos efeitos ambientais, estabilidade, adaptabilidade e ganho genético em linhagens de soja (Glicine Max (L.) Merrill) no Estado do Paraná. Londrina, 1992. 122p. Dissertação (Mestrado) - Universidade Estadual de Londrina.

ALLARD, R.W.; BRADSHAW, A.D. Implications of genotype-environmental interactions in applied plant breeding. Crop Science, v.4, n.5, p.503-508, 1964.

ANNICCHIARICO, P. Additive main effects and multiplicative interaction (AMMI) analysis of genotype-location interaction in variety trials repeates over years. Theoretical and Applied Genetics, v.94, n.8, p.1072-1077, 1997.

ARIEL, C.R.E. Aspectos biológicos e não preferência para alimentação e oviposição de Anticarsia gemmatalis Huber, 1818, em genótipos de soja, Glycine max (L.) Merrill. Piracicaba, 1990. 160p. Dissertação (Mestrado) - Escola Superior de Agricultura "Luiz de Queiroz", Universidade de São Paulo.

ATLIN, G.N.; McRAE, K.B.; LU, X. Genotype x region interaction for two-barley yield in Canada. Crop Science, v.40, n.6, p.1-6, 2000.

BECKER, H.C. Correlations among some statistical measures of phenotypic stability. Euphytica, v.30, n.3, p.835-840, 1981. 
BECKER, H.C.; LÉON, J. Stability analysis in plant breeding. Plant Breeding, v.101, n.1, p.1-23, 1988 .

BELAND, G.L.; HATCHETT, J.H. Expression of antibiosis bollworm in two soybean genotypes. Journal of Economic Entomology, v.69, n. 4, p.557-560, 1976.

BENTO, J.M.S. Perdas por insetos na agricultura. Ação Ambiental, v.4, p.19-21, 1999.

BICKEL, P.; FREEDMAN, D. Some asymptotic theory for the bootstrap. Annals of Statistics, v.1, n. 9, p. 1196-1197, 1981.

BRASIL, E.M. Comparação de métodos no estudo da interação de genótipos com ambientes em milho (Zea mays L.). Goiânia, 1990. 181p. Tese (Mestrado) Universidade Federal de Goiânia - UFG.

BURDEN, D. J.; NORRIS, D. M. Ovarian failure induced in Epilachna varivestis by a 'death-trap' 'Davis' variety of Glycine max. Entomologia Experimentalis et Applicata, v. 73, n. 2, p. 183-186, 1994. / resumo em CAB Abstracts on CDROM, 1993-94.

CAMPO, C.B.H.; GAZZONI, D.L.; TOLEDO, J.F.F. Comparação de métodos para avaliação de linhas de soja resistentes a percevejos (Hemiptera:pentatomidae). Pesquisa Agropecuária Brasileira, v.13, n.5, p.305-316, 1996.

CARBONELL, S.A.M. Análise genética da reação da semente de soja ao dano mecânico avaliada em um dialelo do ciclo precoce. Piracicaba, 1995. 144p. Tese (Doutorado) - Escola Superior de Agricultura "Luiz de Queiroz", Universidade de São Paulo.

CARLINI-GARCIA, L. A. Uso do método de reamostragem bootstrap na estimação de parâmetros genéticos populacionais. Piracicaba, 2001. 162p. Tese (Doutorado) - Escola Superior de Agricultura “Luiz de Queiroz", Universidade de São Paulo. 
CHAVES, L. J. Interação de genótipos com ambientes. In: NASS, L.L.; VALOIS, A.C.C.; MELO, I.S.; VALADARES-INGLIS, M.C. (Ed.). Recursos genéticos \& melhoramento de plantas. Rondonópolis: Fundação MT, 2001. p. 816-858.

CHAVES, L. J.; VENCOVSKY, R.; GERALDI, I.O. Modelo não linear aplicado ao estudo da interação genótipo $\mathrm{x}$ ambiente em milho. Pesquisa Agropecuária Brasileira, v. 24, n.2, p. 259-269, 1989.

CLARK, W.J.; HARRIS, F.A.; MAXWELL, F.G.; HARTWIG, E.E. Resistance of certain soybean cultivars to the bean leaf beetle, striped blister beetle and bollworm. Journal of Economic Entomology, v.65, n. 1, p.1669-1672, 1972.

COCRHRAN, W.G. The combination of estimates from different experiments. Biometrics, v.10, p.101-129, 1954.

COCKERHAM, C.C. Estimation of genetics variance. In: HANSON, W.D.; ROBINSON, H.F. (Eds.). Statistical genetics and plant breeding. Madison: National Academy of Sciences, 1963. p.53-94.

CORNELIUS, P.L. Statistical tests and retention of terms in the additive main affects and multiplicative interaction model for cultivar trials. Crop Science, v.33, n.6, p.1186-1193, 1993.

CORNELIUS, P.L.; CROSSA, J.; SEYEDSADR, M.S. Statistical tests and estimators of multiplicative models for genotype-by-environment interaction. In: KANG, M.S.; GAUCH, H.G. (Ed.) Genotype-by-environment interaction. New York: CRC Press, 1996.416p.

CORNELIUS, P.L.; SEYEDSADR, M.; CROSSA, J. Using the shifted multiplicative model to search for "separability" in crop cultivar trials. Theoretical and Applied Genetics, v.84, n.1-2, p.161-172, 1992.

CROSSA, J. Statistical analyses of multilocation trials. Advances in Agronomy, v.44, p.55-85, 1990. 
CROSSA, J.; FOX, P.N.; PFEIFFER, W.H.; RAJARAM, S.; GAUCH, H.G. AMMI adjustment for statistical analysis of an international wheat yield trial. Theoretical and Applied Genetics, v.81, n.1, p.27-37, 1991.

CROWLEY, P.H. Resampling methods for computation-intensive data analysis in ecology and evolution. Annual Review of Ecology and Systematics, v. 23, p. 405-447, 1992.

CRUZ, C.D.; REGAZZI, A.J. Modelos biométricos aplicados ao melhoramento genético. Viçosa: UFV, 1994. 390p.

CRUZ, C.D. A informática no melhoramento genético In: NASS, L.L.; VALOIS, A.C.C.; MELO, I.S.; VALADARES-INGLIS, M.C. (Eds.). Recursos genéticos \& melhoramento de plantas. Rondonópolis: Fundação MT, 2001. p 1085-1118.

CRUZ, C.D.; TORRES, R.A.A.; VENCOVSKY, R. An alternative approach to the stability analysis proposed by Silva and Barreto. Revista Brasileira de Genética, v.12, n.2, p.567-580, 1989.

DAUGHERTY, D.M.; NEUSTADT, M.H.; GEHRKE, C.W.; CAVANAH, L.E.; WILLIAMS, L.F.; GREEN, D.E. An evaluation of damage to soybeans by brown and green stink bugs. Journal of Economic Entomology, v. 57, n. 5, p.719-722, 1964.

DE CAUWER, I.; ORTIZ, R. Analysis of the genotype $x$ environment interaction in Musa trials. Experimental Agriculture, v. 34, n. 2, p. 177-188, 1998.

DIAS, C.T.S.; KRZANOWSKI, W.J. Model selection and cross-validation in additive main effect and multiplicative interaction (AMMI) models. Crop Science, v. 43, n.3, p. 865-873, 2003.

DICICCIO, T.J.; EFRON, B. Bootstrap confidence interval. Statistical Science, v.11, n. 11, p. 189-228, 1996. 
DUARTE, J.B.; VENCOVSKY, R. Interação genótipos $\mathbf{x}$ ambientes: uma introdução à análise AMMI. Ribeirão Preto: Sociedade Brasileira de Genética, 1999. 60p. (Série Monografias, 9).

DUARTE, J.B. Aspectos gerais da interação genótipos $x$ ambientes com ênfase na formação de redes de avaliação (compact disc). In: CONGRESSO BRASILEIRO DE MELHORAMENTO DE PLANTAS, 1., Goiânia, 2001. Resumos. Goiânia: SBMP, 2001.

DUARTE, J.B. Estudo da adaptabilidade e estabilidade fenotípica em cultivares de feijão mulatinho (Phaseolus vulgaris L.). Goiânia, 1988. 155p. Dissertação (Mestrado) - Escola de Agronomia, Universidade Federal de Goiás.

DUARTE, J.B.; ZIMMERMANN, M.J.O. Correlation among yield stability parameters in common bean. Crop Science, v.35, n.3, p.905-912, 1995.

EBERHART, S.A.; RUSSEL, W.A. Stability parameters for comparing varieties. Crop Science, v.6, n.1, p.36-40, 1966.

ECKART, C.;YOUNG, G. The approximation of one matrix by another of lower rank. Psychometrika, v.1, n.3, p.211-218, 1936.

EFRON, B. Bootstrap methods: another look at jakknife. Annals of Statistics, v. 7, n.1, p. 1-26, 1979.

EFRON, B.; STEIN, C. The jackkinife estimate of variance. Annals of Statistics, v.9, n. 3, p. 586-596, 1981.

EFRON, B.; TIBSHIRANI, R.J. Bootstrap methods for standard errors, confidence intervals and other measures of statistical accuracy. Statistical Science, v.1, n.1, p.54-76, 1986.

EFRON, B.; TIBISHIRANI, R.J. An introduction to the bootstrap. London: Chapman \& Hall, 1993. 579p. 
FALCONER, D.S.; MACKAY, T.F.C. Introduction to quantitative genetics. 4.ed. Harlow: Longman, 1996. 464p.

FALCONER, D.S. Introduction to quantitative genetics. 3.ed. Harlow: Longman, 1989. 438p.

FAO. FAOSTAT Agriculture data. http://www.fao.org/servlet/XteServlejtion (25 jan. 2000).

FEHR, W.R. Principles of cultivar development. New York: Macmillan, 1987. cap.18, p.247-258.

FINLAY, K.W.; WILKINSON, G.N. The analysis of adaptation in a plant-breeding programme. Australian Journal of Agricultural Research, v.14, n.5, p.742754, 1963.

FNP CONSULTORIA \& COMÉRCIO. Agrianual 2004: anuário da agricultura brasileira. São Paulo, 2004. p. 423-462: Soja.

FOX, P. N.; CROSSA, J.; ROMAGOSA, I. Multi-environmental testing and genotype $\mathrm{x}$ environment interaction. In: KENPTON, R.A; FOX, P.N. Statistical methods for plant variety evaluation. London: Chapman \& Hall, 1997. cap.8, p.117-138.

GABRIEL, K.R. The biplot graphic display of matrices with application to principal component analysis. Biometrika, v.58, n.3, p.453-467, 1971.

GAUCH, H.G.; ZOBEL, R.W. Predictive and postdictive success of statistical analysis of yield trials. Theoretical and Applied Genetics, v.76, n.1, p.1-10, 1988.

GAUCH, H.G. Full and reduced models for yield trials. Theoretical and Applied Genetics, v.80, n.1, p.153-160, 1990.

GAUCH, H.G. Statistical analysis of regional yield trial: AMMI analysis of factorial designs. New York: Elsevier Science, 1992. 278p. 
GAUCH, H.G.; ZOBEL, R.W. AMMI analysis of yield trials. In: KANG, M.S.; GAUCH, H.G. (Ed.) Genotype-by-environment interaction. New York: CRC Press, 1996. 416p.

GOLLOB, H.F. A statistical model which combines features of factor analytic and analysis of variance techniques. Psychometrika, v.33, n.1, p.73-115, 1968.

HEINRICH, G.M; FRANCIS, C.A.; EASTIN, J.D. Stability of grain sorghum yield compenents across diverse environments. Crop Science, v.23, n.2, p.209-212, 1983.

Instituto Brasileiro de Geografia e Estatística. http://wwwibge.gov.br/estatistica/indicadores/agropecuária/Ispa/defaut.shtm (22 mar. 2003).

JENSEN, R.L.; NEWSOM, L.D. Effect of stink-damaged soybean seeds on germination, emergence and yield. Journal of Economic Entomology, v. 65, n. 1, p.261-264, 1972.

JOHNSTON, K. A; GATEHOUSE, J.A.; ANSTEE, J.H. Effects of soybean protease inhibitors on the growth and development of larval Helicoverpa armigera. Journal of Insect Physiology, v.39, p.657-664, 1993.

KANG, M.S.; GAUCH JUNIOR., H.G. Genotype by environment interaction. Boca Raton: CRC Press, 1996. cap.4, p.85-122.

KANG, M.S.; MAGARI, R. New developments in selecting for phenotypic stability in crop breeding. In: KANG, M.S.; GAUCH, H.G. Genotype-by-environment interaction. Boca Raton: CRC Press, 1996. cap.1, p.1-14.

KENTY, M.M.; HINSON, K.; QUESENBERRY, K. H. WOFFORD, D.S. Inheritance of resistance to the soybean looper in soybean. Crop Science, v.36, n. 6, p.1532-1537, 1996. 
KILEN, T.C. LAMBERT, L. Genetic control of insect resistance in soybean germplasm PI 417061. Crop Science, v.38, n. 3, p.652-654, 1998.

KOGAN, M. Plant resistance in pest management. In: METCALF, R. L.; LUCKMANN, W. H. (Ed.). Introduction to insect pest management. 3. ed. New York: John Wiley, 1994. cap. 3, p. 73-128.

LAMBERT, A.L.; HEATHERLY, L.G. Influence of irrigation on susceptibility of selected soybean genotypes to soybean looper. Crop Science, v.35, n. 6, p.16571660, 1995.

LAMBERT, L.; KILEN, T.C. Insect resistance factor in soybean PI's 229358 and 227687 demonstrated by grafting. Crop Science, v.24, n. 1, p.163-165, 1984.

LAVORANTI, O.J. Estabilidade e adaptabilidade fenotípica atravéss da reamostragem "Bootstrap" no modelo AMMI. Piracicaba, 2003. 166p. Tese (Doutorado) - Escola Superior de Agricultura "Luiz de Queiroz", Universidade de São Paulo.

LAVORANTI, O.J.; DIAS, C.T.S. VENCOVSKY, R. Estudo comparativo: AMMI x EBERHART E RUSSEL. In: REUNIÃO ANUAL DA REGIÃO BRASILEIRA DA SOCIEDADE INTERNACIONAL DE BIOMETRIA, 46.; SIMPÓSIO DE ESTATÍSTICA APLICADA A EXPERIMENTÇÃO AGRONÔMICA, 9., Piracicaba, 2001. Anais. Piracicaba: ESALQ, 2001a. p. 114-117.

LAVORANTI, O.J.; DIAS, C.T.S. VENCOVSKY, R. Estudo da adaptabilidade e estabilidade genética de progênies de Eucalyptus grandis, através da metodologia AMMI. In: REUNIÃO ANUAL DA REGIÃO BRASILEIRA DA SOCIEDADE INTERNACIONAL DE BIOMETRIA, 46;; SIMPÓSIO DE ESTATÍSTICA APLICADA A EXPERIMENTÇ̃̃O AGRONÔMICA, 9., Piracicaba, 2001. Anais. Piracicaba: ESALQ, 2001b. p. 118-121.

LAVORANTI, O.J.; DIAS, C.T.S. VENCOVSKY, R. Estudo da estabilidade e adaptabilidade fenotípica de progênies de Eucalyptus grandis, através da 
metodologia AMMI. Boletim de Pesquisa Florestal, v. 44, n.1, p. 107-124, jan/jun, 2002.

LERNER, I.M. Genetic homeostasis. London, Oliver and Boyd, 134p, 1954.

LEWIS, D. Gene-environment interaction: A relationship between dominance heterosis phenotype stability and variability. Heredity, v.8, n.3, p.333-356, 1954.

LIN, C.S.; BINNS, M.R. A method of analysing cultivars $\mathrm{x}$ locations $\mathrm{x}$ year experiments: a new stability parameter. Theoretical and Applied Genetics, Berlin, v.76, n.1, p.425-430, 1988.

LIN, H.; KOGAN, M.; FISCHER, D.C. Inducible resistance in soybean the Mexican ben beetle (Coleoptera: coccinellidae): comparisons of inducing factors. Enviromental Entomology, v.9, p.1852-1857, 1990.

LIN, C.S.; BINNS, M.R.; LEFKOVICTH, L.P. Stability analysis: where do we stand? Crop Science, v.26, n.5, p.894-900, 1986.

LOURENÇÃO, A. L.; PEREIRA, J. C. V. N. A.; MIRANDA, M. A. C.; AMBROSANO, G. M. B. Danos de percevejos e de lagartas em cultivares e linhagens de soja de ciclos médio e semi-tardio. Anais da Sociedade Entomológica do Brasil, v. 28, n. 1, p. 157-167, 1999.

MAGARI, R.; KANG, M.S. SAS STABLE: stability analysis of balanced and unbalanced data. Agronomy Journal, v.89, n.5, p.929-932, 1997.

MANDEL, J.A. A new analysis of variance model for non-adittive data. Technometrics, v.13, n.1, p.1-18, 1971.

MANLY, B.F.J. Randomization, bootstrap and Monte Carlo methods in biology. 2. ed. London: Chapman \& Hall, 1997. 399p.

MARIOTTI, J.A.; OYARZABAL, E.S.; OSA, J.M.; BULACIO, A.N.R.; ALMADA, G.H. Analisis de estabilidad y adaptabilidad de genótipos de caña de azucar. I. 
Interacciones dentro de una localidad experimental. Revista Agronomica del Noroeste Argentino, v.13, n.1-4, p.105-127, 1976.

MAY, K.W.; KOZUB, G.C. Genotype x environment interactions for two-row barley grain yield and implications for selection of test locations. Canadian Journal of Plant Science, Otawa, v.75, n.2, p.571-575, 1995.

METTHER, L.E.; GREGG, T.G. Genética de populações e evolução. Tradução de R. Vencovsky, J.L. de Azevedo e G. Bandel. São Paulo: USP/Polígono, 1973. 262p.

MILLGAN, S.B. Test sit within and among stages of a sugarcane breeding program. Crop Science, v.34, n.2, p.1184-1190, 1994.

NASS, L.L. Utilização de recursos genéticos vegetais no melhoramento. In: NASS, L.L.; VALOIS, A.C.C.; MELO, I.S.; VALADARES-INGLIS, M.C. (Ed.). Recursos genéticos \& melhoramento de plantas. Rondonópolis: Fundação MT, 2001. p. 27-55.

NUNES, G.H.S. Interação genótipos $\mathbf{x}$ ambientes em eucalipto: implicações sobre a seleção e formas de atenuar seu efeito. Lavras, 2000. 160p. Tese (Doutorado)Universidade Federal de Lavras.

OLIVEIRA, A.B.; DUARTE, J.B.; PINHEIRO, J.B. Emprego da análise AMMI na avaliação da estabilidade produtiva em soja. Pesquisa Agropecuária Brasileira, v. 26, n.1, p.357-364, 2003.

OVERMAN, J. L.; MAcCARTER, L. E. Evaluating seedlings of cantaloupe for varietal nonpreference-type resistance to Diabrotica spp. Journal of Economic Entomology, v.65, n. 4, p. 1140-1144, 1972.

PAINTER, R.H. Insect resistance in crop plants. New York: MacMillan, 1951. $520 \mathrm{p}$. 
PANIZZI, A.R.; SLANSKY Jr. F. Review of phytophagous pentatomids (Hemiptera: Pentatomidade) associated with soybean in the Americas. Florida Entomologist, v.68, p.184-214, 1985.

PIEPHO, H.P. Robustness of statistical test for multiplicative terms in the additive main effects and multiplicative interaction model for cultivar trial. Theoretical and Applied Genetics, v.90, n.3-4, p.438-443, 1995.

PIMENTEL GOMES, F. Curso de estatística experimental. 13.ed. Piracicaba: Nobel, 1990.467p.

PINHEIRO, J.B. Seleção para caracteres agronômicos em diferentes épocas de cultivo, de populações de soja com resistência a insetos. Piracicaba. 143p. 1998. Tese (Doutorado) - Escola Superior de Agricultura "Luiz de Queiroz", Universidade de São Paulo.

QUENOUILLE M.H. The joint distribuition of serial correlation coefficients. Annual Mathematics and Statistics, v.1, n.20, p.561-571, 1949.

QUENOUILLE M.H. Notes on bias in estimation. Biometrika, v. 43, n. 3-4, p.353$360,1956$.

RAMALHO, M.A.P.; SANTOS, J.B.; ZIMMERMANN, M.J.O. Genética quantitativa em plantas autógamas: aplicações ao melhoramento do feijoeiro. Goiânia: UFG, 1993. 271p.

RAO, C.R. Linear statistical and its applications. New York: Wiley, 1965. 468p.

RIBEIRO, P.H.E. Adaptabilidade e estabilidade de cultivares de milho em diferentes épocas de semeadura, níveis de adubação e locais do estado de Minas Gerais. Lavras, 1999. 126p. Tese (Doutorado) - Universidade Federal de Lavras.

ROCHA, M.M. Interação genótipos x locais em linhagens experimentais de soja com diferentes ciclos de maturação. Piracicaba, 1998. 98p. Dissertação (Mestrado) Escola Superior de Agricultura “Luiz de Queiroz”, Universidade de São Paulo. 
ROCHA, M.M. Seleção de linhagens experimentais de soja para adaptabilidade e estabilidade fenotípica. Piracicaba, 2002. 173p. Tese (Doutorado) - Escola Superior de Agricultura "Luiz de Queiroz", Universidade de São Paulo.

ROSSE, L.N. Modelo de regressão não linear aplicado na avaliação da estabilidade fenotípica em plantas. Piracicaba, 1999. 179p. Tese (Doutorado) - Escola Superior de Agricultura “Luiz de Queiroz”, Universidade de São Paulo.

ROSSETTO, C.J.; GALLO, P.B.; RAZERA, L.F.; BORTOLETTO, N.; IGUE, T.; MEDINA, P.F.; TISSELLI FILHO, O.; AQUILERA, V.; VIEGA, R.F.A.; PINHEIRO, J.B. Mechanisms of resistance to stink bug complex in the soybean cultivar IAC-100. Anais Sociedade Entomológica do Brasil, v.24, n.3, p.517$522,1995$.

ROWAN, G.B.; BOERMA, H.M.; ALL, J.N.; TODD, J.W. Soybean maturity effect on expression of resistance to lepdopiterous insects. Crop Science, v.33, n. 3, p.433-436, 1993.

SHAFII, B.; PRICE, W.J. Analysis of genotype-by-environment interaction using the additive main effects and multiplicative interaction model and stability estimates. Journal of Agricultural, Biological and Environmental Statistics, v.3, n.3, p.335-345, 1998.

SHUKLA, G.K. Some statistical aspects of partitioning genotype-environmental components of variability. Heredity, v.29, n.2, p.237-245, 1972.

SILVA, J.G.C.; BARRETO, J.N. Aplicação da regressão linear segmentada em estudos da interação genótipo por ambiente. In: SIMPÓSIO DE ESTATÍSTICA APLICADA À EXPERIMENTAÇÃO AGRONÔMICA, Piracicaba, 1985. Anais. Campinas: Fundação Cargill, 1985. p. 49-50.

SOLDINI, D.O. Potencial genético de cruzamentos dialélicos parciais de soja com ênfase nas produtividades de grãos e óleo. Piracicaba, 1998. 80p. Tese (Doutorado) -Escola Superior de Agricultura “Luiz de Queiroz", Universidade de São Paulo. 
SOUZA, R.F.; TOLEDO, L.F.F. Genetic analysis of soybean resistance to stink bug. Revista Brasileira de Genética, v.18, n.4, p.593-598, 1995.

STATISTICAL ANALYSIS SYSTEM INSTITUTE. SAS/STAT software: changes and enhancements through release 6.12. (software). Cary: SAS Institute, 1997. $1116 \mathrm{p} .+1 \mathrm{~cd}$.

STORK, L. Modelos de regressão bi-segmentados descontínuos com erros de medidas aplicadas na análise de estabilidade de cultivares. Piracicaba, 1989. 217p. Tese (Doutorado) - Escola Superior de Agricultura "Luiz de Queiroz", Universidade de São Paulo.

THILLAINATHAN, M.; FERNANDEZ, G.C.J. SAS application for Tai's stability analysis and AMMI model in genotype $\mathrm{x}$ environmental interaction (GEI) effects. Journal of Heredity, v.92, n.4, p.367-373, 2001.

TINGEY, W. M. The environmental control of insect using plant resistance. In: PIMENTEL, D. (Ed.). Handbook of pest management in agriculture. Boca Raton: CRC Press, 1981. p. 175-197. (CRC Series in Agriculture).

TODD, J.W.; JELLUM, M.D.; LEUCK, D.B. Effects of Southern green stink bug damage on fatty acid composition of soybean oil. Environmental Entomology, v.2, p.285-289, 1973.

TUKEY, J.W. Bias and confidence in not quite large sample, abstract. Annals of Mathematics Statistics, v.29, n. 2, p.614-623, 1958.

VAN DER PLANK, J.E. Disease resistance in plants. New York: Academy Press, 1968. 206p.

VAN DUYN, J. W.; TURNIPSEED, S. G.; MAXWELL, J. D. Resistance in soybeans to the Mexican bean beetle. I. Sources of resistance. Crop Science, v. 11, n. 4, p. 572-573, 1971. 
VARGAS, M.; CROSSA, J.; VAN EEUWIJK, F.; SAYRE, K.D.; REYNOLDS, M.P. Interpreting treatment $x$ environment in agronomy trials. Agronomy Journal, v.93, n.4, p.949-960, 2001

VELLO, N.A. Ampliação da base genética do germoplasma e melhoramento de soja na ESALQ/USP. In: SIMPÓSIO SOBRE A CULTURA E PRODUTIVIDADE DA SOJA. Piracicaba, 1991. Anais. Piracicaba: FEALQ, 1992. p. 60-81.

VELLO, N.A. Ampliação da base genética do germoplasma e melhoramento de soja na ESALQ/USP. In: SIMPÓSIO SOBRE A CULTURA E PRODUTIVIDADE DA SOJA, Piracicaba, 1991. Anais. Piracicaba: FEALQ, 1992. p. 60-81.

VELLO, N.A. Efeitos da introdução de germoplasma exótico sobre a produtividade e relações com a base genética das cultivares de soja (Glycine max (L.) Merrill). Piracicaba, 1985. 91p. Tese (Livre-Docência) - Escola Superior de Agricultura "Luiz de Queiroz". Universidade de São Paulo.

VENCOVSKY, R. Melhoramento genético em vegetais. Ciência e Cultura, v.38, n. 7, p.1155-1160, 1986.

VENCOVSKY, R. Herança quantitativa. In: PATERNIANI, E.; VIÉGAS, G.P. (Coords.) Melhoramento e produção do Milho. Campinas: Fundação Cargill, 1987. v.1, p.137-214.

VENCOVSKY, R.; BARRIGA, P. Genética biométrica no fitomelhoramento. Ribeirão Preto: Sociedade Brasileira de Genética, 1992. 486p.

VENCOVSKY, R.; TORRES, R.A.A. Estabilidade geográfica e temporal de algumas cultivares de milho. In: CONGRESSO NACIONAL DE MILHO E SORGO, 16., Belo Horizonte, 1988. Anais. Belo Horizonte: EMBRAPA, CNPMS, 1988. p.294-300.

VERMA, M.M.; CHAHAL, G.S.; MURTY, B.R. Limitations of conventional regression analysis, a proposed modification. Theoretical and Applied Genetics, v.53, n.2, p.89-91, 1978. 
WRICKE, G.; WEBER, E.W. Quantitative genetics and selection in plant breeding. Berlin: Walter de Gruyter, 1986. 406p.

YAN, W.; CORNELIUS, P.L.; CROSSA, J.; HUNT, L.A. Two types of GGE biplots for analyzing multi-environment trial data. Crop Science, v.41, n..3, p.656-663, 2001.

YATES, F.; COCHRAN, W. G. The analysis of groups of experiments. Journal of Agricultural Sciences, v.28, n..4, p.556-580, 1938.

YEARGAN, K.V. Effects of green stink bug damage on yield and quality of soybean. Journal of Economic Entomology, v.70, n. 5, p.619-622, 1977.

YUE, G.L.; ROOZEBOOM, K.L.; SCHAPAUGH Jr., W.T.; LIANG, G.H. Evaluation of soybean cultivars using parametric and nonparametric stability estimates. Plant Breeding, v.116, n.3, p.271-275, 1997.

ZOBEL, R.W.; MADISON, J.W.; GAUCH, H.G. Statistical analysis of a yield trial. Agronomy Journal, v.80, n.3, p.388-393, 1988. 
